NUREG/CR-6228

ORNL/TM-12735

\title{
Preliminary Assessment of the Fracture Behavior of Weld Material in Full-Thickness Clad Beams
}

Manuscript Completed: May 1994

Date Published: October 1994

Prepared by

J. A. Keeney, B. R. Bass, W. J. McAfee, S. K. Iskander

Oak Ridge National Laboratory

Managed by Martin Marietta Energy Systems, Inc.

Oak Ridge National Laboratory

Oak Ridge, TN 37831-6285

Prepared for

Division of Engineering

Office of Nuclear Regulatory Research

U.S. Nuclear Regulatory Commission

Washington, DC 20555-0001

NRC FIN B0119

Under Contract No. DE-ACO5-84OR21400 


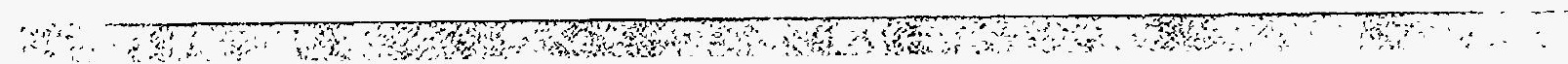




\section{DISCLAIMER}

This report was prepared as an account of work sponsored by an agency of the United States Government. Neither the United States Government nor any agency thereof, nor any of their employees, make any warranty, express or implied, or assumes any legal liability or responsibility for the accuracy, completeness, or usefulness of any information, apparatus, product, or process disclosed, or represents that its use would not infringe privately owned rights. Reference herein to any specific commercial product, process, or service by trade name, trademark, manufacturer, or otherwise does not necessarily constitute or imply its endorsement, recommendation, or favoring by the United States Government or any agency thereof. The views and opinions of authors expressed herein do not necessarily state or reflect those of the United States Government or any agency thereof. 


\section{DISCLAIMER}

Portions of this document may be illegible in electronic image products. Images are produced from the best available original document. 


\begin{abstract}
This report describes a testing program that utilizes fullthickness clad beam specimens to quantify fracture toughness for shallow cracks in material for which metallurgical conditions are prototypic of those found in reactor pressure vessels (RPVs). The beam specimens are fabricated from a section of an RPV wall (removed from a canceled nuclear plant) that includes weld, plate, and clad material. Metallurgical factors potentially influencing fracture toughness for shallow cracks in the beam specimens include material gradients due to welding and cladding applications, as well as material inhomogeneities in welded regions due to reheating in multiple weld passes. A summary of the testing program includes a description of the specimen geometry, material properties, the testing procedure, and the experimental results from three specimens. The yield strength of the weld material was determined to be $36 \%$ higher than the yield strength of the base material. An irradiation-induced increase in yield strength of the weld material could result in a yield stress that exceeds the upper limit where code curves are valid. The high yield strength for prototypic weld material may have implications for RPV structural integrity assessments. Analyses of the test data are discussed, including comparisons of measured displacements with finite-element analysis results,
\end{abstract}

Abstract applications of toughness estimation techniques, and interpretations of constraint conditions implied by stress-based constraint methodologies. Metallurgical conditions in the region of the cladding heat-affected zone are proposed as a possible explanation for the lower-bound fracture toughness measured with one of the shallow-crack clad beam specimens. Fracture toughness data from the three clad beam specimens are compared with other shallow- and deep-crack uniaxial beam and cruciform data generated previously from A 533 Grade B plate material. Difficulties with interpreting lower-bound fracture toughness curves constructed from the shallow-crack data are essentially resolved by adopting a single normalizing temperature parameter, namely, the nil-ductility temperature (NDT). When normalized to NDT, the combined shallow-crack data base from the plate and weld material exhibit an elevated mean fracture toughness in the transition temperature region, accompanied by increased data scatter that tends toward the same lower bound associated with highly constrained deep-crack data. Additional full-thickness clad beam testing is proposed to complete the investigation of shallow-crack fracture toughness behavior in prototypic weld and plate material. This report is designated as HSST Report No. 143. 


\section{Contents}

Abstract

List of Figures

vii

List of Tables

ix

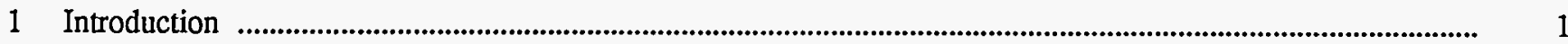

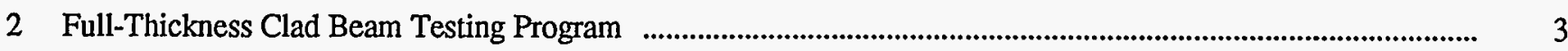

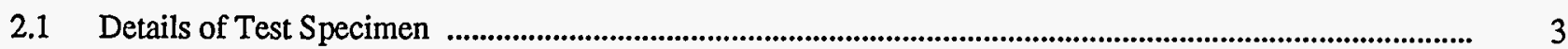

2.2 Characterization of the Circumferential Weld ............................................................................................... 5

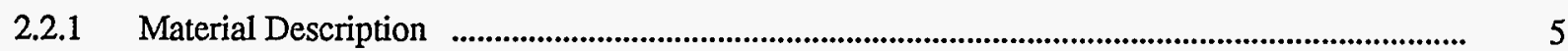

2.2.2 Results of Testing CVN Specimens in the L-S and L-T Orientations _.......................................... 6

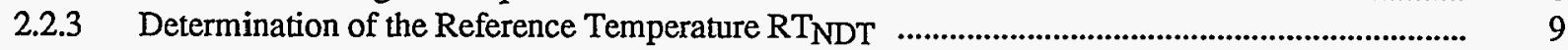

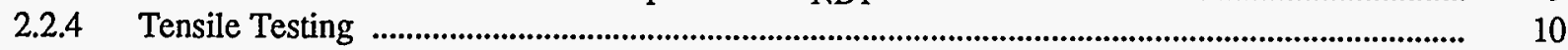

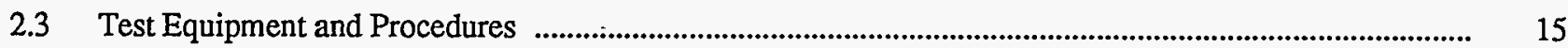

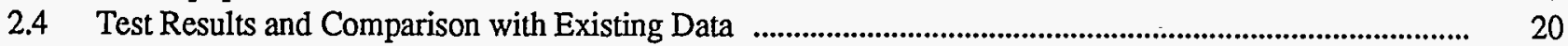

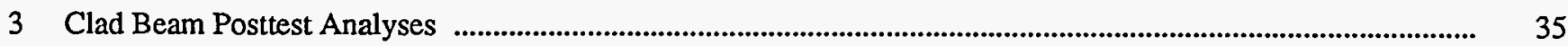

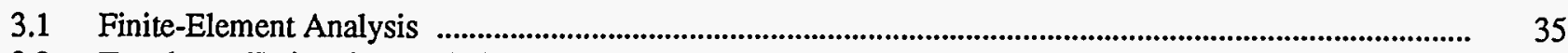

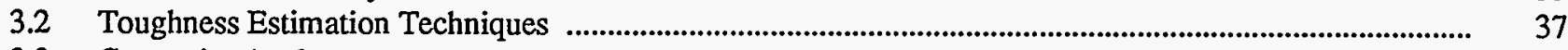

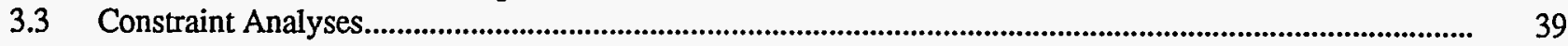

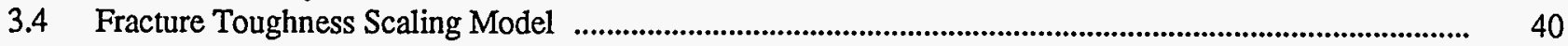

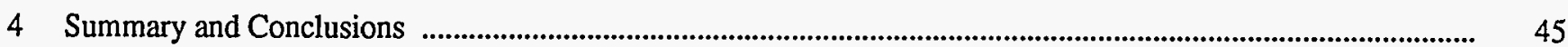

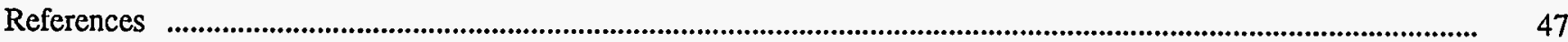

Appendix A: Summary of SENB Shallow- and Deep-Crack Fracture Toughness Data for A 533 B Plate Material and Submerged-Arc Pressure Vessel Weld Material

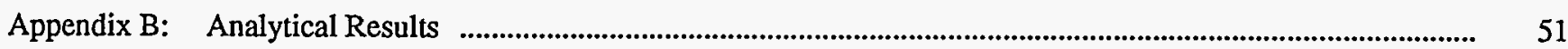





\section{List of Figures}

Figure

2.1 Sketch of RPV shell segment used as source material for full-thickness clad beam specimens

2.2 Cut-up plan for full-thickness clad beam blanks

2.3 Full-thickness clad beam blank before final machining

2.4 Coupon from full-thickness clad beam material showing metallurgical details of test weld

2.5 Sketch of full-thickness clad beam specimen

2.6 Details of welds used in full-thickness clad beam studies: (a) the axial weld and

(b) the circumferential weld

2.7 Cut-up of characterization block containing circumferential weld of unused RPV showing

location of tensile, CVN, and drop-weight specimens

2.8 CVN impact test results on specimens machined in T-S orientation from midthickness of circumferential weld of unused RPV: (a) CVN impact energy, (b) percent SFA, and (c) lateral expansion

2.9 CVN impact test results on specimens machined in T-L orientation from midthickness of circumferential weld of unused RPV: (a) CVN impact energy, (b) percent SFA, and (c) lateral expansion

2.10 Comparison of CVN-impact energy in T-S orientation to that in T-L orientation for midthickness material from circumferential weld of unused RPV

2.11 CVN impact energy of T-L orientation specimens machined from the circumferential weld of unused RPV

2.12 Tensile specimen machined in T-orientation from midthickness material from circumferential weld of unused RPV (dimensions taken from machining specificiation)

2.13 Yield and ultimate tensile strengths of T-orientation specimens for midthickness material from circumferential weld of unused RPV

2.14 Stress-strain behavior at different temperatures of SAW metal from midthickness of circumferential weld

2.15 Distinction between upper and lower yield becoming less pronounced as temperature decreases

2.16 Full-thickness clad beam specimen thermocouple configuration used in demonstration of temperature control (as provided by NIST)

2.17 Typical temperature histogram for demonstration of temperature control in clad beam tests

2.18 Location of crack-mouth-opening gages used on clad beam specimens

2.19 Strain gage layout for clad beam specimen CB-1 (as provided by NIST)

2.20 Fixture used to measure LLD on clad beam tests: $(a)$ side view and $(b)$ end view

2.21 (a) Full-thickness clad beam specimen CB-1 shown mounted in test fixture during fatigue precracking and

(b) sample, bridge amplifiers, and some of the data collection system shown in relative positions 
2.23 Correct operation of all instrumentation and data collection systems demonstrated during fatiguing of demonstration beam $\mathrm{CB}-1$

2.24 Full-thickness clad beam mounted in test fixture before failure test showing $\mathrm{LN}_{2}$ manifold in place

2.25 Fracture surface of full-thickness clad beam specimen $\mathrm{CB}-1$

2.26 Fracture surface of full-thickness clad beam specimen $\mathrm{CB}-2$

2.27 Fracture surface of full-thickness clad beam specimen CB-3

2.28 Load vs LLD response for clad beam specimens

2.29 Load vs CMOD response for clad beam specimens

2.30 Deep-crack fracture toughness results as function of normalized temperature $\mathrm{T}-\mathrm{RT}$ NDT

2.31 Shallow-crack fracture toughness results as function of normalized temperature $\mathrm{T}-\mathrm{RT}$ NDT

2.32 Deep-crack fracture toughness results as function of normalized temperature $\mathrm{T}$ - NDT

2.33 Shallow-crack fracture toughness results as function of normalized temperature T - NDT

2.34 HSST shallow-crack fracture toughness results as function of normalized temperature $\mathrm{T}-\mathrm{RT}$ NDT

2.35 HSST shallow-crack fracture toughness results as function of normalized temperature T-NDT

3.1 (a) Finite-element mesh of clad beam specimen with $\mathrm{a} / \mathrm{W}=0.05,(b)$ crack-plane region, and

(c) crack-tip region

3.2 Material representation for clad beam at $\mathrm{T}=-25^{\circ} \mathrm{C}$

3.3 Comparison of calculated and measured LLD for clad beam specimens

3.4 Comparison of calculated and measured CMOD for clad beam specimens

3.5 Variation of $\eta_{\mathrm{pl}}^{\ell}$ with $\mathrm{U}_{\mathrm{pl}}$ (based on LLD) for clad beam specimens: $(a) \mathrm{a} / \mathrm{W}=0.50,(b) \mathrm{a} / \mathrm{W}=0.10$, and (c) $\mathrm{a} / \mathrm{W}=0.05^{\mathrm{p}}$

3.6 Variation of $\eta_{\mathrm{pl}}^{\mathrm{c}}$ with $\mathrm{A}_{\mathrm{pl}}$ (based on CMOD) for clad beam specimens: $(a) \mathrm{a} / \mathrm{W}=0.50,(b) \mathrm{a} / \mathrm{W}=0.10$, and (c) $\mathrm{a} / \mathrm{W}=0.05^{\mathrm{p}}$

3.7 Comparison of calculated J values for clad beam specimens: $(a) \mathrm{a} / \mathrm{W}=0.50,(b) \mathrm{a} / \mathrm{W}=0.10$, and

(c) $\mathrm{a} / \mathrm{W}=0.05$

3.8 Distributions of normalized opening-mode stress for deep-crack clad beam specimen as function of applied $\mathrm{J}$ up to crack initiation

3.9 Distributions of normalized opening-mode stress for clad beam specimens as function of applied

$J$ up to crack initiation

3.10 HSST fracture toughness results as function of normalized temperature $\mathrm{T}-\mathrm{NDT}$

3.11 SSY toughness $\left(\mathrm{K}_{\mathrm{o}}\right)$ results as function of normalized temperature $\mathrm{T}-\mathrm{NDT}$ 


\section{List of Tables}

Table

2.1 Parameters defining specimen geometry of full-thickness clad beam specimens

2.2 Specimens machined for characterizating the circumferential weld for the full-thickness clad beam specimens

2.3 Results of testing T-S orientation CVN impact specimens machined from the midthickness of the circumferential weld of an unused RPV. The axis of T-S orientation specimens is normal to welding direction, and crack propagates into the thickness

2.4 Results of testing T-L orientation CVN impact specimens machined from the midthickness of the circumferential weld of an unused RPV. The axis of T-L orientation specimens is normal to welding direction, and crack propagates in the welding direction

2.5 Summary of test results to determine the CVN impact energy in the T-S and T-L orientations, drop-weight NDT temperature, and RTNDT of midthickness material from the circumferential weld of an unused RPV

2.6 Results of drop-weight testing P-3 size specimens from the circumferential weld between nozzle-ring to shell course. Specimens were machined from midthickness material and the crack-starter bead was a single pass weld as defined in ASTM E 208

2.7 Tensile properties of midthickness material from the circumferential weld of an unused RPV. The axis of the specimens was normal to the welding direction (T-orientation), and the gage diameter was $6.35 \mathrm{~mm}(0.25 \mathrm{in}$.)

2.8 Yield strength derived at room temperature from $A B I$ for midthickness material from the circumferential and axial welds of an unused RPV

2.9 Material properties at test temperature of $-25^{\circ} \mathrm{C}$

2.10 Fatigue precracking parameters for full-thickness clad beam specimens

2.11 Summary of results from the full-thickness clad beam testing program

3.1 Results of scaling model applied to clad beam data

A.1 Fracture toughness data

B.1 Analytical results for specimen CB-1

B.2 Analytical results for specimen $\mathrm{CB}-2$

B.3 Analytical results for specimen $\mathrm{CB}-3$ 


\section{Introduction}

Maximum tensile thermal stresses induced in a reactor pressure vessel (RPV) by a pressurized-thermal-shock (PTS) transient event occur near the inner surface of the vessel. Maximum irradiation-induced embrittlement also occurs in material adjacent to the inner surface of the RPV. Flaws located in this region of the RPV are, therefore, particularly susceptible to crack initiation during a PTS transient. Evaluations of RPV integrity under PTS loading are based on the Marshall flaw distribution, ${ }^{1}$ U.S. Nuclear Regulatory Commission (NRC) Guide $1.154,{ }^{2}$ and data from deep-crack fracture toughness specimens. The Marshall flaw distribution predicts more small than large flaws, while NRC Regulatory Guide 1.154 requires that all flaws be considered as surface flaws. Probabilistic fracturemechanics (PFM) analyses of RPVs indicate that a high percentage of the cracks that initiate in cleavage, initiate from shallow flaws. ${ }^{3}$ Because the postulated existence of shallow flaws has a dominant influence on the results of PFM analyses and, ultimately, the conditional probability of vessel failure in a PTS evaluation, the shallow surface crack is of major importance in RPV structural integrity assessments.

The Heavy-Section Steel Technology (HSST) shallowcrack fracture toughness testing program ${ }^{4}$ has provided data from shallow-crack specimens (cut from homogeneous plate material) that exhibit a fracture toughness significantly higher than that obtained from conventional deepcrack specimens tested in the transition temperature region. The shallow-crack program has tested A 533 Grade B (A 533 B) Class 1 steel, single-edge notch bend (SENB) specimens with an approximate $100-\mathrm{mm}$ beam depth and beam thicknesses of 51,102 , and $152 \mathrm{~mm}$. The shallowcrack data exhibit an elevation in mean fracture toughness and an increase in data scatter relative to the deep-crack toughness data in the transition temperature region. Shallow cracks experience a loss of constraint in the transition region because of the interaction of the crack-tip plastic zone with the free surface of the test specimen.

The influence of biaxial loads on the fracture toughness of shallow-crack specimens under conditions prototypic of an RPV is being investigated in another HSST testing program. ${ }^{5,6}$ Specially developed cruciform specimens containing shallow through-thickness or semi-elliptical surface cracks are being utilized in the program. Toughness values for shallow through-thickness cracks in the cruciform specimen ${ }^{5}$ were compared with data from the uniaxially loaded HSST/SENB deep- and shallow-crack specimens. ${ }^{4}$ The results indicate that the cruciform toughness data are clustered near the lower-bound curve to the HSST shallowcrack data and exhibit reduced scatter when compared with the fracture toughness data from uniaxial specimens.
Additional data are required to verify these preliminary observations, which are based on a very limited biaxial fracture toughness data set.

In addition to the shallow-crack effect, other differences in material conditions exist between conventional deep-crack laboratory specimens and RPVs that could significantly affect fracture toughness. A summary of these differences is as follows: (1) Shallow cracks in an RPV are located in the near-surface region of the vessel plate or weld material where metallurgical gradients or inhomogeneities exist as a result of application of the stainless steel cladding. Irwin and Zhang ${ }^{7}$ performed material gradient studies on a large weld section joining two forged A 508 shells from a stainless-steel-clad RPV. They found hardness elevations in the region of A 508 material near the clad/base material interface, an area of the vessel that was affected by the reheat cycle of the cladding process. Irwin and Zhang indicate that these hardness elevations probably translate into a reduction of cleavage initiation toughness.

(2) Fracture toughness curves used in RPV assessments are based on data from deep-crack L-T oriented fracture toughness specimens taken from the $1 / 4$ thickness (1/4t), homogeneous region of source plates. Axial cracks in plate material of an RPV are oriented in the L-S material direction rather than the L-T orientation. (3) Reheating due to multiple passes in the welding process leads to inhomogeneities of microstructure and hardness within the weld metal. ${ }^{7}$ (4) Residual stresses that remain after the postweld stress relief heat treatment cycle could affect fracture behavior.

This report describes preliminary results from an HSST testing program designed to investigate some of the effects on fracture toughness of the conditions outlined above. In the initial phase of the investigation, three full-thickness clad beam specimens taken from the RPV of a canceled nuclear plant were fabricated at Oak Ridge National Laboratory (ORNL) and tested at the National Institute for Standards and Technology (NIST), Gaithersburg, Maryland. ${ }^{*}$ These tests were performed to investigate the influence of metallurgical gradients, weld inhomogeneities, and the cladding process on the fracture toughness of material containing shallow cracks. Specifically, fracture toughness data were generated from three-point arc-bend specimens (229- by 226-mm cross section and $\sim 1300$-mm chord length) fabricated from full-thickness RPV clad, weld, and plate material. Shallow cracks in these beams were located in the weld material. Comparison of results from these tests

\footnotetext{
"NIST Test Report for Full-Thickness Clad Beam Fracture-Toughness Test Bendbar \#I tested April 6, 1993 (report dated March 10 1994); Bendbar \#2 tested January 13, 1994 (report dated March 10, 1994); and Bendbar \#3 tested February 24,1994 (report dated March 21, 1994).
} 


\section{Introduction}

with those from homogeneous shallow-crack test specimens provides an opportunity to quantify the effects of some near-surface conditions on fracture toughness. In addition, the effective fractuire toughness from these large beams can be compared with the toughness as determined by current American Society of Mechanical Engineers (ASME) Section XI rules. ${ }^{8}$

Chapter 2 provides a summary of the HSST full-thickness clad beam testing program, including a description of specimen geometry, material characterization, testing procedures, experimental results, and comparisons with other deep- and shallow-crack fracture toughness data. Analyses of the test data, including comparisons of test data with finite-element analysis results, and applications of toughness estimation techniques, are described in Chap. 3. Applications of the stress-based constraint characterizations developed by O'Dowd and Shih ${ }^{9-11}$ and by Dodds and Anderson ${ }^{12-14}$ to the clad beam data are also included in Chap. 3. A summary and some preliminary conclusions, together with a review of future plans for the clad beam testing program, are given in Chap. 4 . 


\section{Full-Thickness Clad Beam Testing Program}

\subsection{Details of Test Specimen}

The full-thickness clad beam specimens were fabricated from an RPV shell segment that was available from a canceled pressurized-water reactor plant (the plant was canceled during construction, and the vessel was never in service). The RPV material is A 533 B with a stainless steel clad overlay on the inner surface. A sketch of the vessel shell segment is shown in Fig. 2.1. The shell segment includes two circumferential welds and one longitudinal weld. The "lower" circumferential weld (see Fig. 2.1) connects two shell courses, and the "upper" circumferential weld connects a shell course with the nozzle ring. The longitudinal weld is located near the mid-width of the shell segment and runs from the "upper" circumferential weld through the lower end of the shell segment. The welds are submerged-arc welds (SAWs) with A 533 B class 1 filler metal. The plate material, clad overlay, and weldment are prototypic of a production-quality RPV. The shell has a nominal inner radius of $2210 \mathrm{~mm}$ ( $87 \mathrm{in}$.) and a thickness of $232 \mathrm{~mm}$ (9.125 in.).

Because the initial series of three specimens was intended to investigate the fracture behavior of the longitudinal weld material, the test beams were cut in the circumferential direction of the shell. A longitudinal master blank with a length sufficient to fabricate three test beams was first flame-cut from the shell (see Fig. 2.2). The three required blanks were then saw-cut from the master blank. Sawcutting was used at this stage to ensure that any effects of the flame-cutting would not be contained in the test beams. One of the beam blanks, before final machining, is shown in Fig. 2.3. The weld location was polished and etched to accurately locate the centerline of the weld, which joins the two beam halves. This centerline was then marked for machining reference. A circumferential coupon containing the test weld, shown in Fig. 2.4, was removed from the master blank during the process of cutting the test beam blanks. The metallurgical details of the material being tested can be seen in Fig. 2.4. The base material, the test weld with its multiple layers, the heat-affected zone (HAZ) between the weld and the shell material, and the clad layer with its HAZ are clearly visible. Indentation marks are visible on the weld, base metal, and cladding where hardness and Automated Ball Indentation (ABI) technique measurements of yield stress were made (see Sect. 2.2).

After saw-cutting, the specimens were machined to final dimensions, incorporating handling, load contact, and flaw details. A sketch of the specimen geometry is shown in Fig. 2.5. The specimen was designed to be tested in threepoint bending with a load span (S) of $1219.2 \mathrm{~mm}$ (48 in.). Flat, parallel load contact points were machined on the top and bottom surfaces of the beam (see Fig. 2.5) to remove surface irregularities and to ensure uniform load application across the width of the beam. The centerline of

ORNL-DWG 94-3067ETD

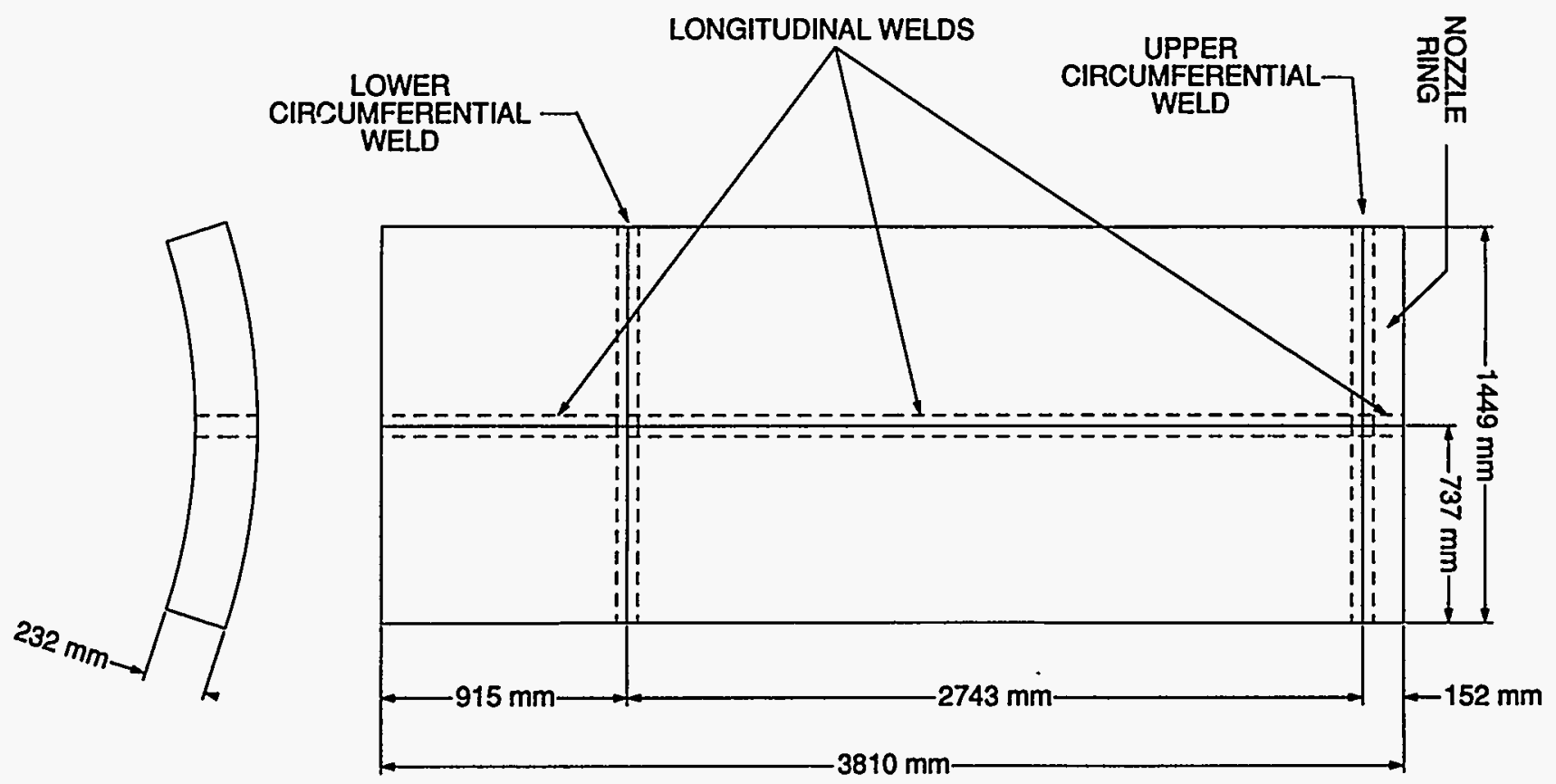

Figure 2.1 Sketch of RPV shell segment used as source material for full-thickness clad beam specimens 
Full-Thickness

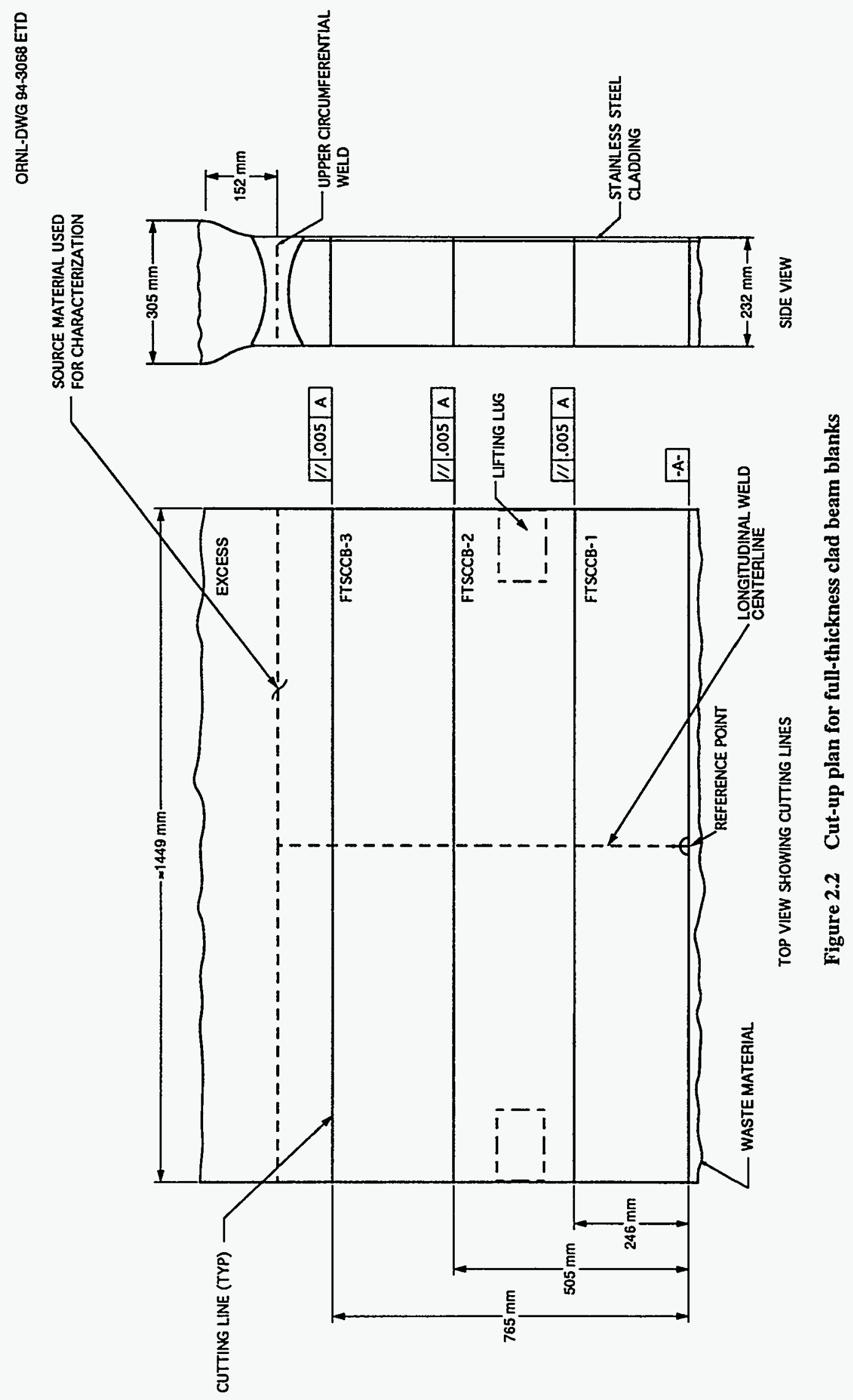




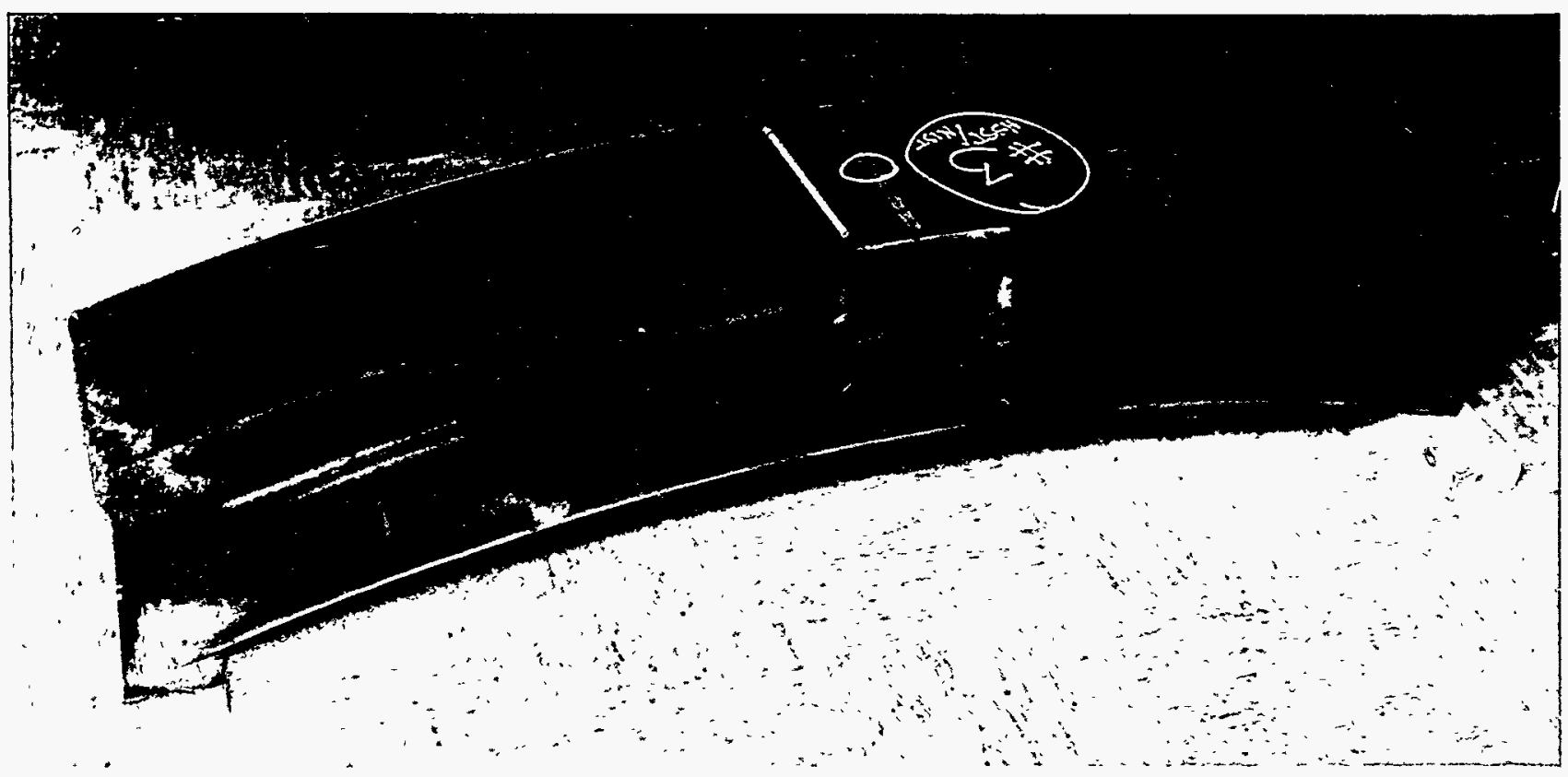

Figure 2.3 Full-thickness clad beam blank before final machining

the weld was located and used as a reference in machining the specimen details such that a radial plane, nominally passing through the center of the weld, would be a plane of symmetry for the specimen. The flaw was machined to lie in this plane. The flaw was machined into the beam using the wire electro-discharge machining (EDM) process and extended from the shell inner surface, that is, the clad surface, to predetermined depths into the beam. Using the EDM process, flaws with a very narrow width $(0.5 \mathrm{~mm})$ and uniform depth can be machined into thick sections with minimum impact on the surrounding material. Heating and the associated potential for introduction of surface residual stresses is minimized, and only small amounts of material are removed. The final dimensions for each clad beam specimen are shown in Table 2.1. Note that the flaw in each beam was machined to a different depth. One deepflaw specimen (CB-1) and two shallow-flaw specimens (CB-2 and CB-3) were produced. The crack depth (a) listed for each beam is the final depth after fatigue precracking. Part of the test procedure, to be discussed in Sect. 2.3, was. to sharpen the flaw by fatigue precracking to achieve $\sim 2.5 \mathrm{~mm}(0.1 \mathrm{in}$.) of flaw growth.

After machining, the beams were covered with a light oil, wrapped in moisture-resistant material, put in an enclosed, weatherproof crate, and shipped to NIST. The crate was opened after being received and stored inside the test facility building. These precautions were taken to ensure that the machined flaws were not exposed to any undesired environmental effects.

\subsection{Characterization of the Circumferential Weld}

This section describes the characterization of the SAW used in the full-thickness clad beam tests. As described in Sect. 2.1, the shell contained both axial and circumferential welds. In the course of cutting the beam blanks, the upper circumferential weld was made available for the characterizations. Tests using the $\mathrm{ABI}$ technique indicate that the tensile properties of the axial and circumferential weld are similar. The characterization of the circumferential weld included Charpy V-notch (CVN) tests, reference nilductility temperature ( $R T_{N D T}$ ) determinations (defined in Ref. 15), and tensile tests. To determine the RT NDT, both drop-weight and CVN tests are required.

\subsubsection{Material Description}

The location of the block of material used to characterize the circumferential weld is shown in Fig. 2.2. The axial weld, which was used to manufacture the full-thickness clad beam specimens, is also shown in Fig. 2.2. The circumferential weld was used to join the shell and nozzle courses of the RPV, the nozzle course being the thicker of the two sections of the vessel wall. Macrographs of the circumferential and axial welds are shown in Fig. 2.6 (a) and $(b)$, respectively. The macrographs show the individual weld passes and the cladding on the inside of the vessel. The dark streaks on the circumferential weld are due to the 


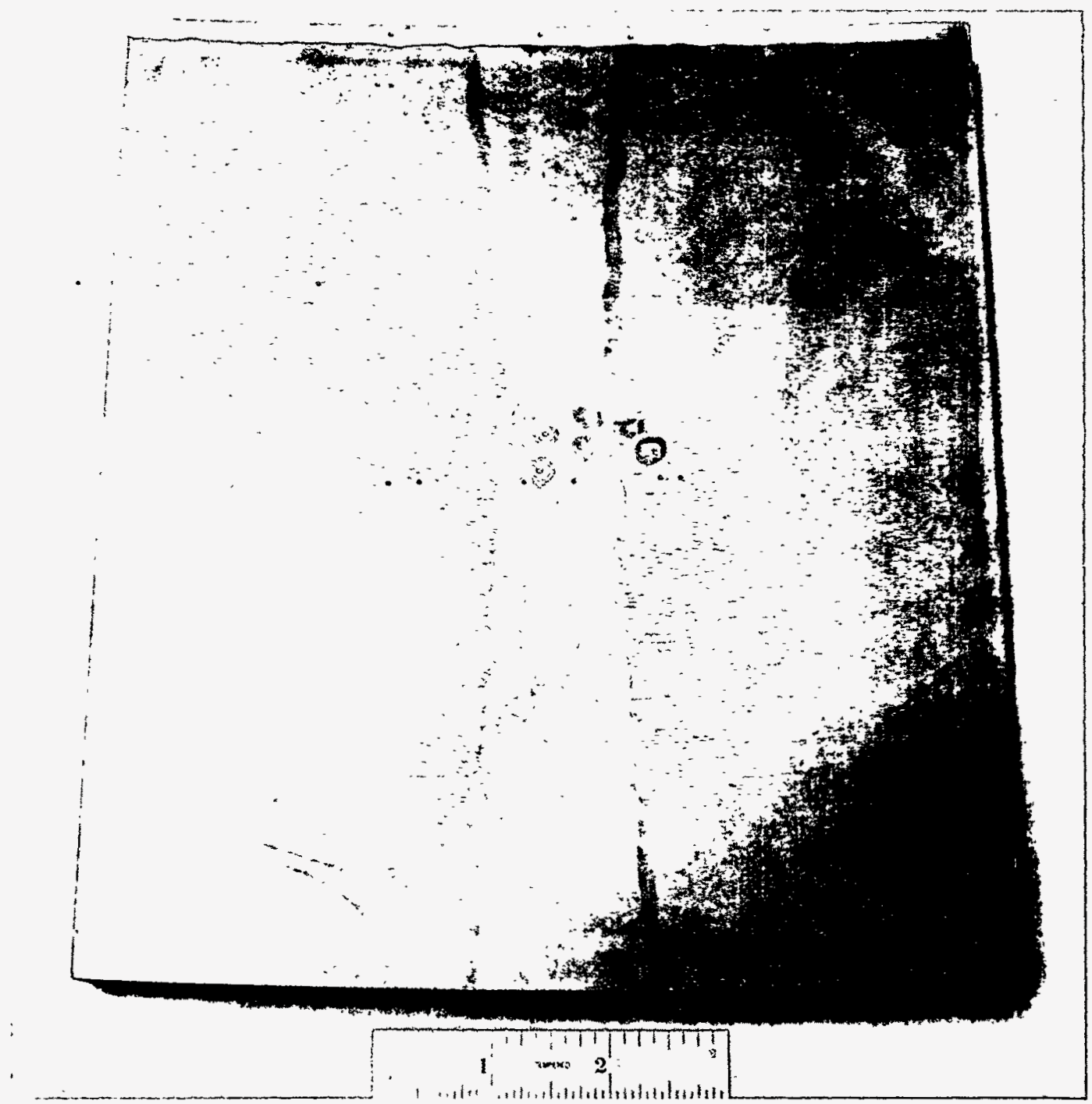

Figure 2.4 Coupon from full-thickness clad beam material showing metallurgical details of test weld

cladding being entrained during the flame-cutting of this particular section.

The specimens used for the preliminary characterization, listed in Table 2.2, were machined from the circumferential weld, as shown in Fig. 2.7. Characterization specimens taken from the region of the weld in which the shallow cracks were located will be tested within the next year. The nomenclature used to define specimen orientation with respect to the major rolling direction and the thickness is standardized ${ }^{16}$ for plates but not for welds. For the purpose of these characterizations, a method similar to that used for plates was used for welds; this method consists of one- or two-letter identifiers. The letters " $L$ " and " $S$ " were used for directions parallel to the welding direction and thickness direction, respectively. The letter " $T$ " was used to indicate a direction normal to both $\mathrm{L}$ and $\mathrm{S}$. Using this method, the first letter given is the longitudinal axis of a specimen, which is also normal to the fracture plane. One letter was sufficient to define the orientation of tensile specimens. For $\mathrm{CVN}$ specimens, a second letter was added to indicate the direction of crack propagation. The CVN specimens shown in Fig. 2.7 are in the " $T$ " orientation. Because the specimen is square in cross section, the specimens could be configured to be either T-L or T-S by properly orienting the notch. These letter designations are shown in Fig. 2.7.

\subsubsection{Results of Testing CVN Specimens in the L-S and T-L Orientations}

The three full-thickness beam specimens were tested in the T-S orientation, and, accordingly, CVN tests were per- 
Full-Thickness

ORNL-DWG 94-3069 ETD
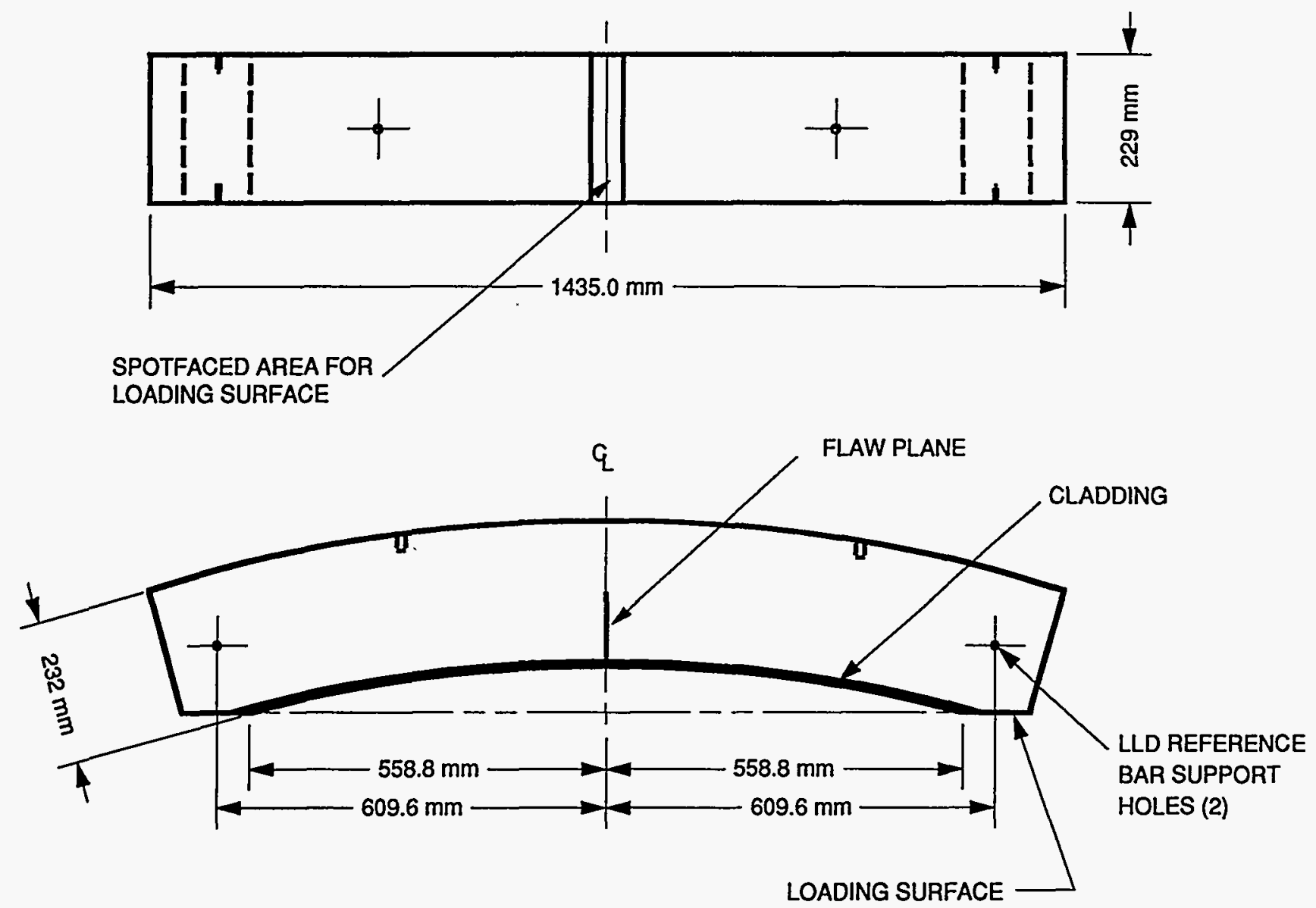

Figure 2.5 Sketch of full-thickness clad beam specimen

Table 2.1 Parameters defining specimen geometry of full-thickness clad beam specimens

\begin{tabular}{lccc}
\hline & CB-1 $^{a}$ & CB-2 & CB-3 \\
\hline Load span, S (mm) & 1219.2 & 1219.2 & 1219.2 \\
Thickness, B (mm) & 230.2 & 230.2 & 229.6 \\
Width, W (mm) & 225.7 & 224.3 & 224.3 \\
Crack depth, a (mm) & 117.5 & 10.8 & 23.7 \\
Ratio, a/W & 0.50 & 0.05 & 0.10 \\
\hline
\end{tabular}

${ }^{a_{\text {Used }}}$ as development beam.

formed in that orientation. The determination of RT NDT required the use of T-L oriented $C V N$ specimens because the T-S orientation for the axial weld corresponds to the $T-L$ orientation for the circumferential weld. The CVN impact test results obtained for both orientations were the impact energy, lateral expansion, and percent shear fracture appearance (SFA). The $10 \times 10 \times 55 \mathrm{~mm}$ CVN specimen used for these tests is recommended by the American
Society for Testing and Materials (ASTM) Standard Method for Notched Bar Impact Testing of Metallic Materials (ASTM E 23). ${ }^{16}$

Detailed results from the Charpy tests are given in Tables 2.3 and 2.4 and are shown in Figs. 2.8 and 2.9 for the T-S and T-L orientations, respectively. Approximately 20 specimens from the midthickness of the weld metal were tested in each of the T-S and T-L orientations. A regression fit of a hyperbolic tangent equation to the experimental data was performed, and Table 2.5 gives the resulting parameters. For the regression fit, the lower-shelf energy (LSE) was prescribed to be $2.7 \mathrm{~J}$ ( $2 \mathrm{ft}-\mathrm{lb}$ ). This value of the LSE is based on an average of five CVN impact tests at $-196^{\circ} \mathrm{C}\left(-321^{\circ} \mathrm{F}\right)$ on material from the WF-70 Midland weld. ${ }^{17}$ The 20-, 41-, and the 68-J impact energy transition temperatures were calculated from the resulting hyperbolic tangent equation. Table 2.5 also contains the drop-weight nil-ductility transition (NDT) temperature and related energy level, as well as the

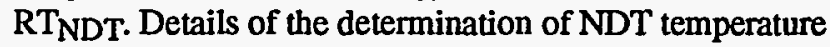
and $\mathrm{RT}_{\mathrm{NDT}}$ are given later. 


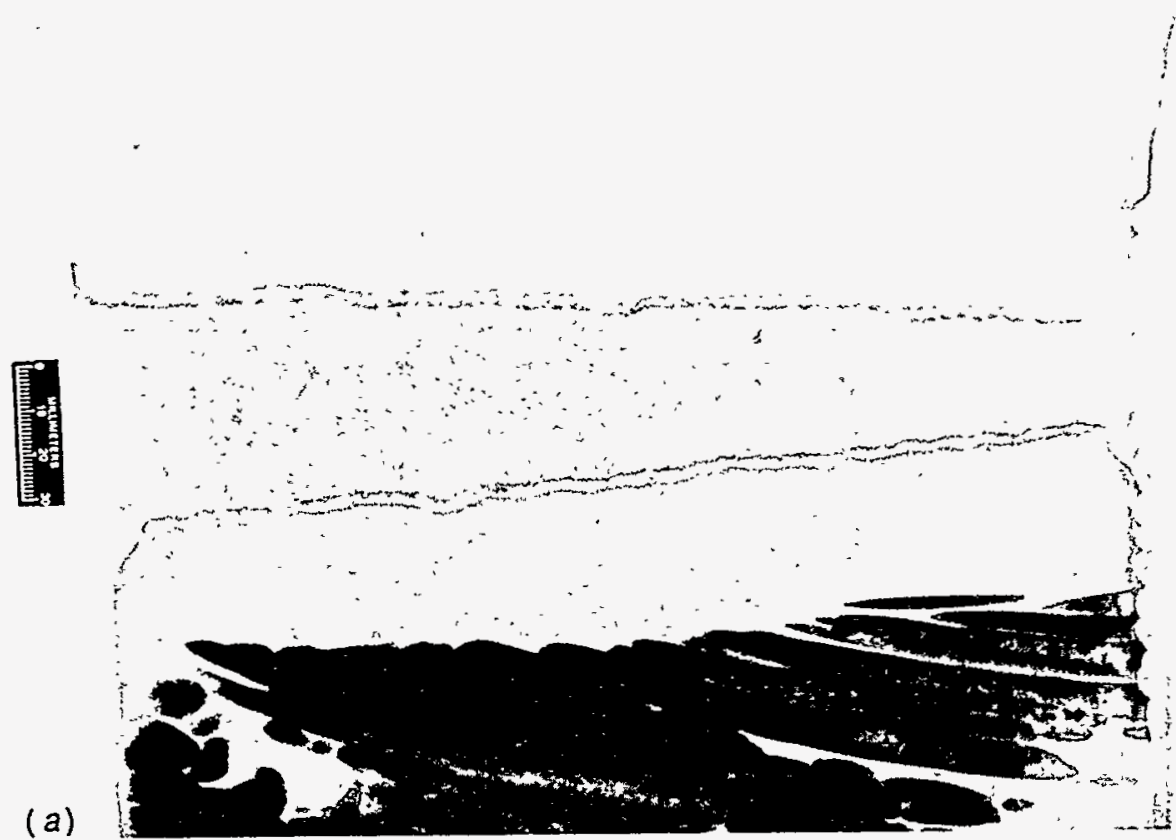

(a)

(b)

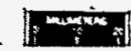

Figure 2.6 Details of welds used in full-thickness clad beam studies: $(a)$ the axial weld and $(b)$ the circumferential weld

The CVN impact energy in the T-S orientation is compared to that in the T-L orientation in Fig. 2.10. From this figure and Table 2.5, it can be seen that, for this weld, there is no significant directional difference in the CVN impact energy behavior.
For the purposes of determining the transition temperature shift of irradiated RPV steels, the NDT temperature is generally assumed to correspond to the 41-J ( $30 \mathrm{ft}-\mathrm{lb})$ CVN impact energy level for $1 / 4 \mathrm{t}$, T-L orientation material. At midthickness, the temperature corresponding to the 41-J 
Table 2.2 Specimens machined for characterizing the circumferential weld for the full-thickness clad beam specimens

\begin{tabular}{|c|c|c|c|c|}
\hline & \multicolumn{2}{|c|}{ CVN } & \multirow{2}{*}{$\frac{\begin{array}{c}\text { P-3 drop } \\
\text { weight }\end{array}}{\mathrm{NA}^{b}}$} & \multirow{2}{*}{$\begin{array}{c}6.35 \text {-mm gage } \\
\begin{array}{c}\text { diameter } \\
\text { tensile }\end{array} \\
\mathrm{T}\end{array}$} \\
\hline Orientation & $\mathrm{T}-\mathrm{S}$ & $\mathrm{T}-\mathrm{L}^{a}$ & & \\
\hline $\begin{array}{l}\text { Number of } \\
\text { specimens }\end{array}$ & 17 & 23 & 10 & 6 \\
\hline $\begin{array}{l}\text { Specimen } \\
\text { identification }\end{array}$ & $\begin{array}{l}\text { SNU01 } \\
\text { through } \\
\text { SNU17 }\end{array}$ & $\begin{array}{l}\text { SNU18 } \\
\text { through } \\
\text { SNU40 }\end{array}$ & $\begin{array}{l}\text { SNU01 } \\
\text { through } \\
\text { SNU10 }\end{array}$ & $\begin{array}{l}\text { SNU01 } \\
\text { through } \\
\text { SNU06 }\end{array}$ \\
\hline
\end{tabular}

$a_{\text {Required for }}$ RT NDT determination.

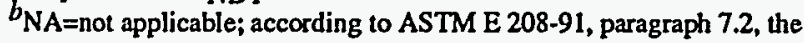
drop-weight NDT is generally considered to be insensitive to specimen orientation with respect to rolling or forging direction.

energy level is $\sim 27^{\circ} \mathrm{C}\left(49^{\circ} \mathrm{F}\right)$ higher than the drop-weight NDT temperature. The temperature corresponding to the 20-J ( $15 \mathrm{ft}-\mathrm{lb}$ ) energy level would have been a better correlation to the NDT temperature.

\subsubsection{Determination of the Reference Temperature $\mathbf{R T}_{\text {NDT }}$}

In accordance with Subarticle NB-2330 in Sect. III of the ASME Boiler and Pressure Vessel Code, ${ }^{15}$ the reference temperature $\mathrm{RT}_{\mathrm{NDT}}$ is the higher of (1) the drop-weight NDT temperature or $(2)(T-33)^{\circ} \mathrm{C}$, where $\mathrm{T}$ is the temperature at which T-L orientation Charpy specimens attain at least a $68-\mathrm{J}$ (50 ft-lb) impact energy and a lateral expansion of $0.89 \mathrm{~mm}$ ( $35 \mathrm{mils}$ ).

The drop-weight testing was performed in accordance with the ASTM Test for Conducting Drop-Weight Test to Determine Nil-Ductility Transition Temperature of Ferritic Steels (ASTM E 208), ${ }^{16}$ and the results are shown in Table 2.6. The NDT temperature is defined in ASTM E 208 to be the highest temperature at which a specimen breaks, providing that two tests at a temperature $5^{\circ} \mathrm{C}$ higher show no-break performance. Thus the NDT temperature is $-50^{\circ} \mathrm{C}\left(-58^{\circ} \mathrm{F}\right)$. The specimen size used was $\mathrm{P}-3$ and, in accordance with ASTM E 208, had a single-pass crackstarter weld bead.

ORNL-DWG 93-13499

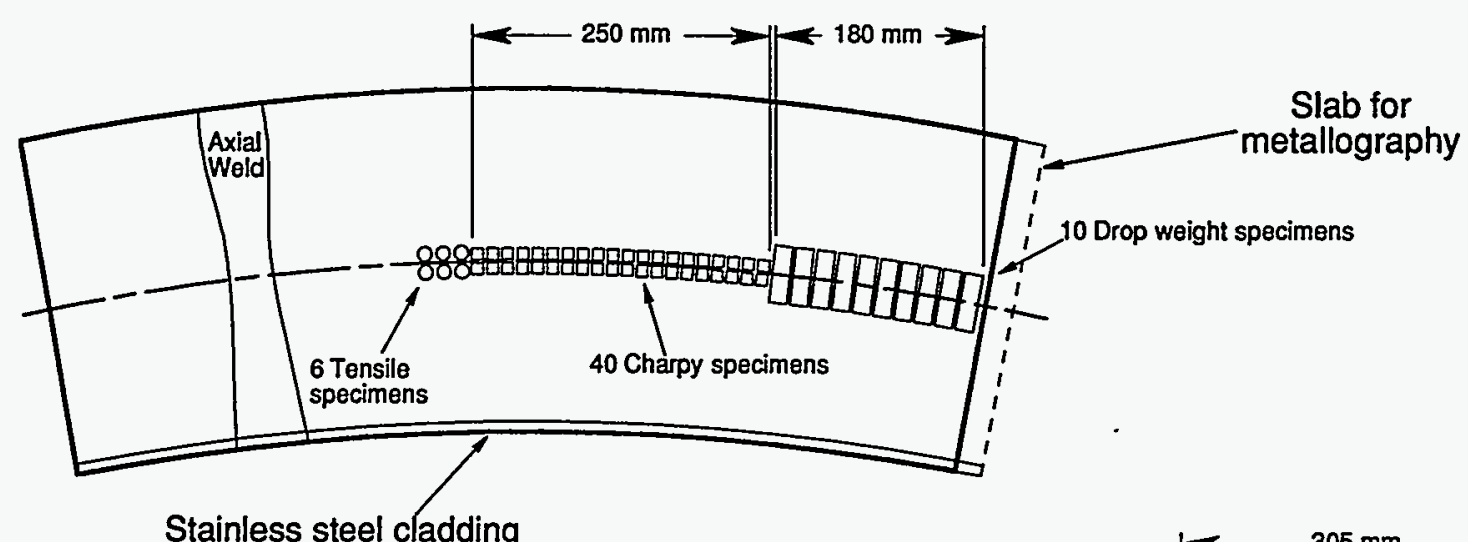

Stainless steel cladding
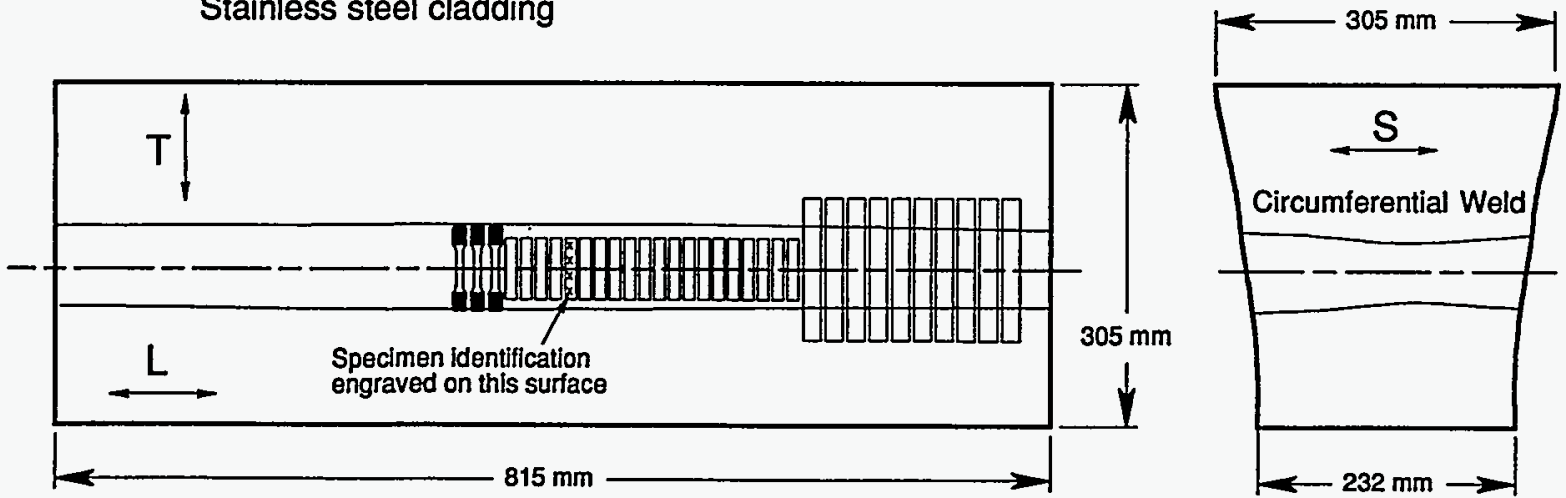

Figure 2.7 Cut-up of characterization block containing circumferential weld of unused RPV showing location of tensile, CVN, and drop-weight specimens 
Table 2.3 Results of testing T-S orientation CVN impact specimens machined from the midthickness of the circumferential weld of an unused RPV. The axis of T-S orientation specimens is normal to welding direction, and crack propagates into the thickness

\begin{tabular}{|c|c|c|c|c|}
\hline \multirow{2}{*}{ Specimen } & \multirow{2}{*}{$\frac{\text { Temperature }}{\left.{ }^{\circ} \mathrm{C}\left({ }^{\circ} \mathrm{F}\right)\right]}$} & \multirow{2}{*}{$\frac{\text { Energy }}{[\mathrm{J}(\mathrm{ft}-\mathrm{lb})]}$} & \multirow{2}{*}{$\frac{\text { Lateral expansion }}{[\mathrm{mm}(\mathrm{mil})]}$} & \multirow{2}{*}{$\begin{array}{c}\text { Shear } \\
(\%)\end{array}$} \\
\hline & & & & \\
\hline SNU39 & $-101(-150)$ & $4(2.9)$ & $0.051 \quad(2)$ & 0 \\
\hline SNU38 & $-101 \quad(-150)$ & $7(5.2)$ & 0.152 (6) & 3 \\
\hline SNU34 & $-73(-100)$ & $9(6.6)$ & $0.152(6)$ & 5 \\
\hline SNU25 & $-59(-75)$ & $19(13.8)$ & $0.279 \quad(11)$ & 15 \\
\hline SNU32 & $-46(-50)$ & $9(6.6)$ & 0.229 (9) & 10 \\
\hline SNU24 & $-46(-50)$ & $12(8.8)$ & $0.330 \quad(13)$ & 15 \\
\hline SNU33 & $-46(-50)$ & $29(21.4)$ & $0.457 \quad(18)$ & 20 \\
\hline SNU40 & $-32(-25)$ & $13(9.7)$ & $0.381 \quad(15)$ & 15 \\
\hline SNU23 & $-32(-25)$ & $50(36.9)$ & $0.787 \quad(31)$ & 30 \\
\hline SNU22 & $-18(0)$ & $52(38.5)$ & 0.864 (34) & 35 \\
\hline SNU26 & $-4(25)$ & 71 (52.6) & $1.143 \quad(45)$ & 60 \\
\hline SNU29 & $10(50)$ & $63(46.8)$ & 1.092 & 75 \\
\hline SNU27 & $10(50)$ & $86(63.5)$ & $1.448 \quad(57)$ & 70 \\
\hline SNU18 & $22(71)$ & $86(63.4)$ & $1.473 \quad(58)$ & 75 \\
\hline SNU31 & $22(72)$ & 91 (67) & $1.448 \quad(57)$ & 90 \\
\hline SNU30 & $22(72)$ & $95(70.4)$ & $1.549(61)$ & 90 \\
\hline SNU28 & $38(100)$ & $98(72)$ & $1.651 \quad(65)$ & 97 \\
\hline SNU19 & 52 (125) & $102(74.9)$ & $1.702(67)$ & 90 \\
\hline SNU20 & $93(200)$ & $118(86.7)$ & $1.930(76)$ & 100 \\
\hline SNU35 & $149(300)$ & $106(78.3)$ & 1.854 (73) & 100 \\
\hline SNU21 & $149(300)$ & $117(86.5)$ & $1.956(77)$ & 100 \\
\hline SNU37 & $288(550)$ & $110(81)$ & $1.905 \quad(75)$ & 100 \\
\hline SNU36 & $288(550)$ & $111(81.7)$ & $1.930(76)$ & 100 \\
\hline
\end{tabular}

The results from CVN impact tests at a temperature of $-17^{\circ} \mathrm{C}(\mathrm{NDT}+33)$ in the T-L orientation are listed in Table 2.4. The minimum 68-J energy level was not attained for three specimens at this temperature. The 68-J energy level and the $0.89-\mathrm{mm}$ lateral expansion requirement were achieved at a temperature of $10^{\circ} \mathrm{C}\left(50^{\circ} \mathrm{F}\right)$, which resulted in an $\mathrm{RT}_{\mathrm{NDT}}$ of $-23^{\circ} \mathrm{C}\left(-10^{\circ} \mathrm{F}\right)$.

Subarticle NB-2330 ${ }^{15}$ also permits the determination of the $68-\mathrm{J} / 0.89-\mathrm{mm}$ temperature "from a full Charpy Vnotch impact curve developed from the minimum data points of all the tests performed."15 A portion of the full curve through the minimum of the CVN impact energy data bracketing the 68-J level is shown in Fig. 2.11. The 68-J level occurs at a temperature of $18^{\circ} \mathrm{C}\left(65^{\circ} \mathrm{F}\right)$; thus, the $\mathrm{RT}_{\text {NDT }}$ could have been determined to be $-15^{\circ} \mathrm{C}\left(5^{\circ} \mathrm{F}\right)$. The $0.89-\mathrm{mm}$ requirement is also met. Considering the possible errors and scatter of the various measurements required to determine $\mathrm{RT}_{\mathrm{NDT}}$, the $8^{\circ} \mathrm{C}\left(15^{\circ} \mathrm{F}\right)$ higher value obtained using this second method is not significant but is an illustration of the possible differences that may arise from different interpretations of NB-2330.

\subsubsection{Tensile Testing}

Results from tensile testing two specimens from midthickness, circumferential weld material at each of three temperatures are given in Table 2.7. The machining specifications for the specimens are shown in Fig. 2.12. The specimens had 6.35 -mm (0.25-in.) gage diameters and were transversely oriented to the weld direction plane. The values of total elongation were determined by measuring the change in length of the entire specimen and dividing that change in length by the length of the reduced section. A separate cal- 
Table 2.4 Results of testing T-L orientation CVN impact specimens machined from the midthickness of the circumferential weld of an unused RPV. The axis of T-L orientation specimens is normal to welding direction, and crack propagates in the welding direction

\begin{tabular}{|c|c|c|c|c|}
\hline \multirow{2}{*}{ Specimen } & \multirow{2}{*}{$\frac{\text { Temperature }}{\left.{ }^{\circ} \mathrm{C}\left({ }^{\circ} \mathrm{F}\right)\right]}$} & \multirow{2}{*}{$\frac{\text { Energy }}{[\mathrm{J}(\mathrm{ft}-\mathrm{lb})]}$} & \multirow{2}{*}{$\frac{\text { Lateral expansion }}{[\mathrm{mm}(\mathrm{mil})]}$} & \multirow{2}{*}{$\begin{array}{c}\text { Shear } \\
(\%)\end{array}$} \\
\hline & & & & \\
\hline SNU10 & $-46 \quad(-50)$ & $14 \quad(10.1)$ & 0.279 (11) & 25 \\
\hline SNU09 & $-32 \quad(-25)$ & $35 \quad(25.5)$ & $0.559 \quad(22)$ & 30 \\
\hline SNU01 & $-17 \quad(2)$ & $26 \quad(19.5)$ & $0.559 \quad(22)$ & 40 \\
\hline SNU02 & $-17 \quad(2)$ & $46 \quad(34.1)$ & $0.762 \quad(30)$ & 50 \\
\hline SNU03 & $-17 \quad(2)$ & $56 \quad(41.0)$ & $1.016(40)$ & 50 \\
\hline SNU15 & $7 \quad(45)$ & $55 \quad(40.2)$ & $1.041 \quad(41)$ & 80 \\
\hline SNU17 & 7 (45) & $57 \quad(41.8)$ & $1.016(40)$ & 80 \\
\hline SNU16 & 7 (45) & $90 \quad(66.4)$ & 1.499 (59) & 85 \\
\hline SNU11 & $10 \quad(50)$ & $74 \quad(54.9)$ & 1.245 (49) & 75 \\
\hline SNU12 & $10 \quad(50)$ & $77 \quad(56.5)$ & $1.270 \quad(50)$ & 70 \\
\hline SNU08 & $10 \quad(50)$ & $90 \quad(66.1)$ & $1.245 \quad(49)$ & 90 \\
\hline SNU04 & $22 \quad(72)$ & $87 \quad(63.9)$ & 2.007 (79) & 85 \\
\hline SNU07 & 52 (125) & $102(74.9)$ & $1.626(64)$ & 95 \\
\hline SNU05 & $66(150)$ & $116(85.5)$ & 1.829 (72) & 97 \\
\hline SNU06 & $93 \quad(200)$ & $115 \quad(84.5)$ & $1.956(77)$ & 97 \\
\hline SNU13 & $149(300)$ & $117(86.0)$ & 1.905 (75) & 100 \\
\hline SNU14 & $149(300)$ & $125 \quad(92.0)$ & $1.930(76)$ & 100 \\
\hline
\end{tabular}

Note: USE: $119.74 \mathrm{~J}(88.3 \mathrm{ft}-1 \mathrm{~b})$ MTT: $-1.74^{\circ} \mathrm{C}\left(28.9^{\circ} \mathrm{F}\right)$ TZW: $97.94^{\circ} \mathrm{C}\left(176.3^{\circ} \mathrm{F}\right)$

culation can be performed to obtain the elongation in a gage length of four times the gage diameter (4d). The elongation in $4 \mathrm{~d}$ is about $15 \%$ higher than the values based on the reported total length.

The yield and ultimate strengths shown in Table 2.7 are plotted in Fig. 2.13 as a function of temperature and were regression fit with an Irwin-type equation: ${ }^{18}$

$$
\sigma_{0}=390+\frac{51,650}{\mathrm{~T}+273}, \quad-80 \leq \mathrm{T} \leq 25^{\circ} \mathrm{C}
$$

and

$$
\sigma_{u}=488+\frac{52,830}{\mathrm{~T}+273}, \quad-80 \leq \mathrm{T} \leq 25^{\circ} \mathrm{C}
$$

where $\sigma_{0}$ and $\sigma_{\mathrm{u}}$ are the yield and ultimate strengths in megapascals, respectively, and $\mathrm{T}$ is the temperature in degrees Celsius.
A 25-mm (1-in.) extensometer was attached to the gage length of the specimens to record the loads and extensometer output. The engineering stresses and strains calculated from the digital output are shown in Fig. 2.14 and were used in the analysis of the full-thickness clad beam tests. The initial yield area is shown on a larger scale in Fig. 2.15. The lower yield point is shown to be more pronounced at lower temperatures and becomes less distinct at room temperature.

The ABI technique was used to determine whether the yield strengths of the circumferential weld ${ }^{19}$ and the axial weld were similar. Three $A B I$ indentations were made at the midthickness location for both welds. The tensile tests previously described were performed on midthickness material from the circumferential weld. The comparative results are shown in Table 2.8. The ABI-derived yield strengths for the circumferential weld averaged $508 \mathrm{MPa}$ (73.7 ksi) and ranged from 490 to $531 \mathrm{MPa}(71$ to $77 \mathrm{ksi})$ compared to an average of $565 \mathrm{MPa}(82.0 \mathrm{ksi})$ for the two 

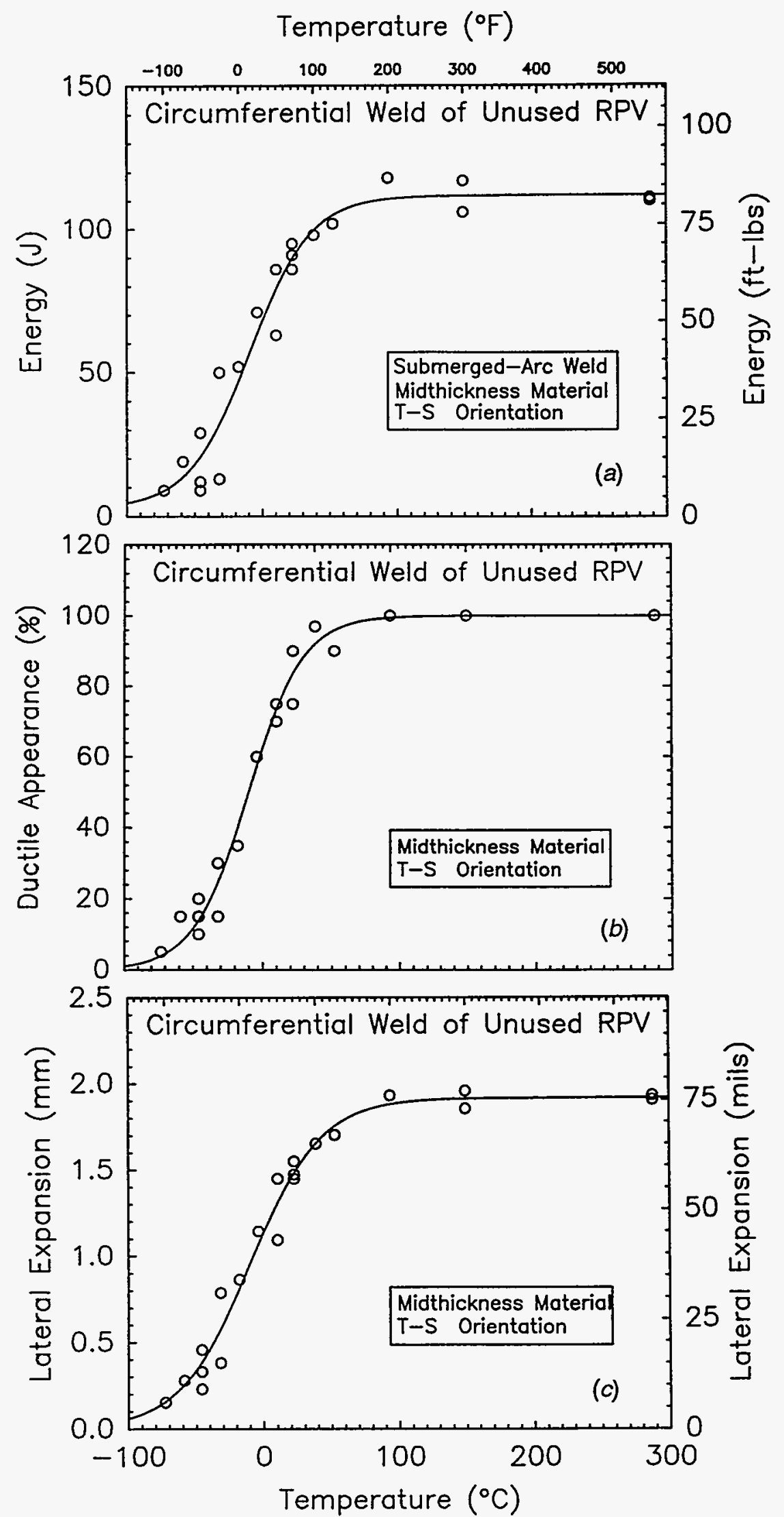

Figure 2.8 CVN impact test results on specimens machined in T-S orientation from midthickness of circumferential weld of unused RPV: (a) CVN impact energy, (b) percent SFA, and (c) lateral expansion 
Full-Thickness

ORNL-DWG 94-3071 ETD

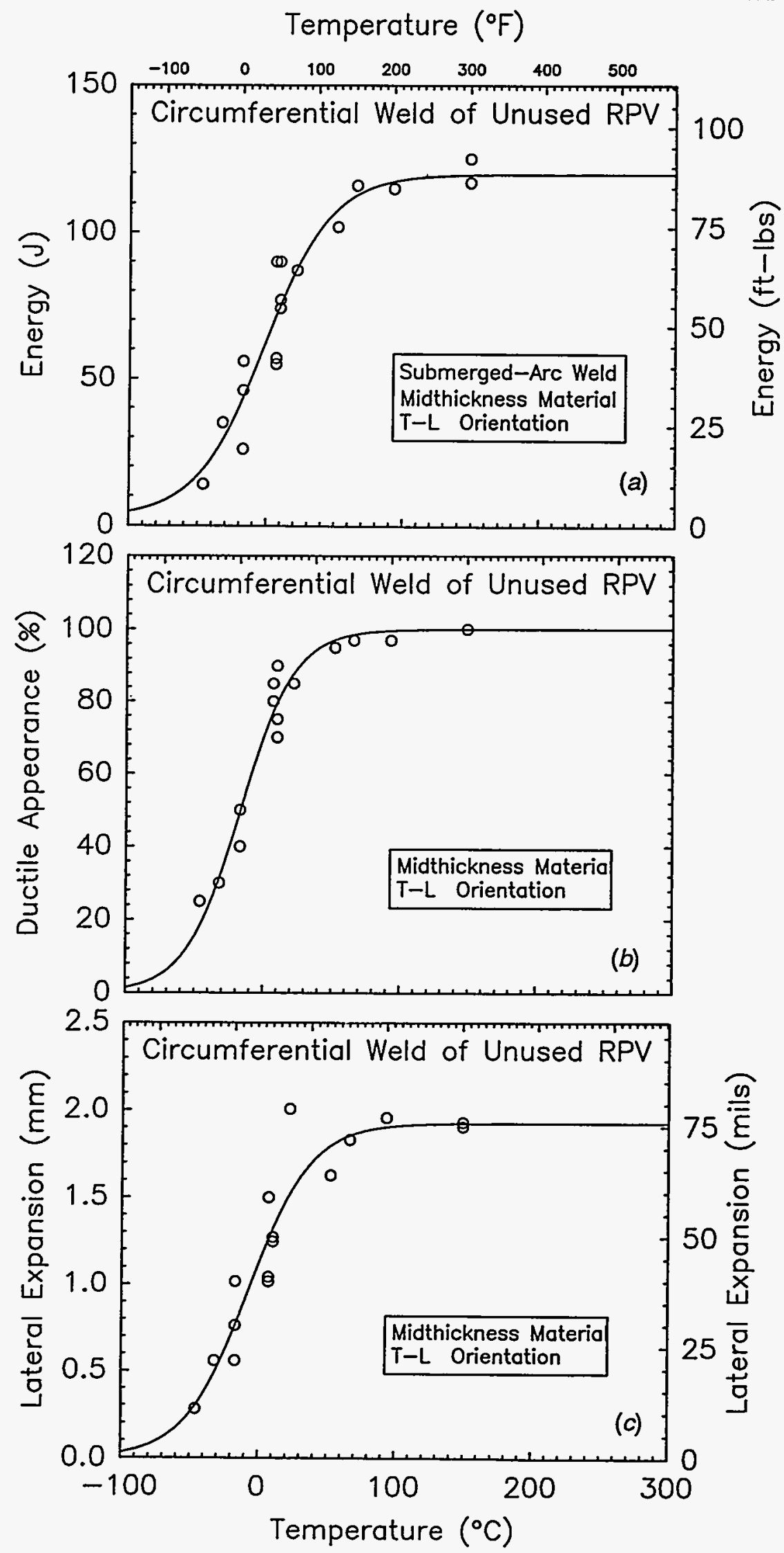

Figure 2.9 CVN impact test results on specimens machined in T-L orientation from midthickness of circumferential weld of an unused RPV: (a) CVN impact energy, (b) percent SFA, and (c) rateral expansion 


\section{Full-Thickness}

Table 2.5 Summary of test results to determine the CVN impact energy in the T-S and T-L orientations, drop-weight NDT temperature, and RT NDT of midthickness material from the circumferential weld of an unused RPV

\begin{tabular}{|c|c|c|c|c|c|c|c|c|c|}
\hline \multicolumn{3}{|c|}{ Tanh fit parameters ${ }^{a}$} & \multicolumn{3}{|c|}{$\begin{array}{c}\text { Temperature }\left[{ }^{\circ} \mathrm{C}\left({ }^{\circ} \mathrm{F}\right)\right] \text { of } \\
\text { an energy level }\end{array}$} & \multirow{2}{*}{$\begin{array}{l}\mathrm{NDT}^{b} \\
{\left[{ }^{\circ} \mathrm{C}\left({ }^{\circ} \mathrm{F}\right)\right]}\end{array}$} & \multirow{2}{*}{$\begin{array}{l}\text { RT }_{\text {NDT }} \\
{\left[^{\circ} \mathrm{C}\left({ }^{\circ} \mathrm{F}\right)\right]}\end{array}$} & \multicolumn{2}{|c|}{ Energy level [J(ft-lb)] at } \\
\hline $\begin{array}{c}\text { USE } \\
{[\mathrm{J}(\mathrm{ft}-\mathrm{lb})]}\end{array}$ & $\begin{array}{c}\text { MTT } \\
{\left[{ }^{\circ} \mathrm{C}\left({ }^{\circ} \mathrm{F}\right)\right]}\end{array}$ & $\begin{array}{c}\text { TZW } \\
{\left[{ }^{\circ} \mathrm{C}\left({ }^{\circ} \mathrm{F}\right)\right]}\end{array}$ & $20 \mathrm{~J}$ & $41 \mathrm{~J}$ & $68 \mathrm{~J}$ & & & NDT & $\mathbf{R T}_{\mathbf{N D T}}$ \\
\hline \multicolumn{10}{|c|}{$T-S$ orientation } \\
\hline $111.8(82.5)$ & $-9.21(15.4)$ & $90.6(163.1)$ & $-47(-53)$ & $-23(-9)$ & $O(32)$ & $-50(-58)$ & $-23(-10)$ & $18(13)$ & $41(30)$ \\
\hline \multicolumn{10}{|c|}{$T-L$ orientation } \\
\hline $119.7(88.3)$ & $-1.742(28.9)$ & $97.9(176.3)$ & $-45(-49)$ & $-19(-2)$ & $4(39)$ & $-50(-58)$ & $-23(-10)$ & $17(13)$ & $37(27)$ \\
\hline
\end{tabular}

${ }^{a}$ The following equation was used to fit the data: Energy $=(\mathrm{USE}+2.7) / 2+[(\mathrm{USE}-2.7) / 2] \cdot \mathrm{Tanh}[(T-M T T) /(T Z W / 2)]$, where USE=upper-shelf energy, 2.7=lower-shelf energy, MTT=midtransition temperature, and TZW=transition zone width. The $2.7 \mathrm{~J}$ is the lower-shelf energy and was determined experimentally from five tests conducted at liquid nitrogen temperature $\left(-196^{\circ} \mathrm{C}\right)$ on a submerged-arc weld.

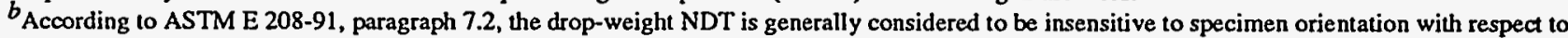
rolling or forging direction.

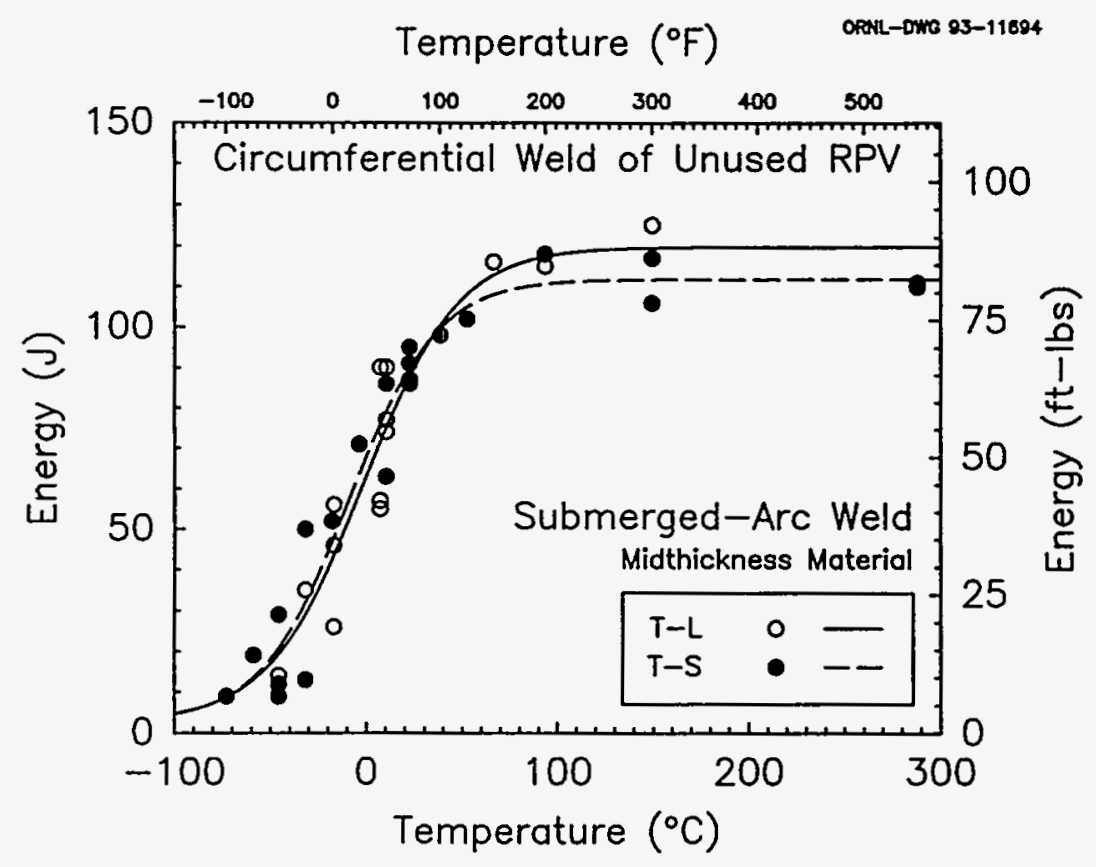

Figure 2.10 Comparison of the CVN-impact energy in T-S orientation to that in T-L orientation for midthickness material from circumferential weld of unused RPV

tensile specimens tested at room temperature. The average and range of $A B I$ values for the axial weld were $515 \mathrm{MPa}$ (74.7 ksi) and 510 to $524 \mathrm{MPa}$ (74 to $76 \mathrm{ksi}$ ), respectively. It was thus concluded that the tensile properties for both welds are similar.
These impact and tensile data were used to develop a consistent set of material properties needed for the clad beam test data evaluation and finite-element analyses. These properties are shown in Table 2.9. The ABI technique was used to determine the yield stress for the 
Table 2.6 Results of drop-weight testing P-3 size specimens from the circumferential weld between nozzle-ring to shell course. Specimens were machined from midthickness material and the crack-starter bead was a single pass weld as defined in ASTM E 208

\begin{tabular}{|c|c|c|c|c|}
\hline \multirow{2}{*}{$\begin{array}{c}\text { Specimen } \\
\text { ID }\end{array}$} & \multirow{2}{*}{$\begin{array}{c}\begin{array}{c}\text { Test } \\
\text { temperature }\end{array} \\
\text { ('C) }\end{array}$} & \multicolumn{3}{|c|}{ Test Results } \\
\hline & & - Break & No break & $\begin{array}{l}\text { NDT }^{a} \\
\left({ }^{\circ} \mathrm{C}\right)\end{array}$ \\
\hline SNU09 & -50 & $\sqrt{ }$ & & \\
\hline SNU08 & -45 & & $\sqrt{ }$ & \\
\hline SNU10 & -45 & & $\sqrt{ }$ & \\
\hline SNU06 & -40 & & $\sqrt{ }$ & \\
\hline \multirow[t]{2}{*}{ SNU02 } & -30 & & $\sqrt{ }$ & \\
\hline & & & & -50 \\
\hline
\end{tabular}

$a_{\text {NDT }}$ is defined in E 208-91 to be the highest temperature at which a specimen breaks, and at least two tests at a temperature $5^{\circ} \mathrm{C}$ higher show no-break performance.

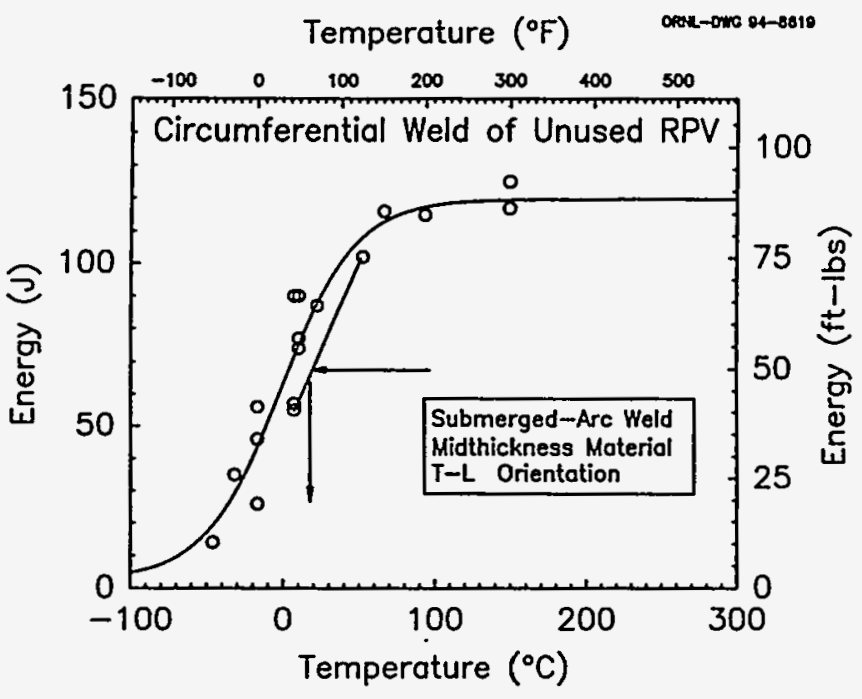

Figure 2.11 CVN impact energy of T-L orientation specimens machined from the circumferential weld of unused RPV

Table 2.7 Tensile properties of midthickness material from the circumferential weld of an unused RPV. The axis of the specimens was normal to the welding direction (T-orientation), and the gage diameter was $6.35 \mathrm{~mm}(0.25 \mathrm{in}$.)

\begin{tabular}{|c|c|c|c|c|c|c|c|c|c|}
\hline \multirow{3}{*}{$\begin{array}{l}\text { Specimen } \\
\text { SNU03 }\end{array}$} & \multirow{2}{*}{\multicolumn{2}{|c|}{$\begin{array}{c}\text { Temperature } \\
{\left[{ }^{\circ} \mathrm{C}\left({ }^{\circ} \mathrm{F}\right)\right]}\end{array}$}} & \multicolumn{4}{|c|}{$\begin{array}{c}\text { Strength } \\
{[\mathrm{MPa}(\mathrm{ksi})]}\end{array}$} & \multicolumn{2}{|c|}{$\begin{array}{c}\text { Elongation } \\
(\%)\end{array}$} & \multirow{3}{*}{$\begin{array}{c}\begin{array}{c}\text { Reduction } \\
\text { of area } \\
\text { (\%) }\end{array} \\
64\end{array}$} \\
\hline & & & \multicolumn{2}{|c|}{$0.2 \%$ Yield } & \multicolumn{2}{|c|}{$\begin{array}{l}\text { Ultimate } \\
\text { strength }\end{array}$} & \multirow{3}{*}{$\begin{array}{c}\text { Uniform } \\
11 \\
11\end{array}$} & \multirow{2}{*}{$\frac{\text { Total }}{25}$} & \\
\hline & -80 & $(-112)$ & 664 & (96.3) & 768 & (111.4) & & & \\
\hline SNU06 & -80 & $(-112)$ & 652 & (94.6) & 761 & (110.4) & & 26 & 64 \\
\hline SNU02 & -25 & $(-13)$ & 600 & $(87.0)$ & 712 & (103.2) & 9 & 23 & 65 \\
\hline SNU05 & -25 & $(-13)$ & 596 & (86.4) & 703 & $(102.0)$ & 10 & 24 & 67 \\
\hline SNU01 & 23 & (73) & 565 & $(82.0)$ & 672 & $(97.5)$ & - & 18 & 63 \\
\hline SNU04 & 23 & (73) & 565 & $(81.9)$ & 665 & (96.4) & 8 & 23 & 66 \\
\hline
\end{tabular}

base and clad material. The tabulated yield stress for the weld material is $36 \%$ higher than the yield stress for the base material. The weld material exhibits a significant overmatch in yield stress as compared to the yield stress for the base material.

\subsection{Test Equipment and Procedures}

The full-thickness clad beam tests were performed at NIST using the 53.4-MN (12-M lb) servo-hydraulic test machine.
It was necessary to modify the existing facility or procure special components to perform the required tests. Because the 53.4-MN actuator does not have dynamic capability, a 2.67-MN (600-kip) actuator was procured for use in fatigue pre-cracking the specimens. To avoid the possibility of warm prestressing the material, the test specification 20 dictated that the specimen not be disturbed after fatigue precracking. A fatigue system was designed that permitted removal of the 2.67-MN actuator after precracking without disturbing the general test set-up. The fracture test was then performed using the 53.4-MN actuator. A three-point bend 


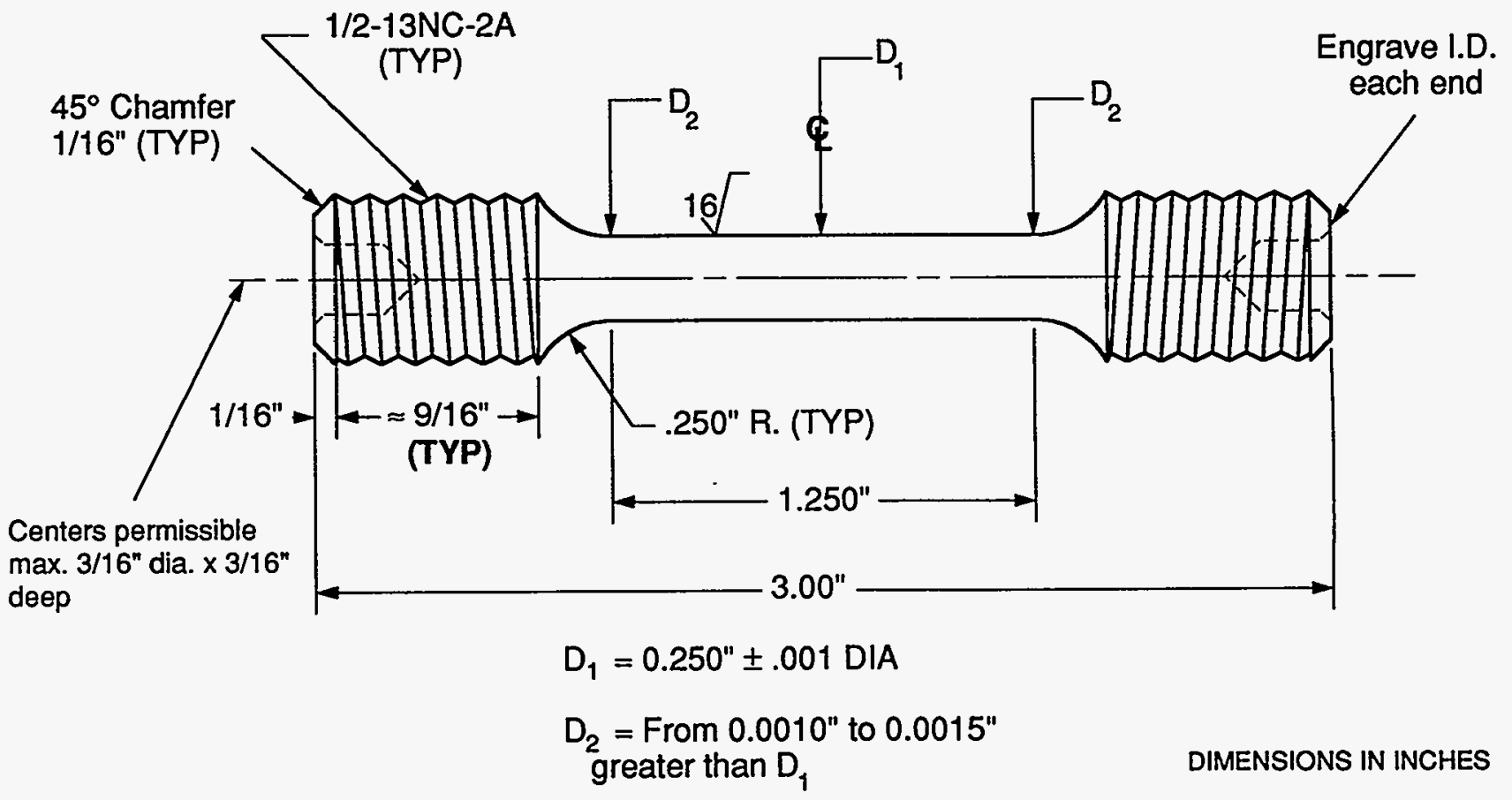

Figure 2.12 Tensile specimen machined in T-orientation from midthickness material from circumferential weld of unused RPV (dimensions taken from machining specificiation)

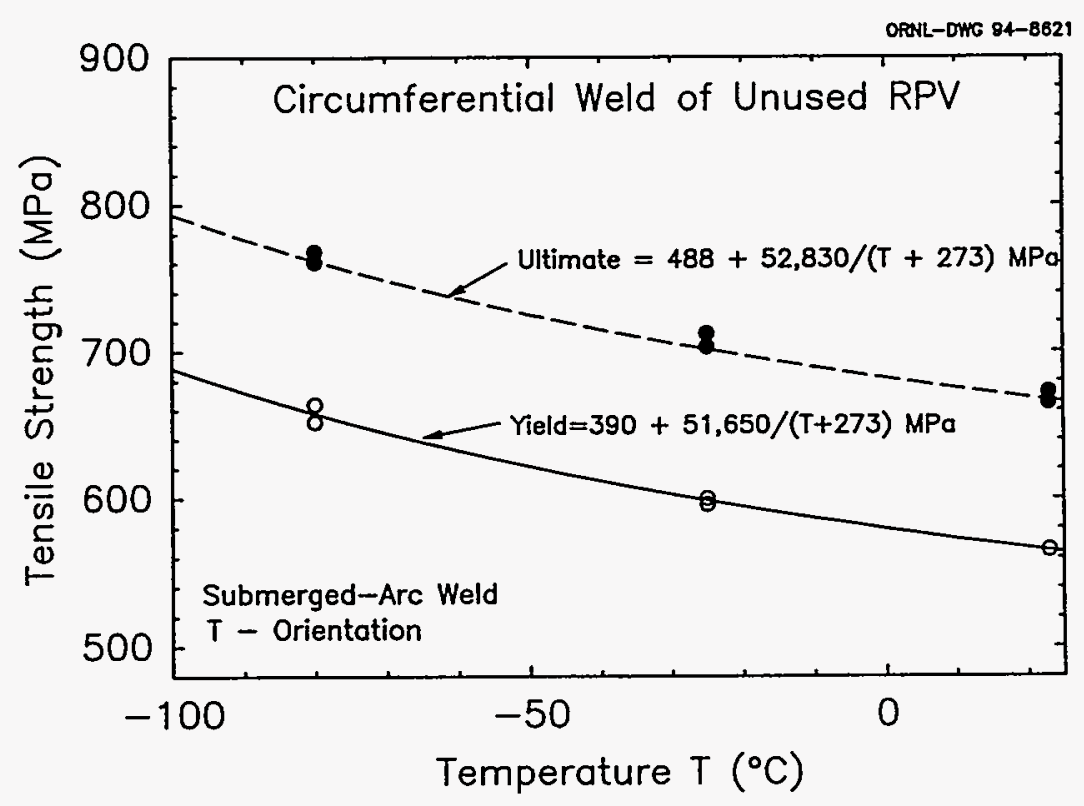

Figure 2.13 Yield and ultimate tensile strengths of T-orientation specimens for midthickness. material from circumferential weld of unused RPV 
Full-Thickness

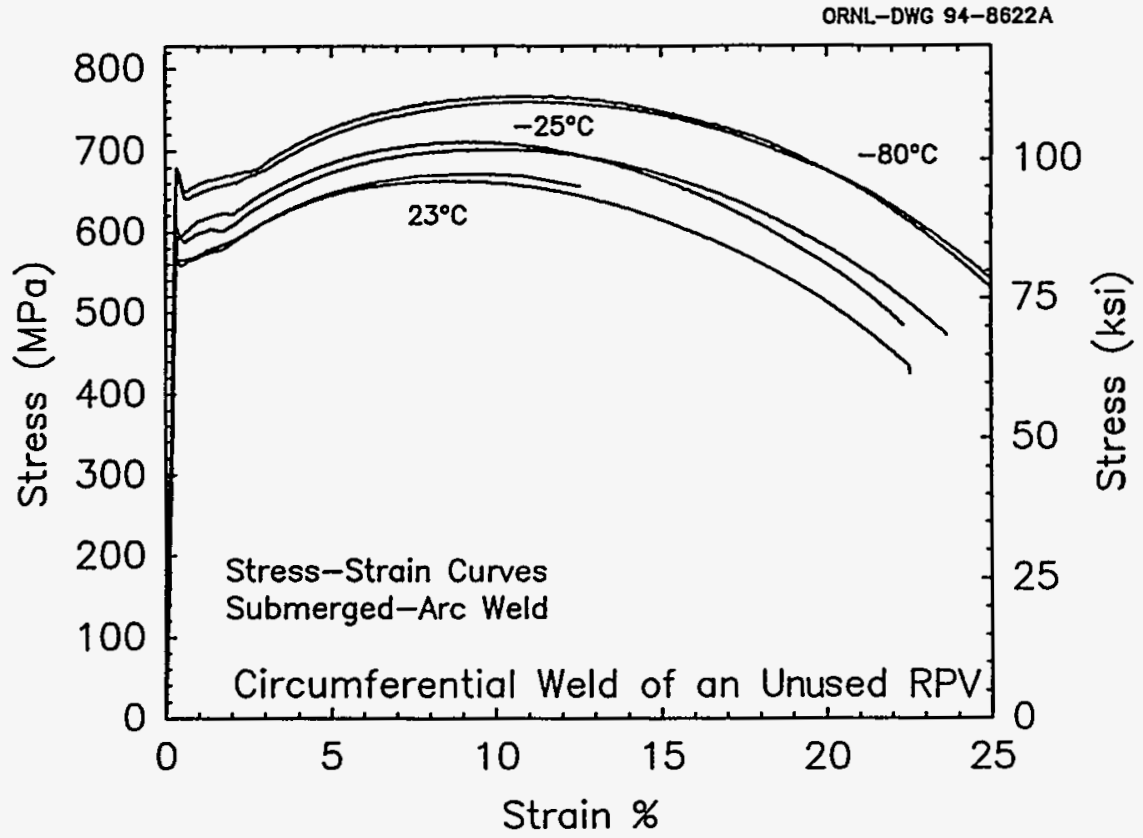

Figure 2.14 Stress-strain behavior at different temperatures of SAW metal from midthickness of circumferential weld

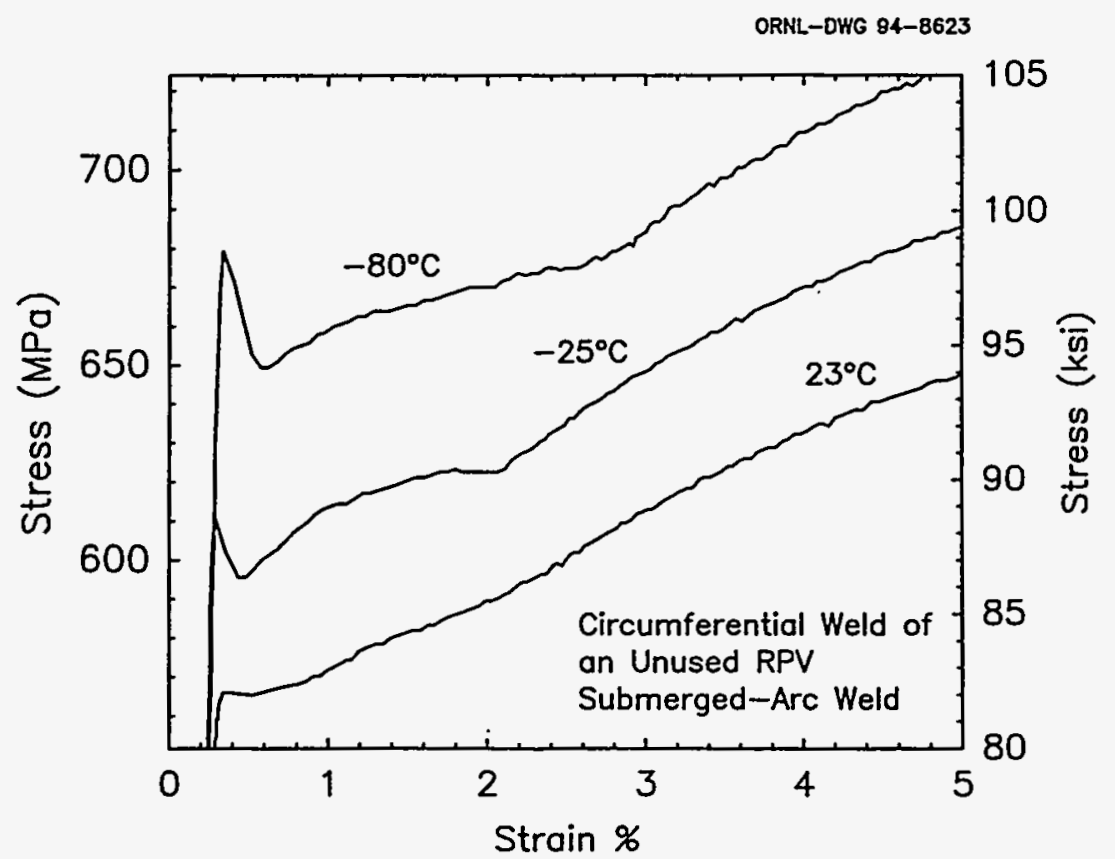

Figure 2.15 Distinction between upper and lower yield becoming less pronounced as temperature decreases 
Table 2.8 Yield strength derived at room temperature from $\mathrm{ABI}$ for midthickness material from the circumferential and axial welds of an unused RPV

\begin{tabular}{|c|c|c|}
\hline ABI Identification & \multicolumn{2}{|c|}{$\begin{array}{c}\text { Yield } \\
{[\mathrm{MPa}(\mathbf{k s i})]}\end{array}$} \\
\hline \multicolumn{3}{|c|}{ Circumferential weld } \\
\hline 21 & 503 & (73) \\
\hline 22 & 531 & (77) \\
\hline 23 & 490 & (71) \\
\hline Average & 508 & (73.7) \\
\hline \multicolumn{3}{|c|}{ Axial weld } \\
\hline 11 & 524 & $(76)$ \\
\hline 13 & 510 & (74) \\
\hline 14 & 510 & (74) \\
\hline Average & 515 & $(74.7)$ \\
\hline
\end{tabular}

Table 2.9 Material properties at test temperature of $-25^{\circ} \mathrm{C}$

\begin{tabular}{lrrc}
\hline & $\begin{array}{c}\text { Base } \\
\text { metal }\end{array}$ & $\begin{array}{r}\text { Weld } \\
\text { metal }\end{array}$ & Cladding \\
\hline Modulus of elasticity & 200,000 & 200,000 & $152,000^{a}$ \\
(E), MPa & & & \\
Poisson's ratio $(v)$ & 0.3 & 0.3 & 0.3 \\
Yield stress $\left(\sigma_{0}\right), \mathrm{MPa}$ & $440^{b}$ & $599^{c}$ & $367^{b}$ \\
Ultimate stress $\left(\sigma_{\mathrm{u}}\right), \mathrm{MPa}$ & $660^{d}$ & $704^{e}$ & 659 \\
$\mathrm{RT}_{\mathrm{NDT}}{ }^{\circ} \mathrm{C}$ & & -23 & \\
NDT, ${ }^{\circ} \mathrm{C}$ & & -50 & \\
\hline
\end{tabular}

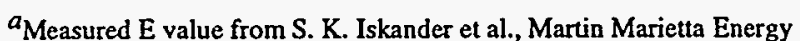
Systems, Inc., Oak Ridge National Laboratory, "Experimental Results of Tests to Investigate Flaw Behavior of Mechanically Loaded Stainless Steel Clad Plates," NUREG/CR-5785 (ORNL/TM-11950) April 1992. $b^{\sigma_{0}}$ measured by $\mathrm{ABI}$ technique.

$c^{c}$ Evaluated from $\sigma_{0}=390+51650 /(T+273)$ where $T$ is the material temperature.

$d_{\sigma_{u} \text { measured by Rockwell B indentation technique. }}$

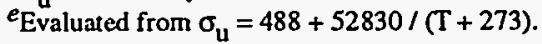

fixture with span and load capacity sufficient to perform these tests was designed and fabricated. This fixture was designed for a load capacity of at least $15 \mathrm{MN}$ (3370 kips), which was calculated to be in excess of that required for these tests. The fixture was designed to meet the general requirements of ASTM E 399 (arc-bend chord-supported tests). ${ }^{16}$ Special large-range crack-opening-displacement gages and associated electronics were obtained specifically for these tests. In addition, dual data acquisition systems (DASs) were purchased to provide redundancy and minimize the possibility of data loss during the tests. The load and DAS components were installed, calibrated, and functionally validated before beginning the fracture tests. All instruments making critical measurements have calibrations traceable to NIST. Because the tests were performed at a low temperature, an environmental chamber was fabricated to completely enclose the test article and load-contact points to facilitate control of both time- and spatial-dependent specimen temperature variations.

The total test sequence for the set of three beams involved three phases: (1) a shakedown and demonstration phase, (2) the fatigue precracking phase, and (3) the failure test phase. A complete series of validation tests was performed before beginning the fracture tests. As indicated by the footnote in Table 2.1, the deep-flaw specimen was designated as a development beam for this series. The primary purpose of the development beam test was to verify and validate the testing procedures for the two remaining tests. The development beam was sent to NIST in the blank form, that is, before final machining and without a notch or crack. It was instrumented with 16 thermocouples, shown schematically in Fig. 2.16, to check out the temperature control system. Two of the thermocouples located on the back surface of the specimen (outer surface of the shell) were recessed $114.3 \mathrm{~mm}$ ( $4.5 \mathrm{in}$.) deep to measure interior specimen temperatures for comparison with those measured on the surface. The beam was mounted in the test facility with the environmental enclosure in place; it was then cooled as it would be for an actual fracture test, and measurements of cooling rate and temperature distribution were made. Cooling was achieved by a spray of liquid nitrogen $\left(\mathrm{LN}_{2}\right)$ onto the beam surface. Figure 2.17 shows a typical temperature record for these temperature control validation tests. In general, during cooldown, there was considerable variation in the temperature record at different locations due to $\mathrm{LN}_{2}$ spraying directly on the thermocouples. When the desired temperature had been negatively exceeded by several degrees, the $\mathrm{LN}_{2}$ spray was stopped, and the beam was allowed to come to thermal equilibrium. Within $1 \mathrm{~h}$, all thermocouples, including those embedded in the beam, were reading within 1 to $2^{\circ} \mathrm{C}$ of one another. The beam then warmed up at a rate of $-3.5^{\circ} \mathrm{C} / \mathrm{h}$, while maintaining or improving the temperature uniformity. Three demonstration tests of this type were performed. Based on the results, a procedure was developed whereby the desired test temperature would be negatively exceeded by $\sim 5^{\circ} \mathrm{C}$, the $\mathrm{LN}_{2}$ spray would be stopped, and the beam would be allowed to thermally equilibrate and warm to the test temperature. This was acceptable because the rate of change in temperature was much less than the time interval required to perform the fracture tests. When these tests were complete, this beam was sent to the machine shop for final machining into the fracture test specimen $\mathrm{CB}-1$. 


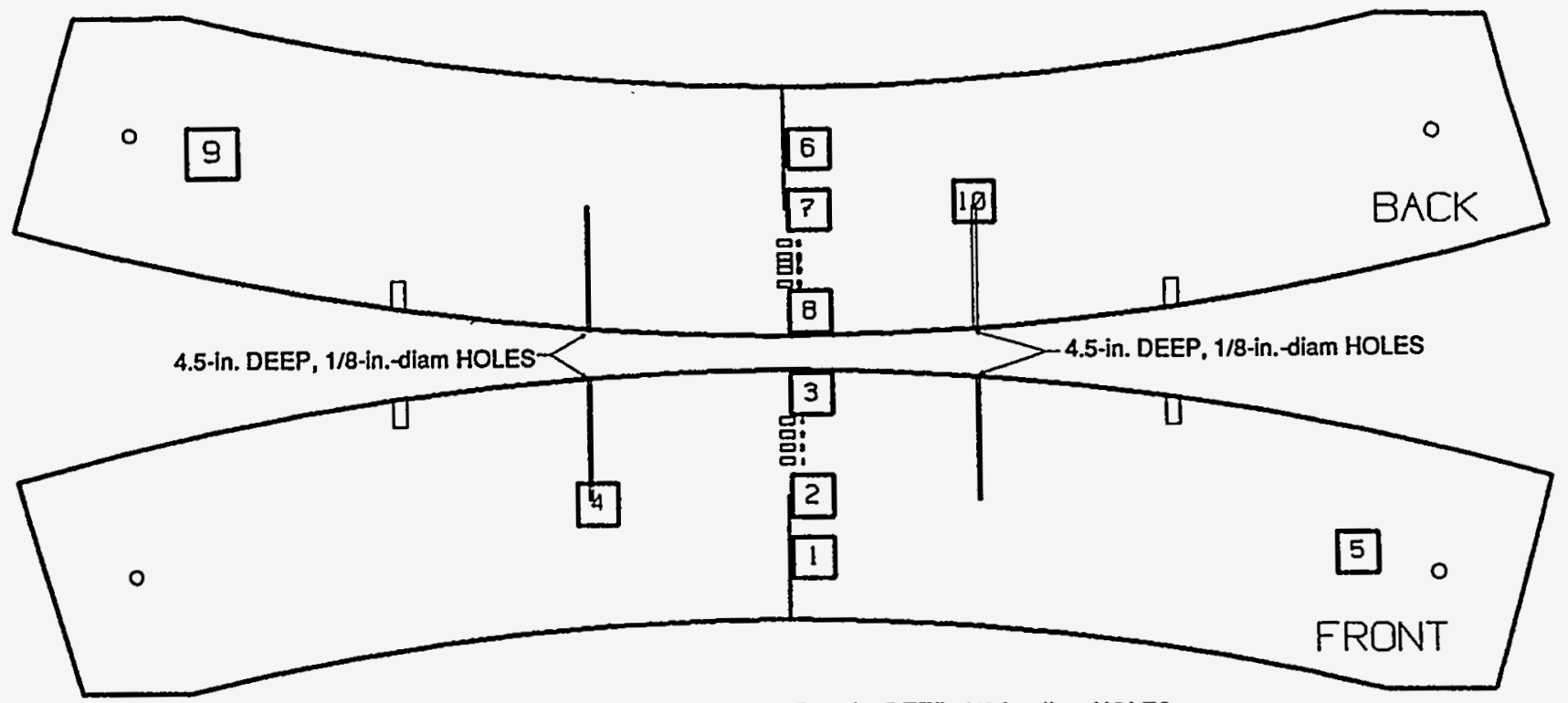

THERMOCOUPLES AT BOTTOM OF 4.5-in. DEEP, 1/8-in.-diam HOLES
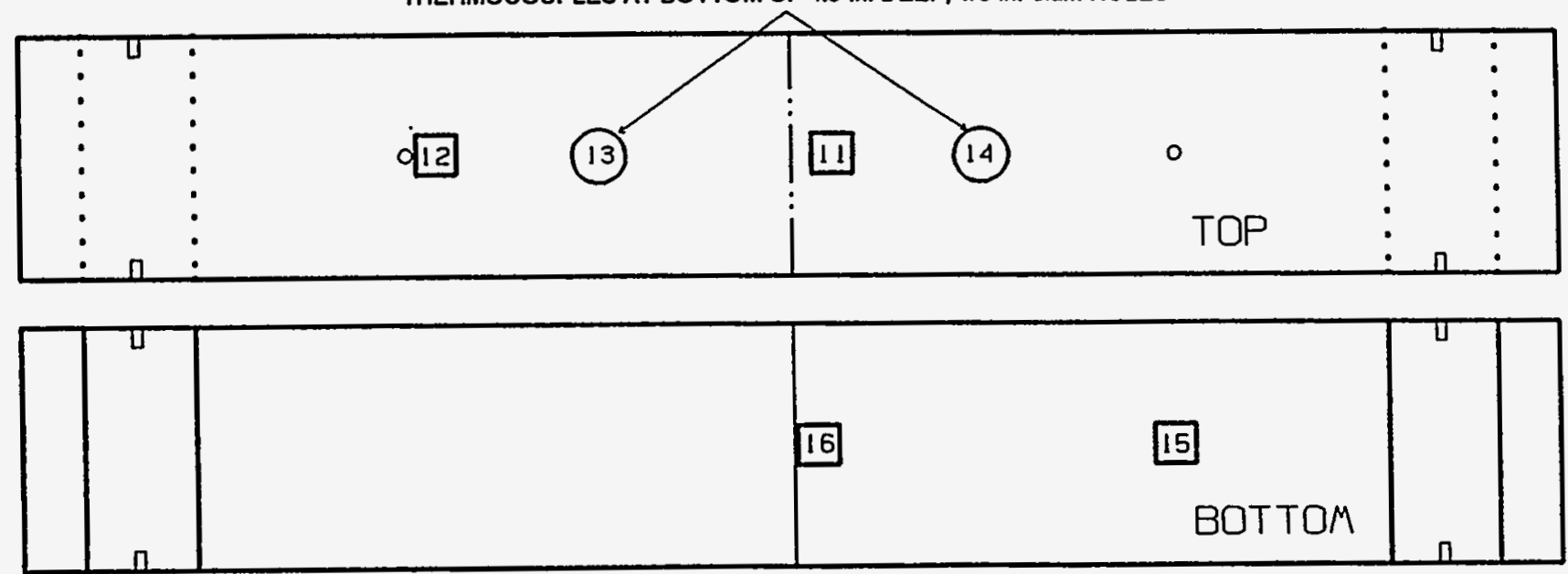

Figure 2.16 Full-thickness clad beam specimen thermocouple configuration used in demonstration of temperature control (as provided by NIST)

When CB-1 was returned as a test specimen, it was fully instrumented with crack-opening-displacement gages, as shown in Fig. 2.18, and surface strain gages, as shown in Fig. 2.19. In addition, a specially designed fixture was used to measure load-line displacement (LLD), shown in Fig. 2.20. The specimen was then installed in the test fixture, and a careful inspection was performed to confirm that the load-contact points mated properly. For the first test (CB-1), the LLD fixture was also installed. For subsequent tests, the LLD fixture was left off during fatigue precracking because the LLD assembly restricted viewing of the crack tip for the determination of crack growth. Figure $2.21(a)$ and $(b)$ shows CB-1 in the test fixture in preparation for the fatigue precracking phase. Figure 2.22 illustrates the test specimen, loading fixture, and the load transfer configuration.
Fatigue precracking of CB-1 was initially carried out at room temperature by cycling between 23 and $227 \mathrm{kN}$ ( 5 and 51 kips), which corresponds to a stress-intensity factor range of $25 \mathrm{MPa} \sqrt{\mathrm{m}}(23 \mathrm{ksi} \sqrt{\mathrm{in}}$. ). After 6510 cycles at frequencies in the range of 0.1 to $0.3 \mathrm{~Hz}$, no fatigue crack appeared to have developed. The loading was increased to a range of 27 to $273 \mathrm{kN}$ ( 6 to $61 \mathrm{kips}$ ), corresponding to $\Delta \mathrm{K}=30 \mathrm{MPa} \sqrt{\mathrm{m}}(27 \mathrm{ksi} \sqrt{\mathrm{in}}$. $)$. An additional $3525 \mathrm{cycles}$ were run $(10,035$ total) with no visible sign of crack growth. The load range was increased a third time, 45 to $318 \mathrm{kN}$ (10 to $71 \mathrm{kips}$ ), corresponding to $\Delta \mathrm{K}=33 \mathrm{MPa} \sqrt{\mathrm{m}}$

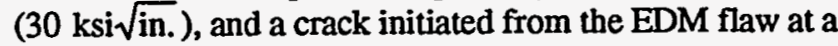
total of 11,400 cycles. The load range was then reduced to 55 to $282 \mathrm{kN}$ ( 12 to $63 \mathrm{kips}$ ) $[\Delta \mathrm{K}=28 \mathrm{MPa} \sqrt{\mathrm{m}}$ $(25 \mathrm{ksi} \sqrt{\mathrm{in} .})]$. At this load range, an additional 19,000 cycles were required to grow the flaw the specified 


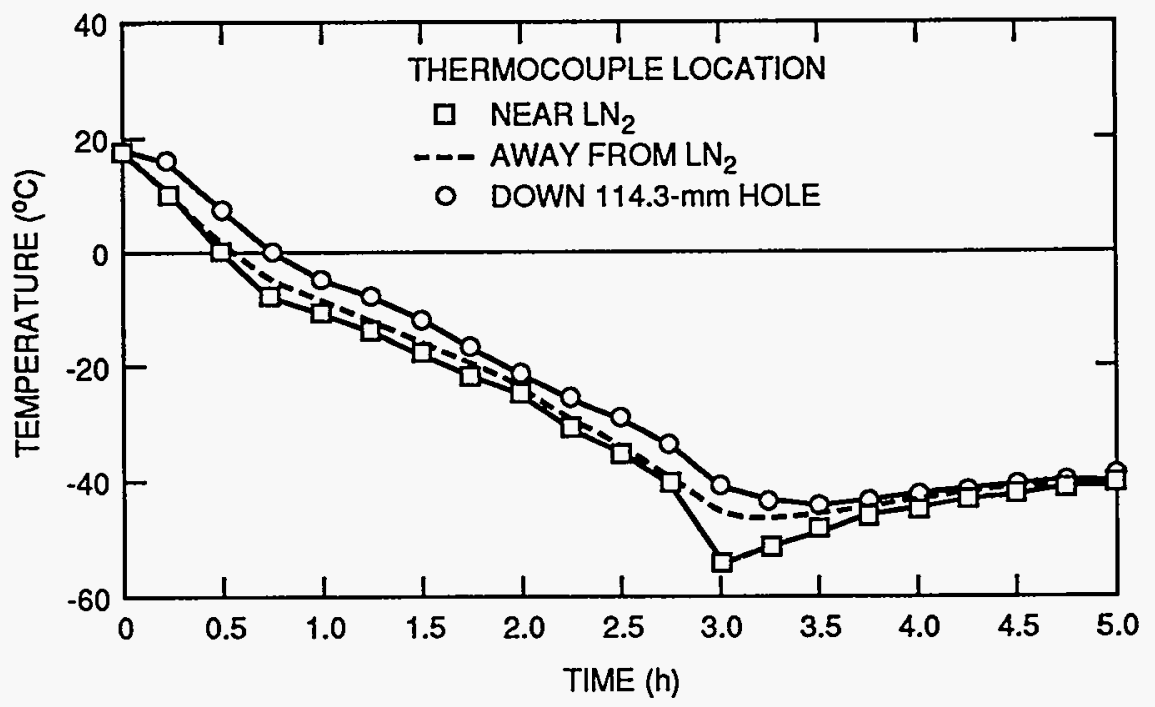

Figure 2.17 Typical temperature histogram for demonstration of temperature control in clad beam tests
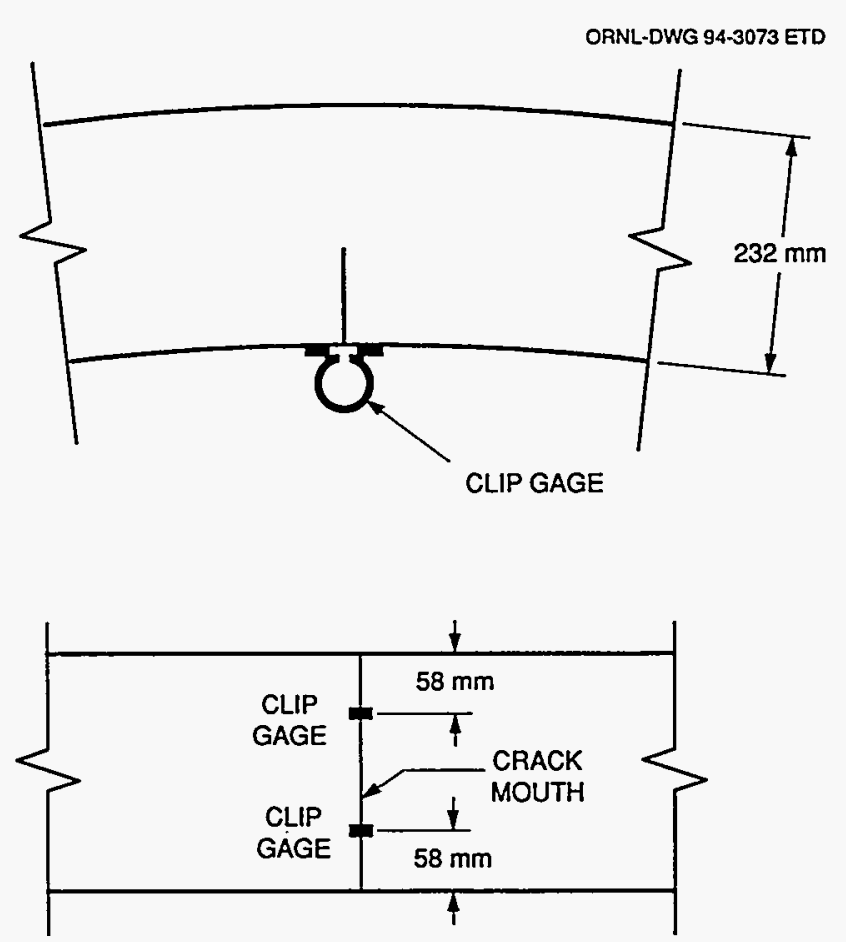

Figure 2.18 Location of crack-mouth-opening gages used on clad beam specimens

$2.5 \mathrm{~mm}$. During the fatigue precracking phase, data were taken using all load, displacement, and strain instrumentation to verify correct function. A brief scan for such data is shown in Fig. 2.23. The amount of crack growth was verified by posttest measurements on the fracture surface. The fatigue precracking parameters for the test beams are summarized in Table 2.10 .
For the fracture phase, the manifold for spraying the $\mathrm{LN}_{2}$ onto the beam surface was mounted around the specimen, and the environmental chamber was used to enclose the assembly. Figure 2.24 shows a test beam mounted in the loading fixture, with the $\mathrm{LN}_{2}$ manifold in place, but with the LLD instrumentation and the environmental chamber not yet installed. Once the specimen was completely enclosed, it was cooled to the test temperature $\left(-25^{\circ} \mathrm{C}\right)$ per the procedures just discussed. The specimen was then loaded to fracture under stroke control using a constant LLD rate. Specimen CB-1 failed at a load (P) of $1232.5 \mathrm{kN}$ (277 kips). The fracture surface for this specimen is shown in Fig. 2.25. The fracture surface can be divided into three parts. The upper part is the machined flaw surface, where the uniformity, or straightness, of the crack front is clearly visible. The second part is the crack-growth surface due to fatiguing. Note that, with the exception of portions of the crack front near the beam sides, the flaw growth was very uniform. The third part is the fracture surface itself, which shows a cleavage fracture. While there are multiple initiation sites, the first initiation location appeared to be near the center of the crack front. The same failure test procedure and the same general instrumentation layout was used for all three specimens. The fracture surfaces for specimens CB-2 and CB-3 are shown in Figs. 2.26 and 2.27, respectively. The general features are similar to those for CB-1.

\subsection{Test Results and Comparison with Existing Data}

The $\mathrm{P}$ vs displacement curves for each of the three beams are shown in Fig. 2.28 for LLD and in Fig. 2.29 for crackmouth-opening displacement (CMOD), respectively. These 


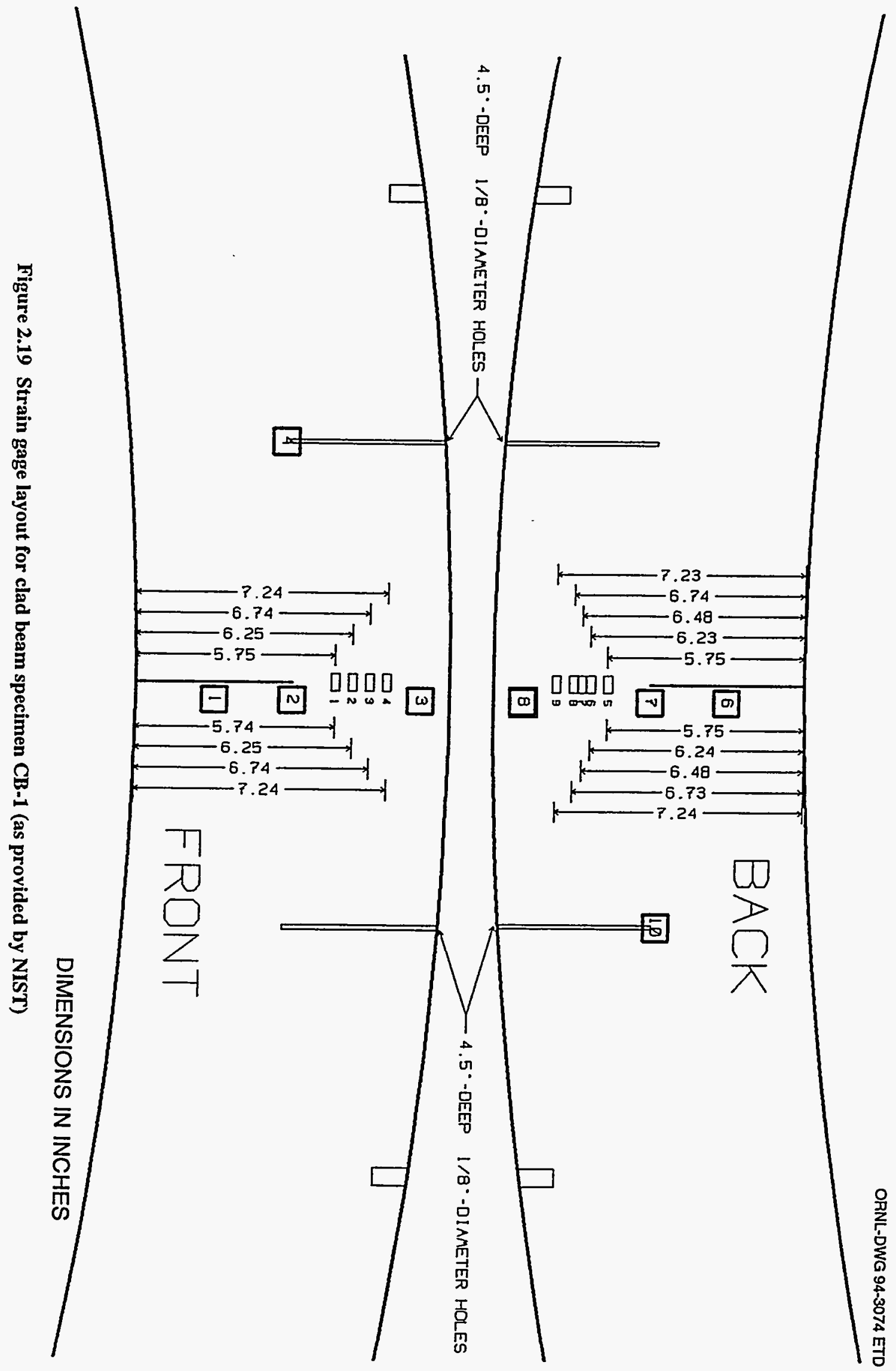


Full-Thickness

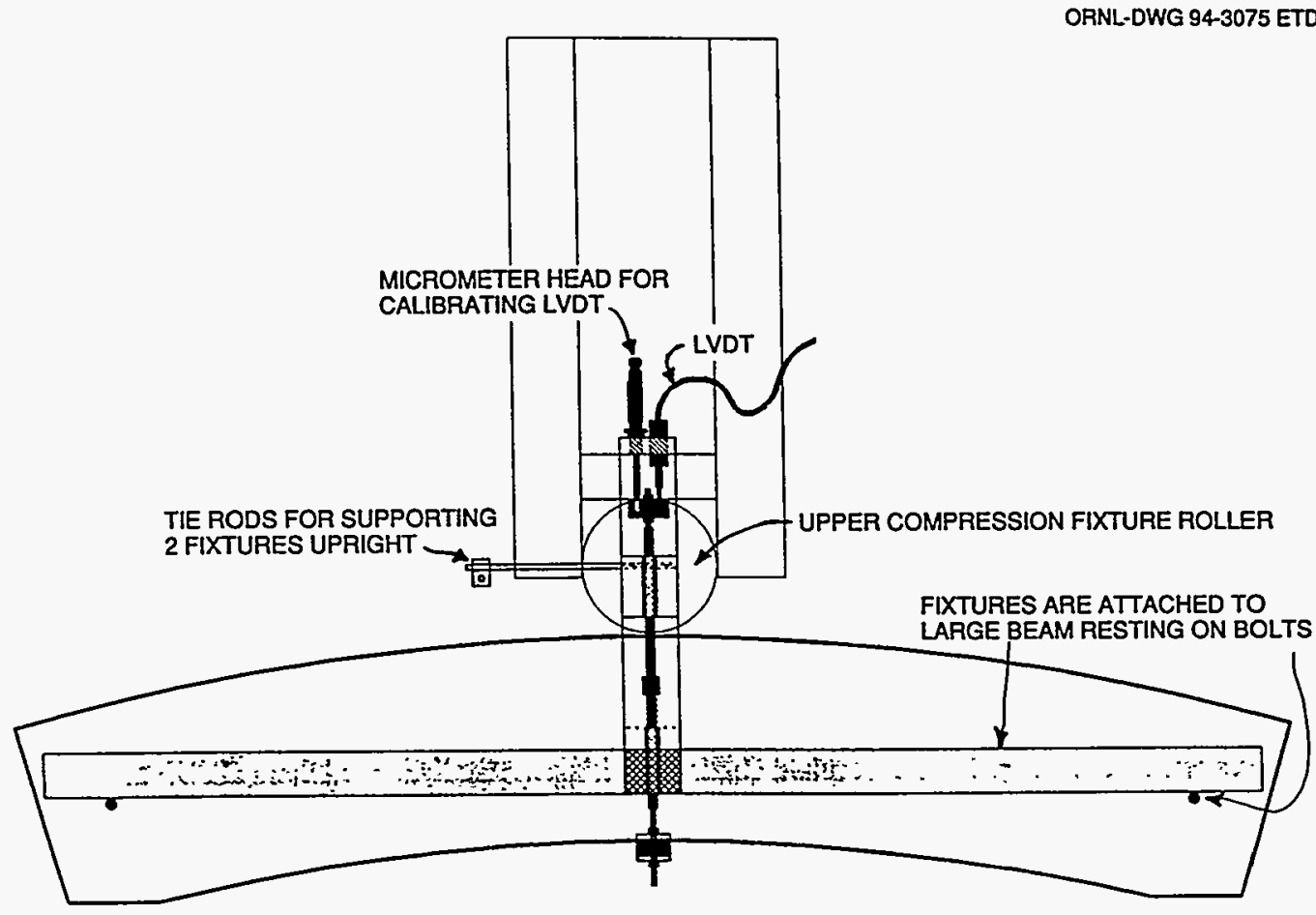

(a) SIDE VIEW

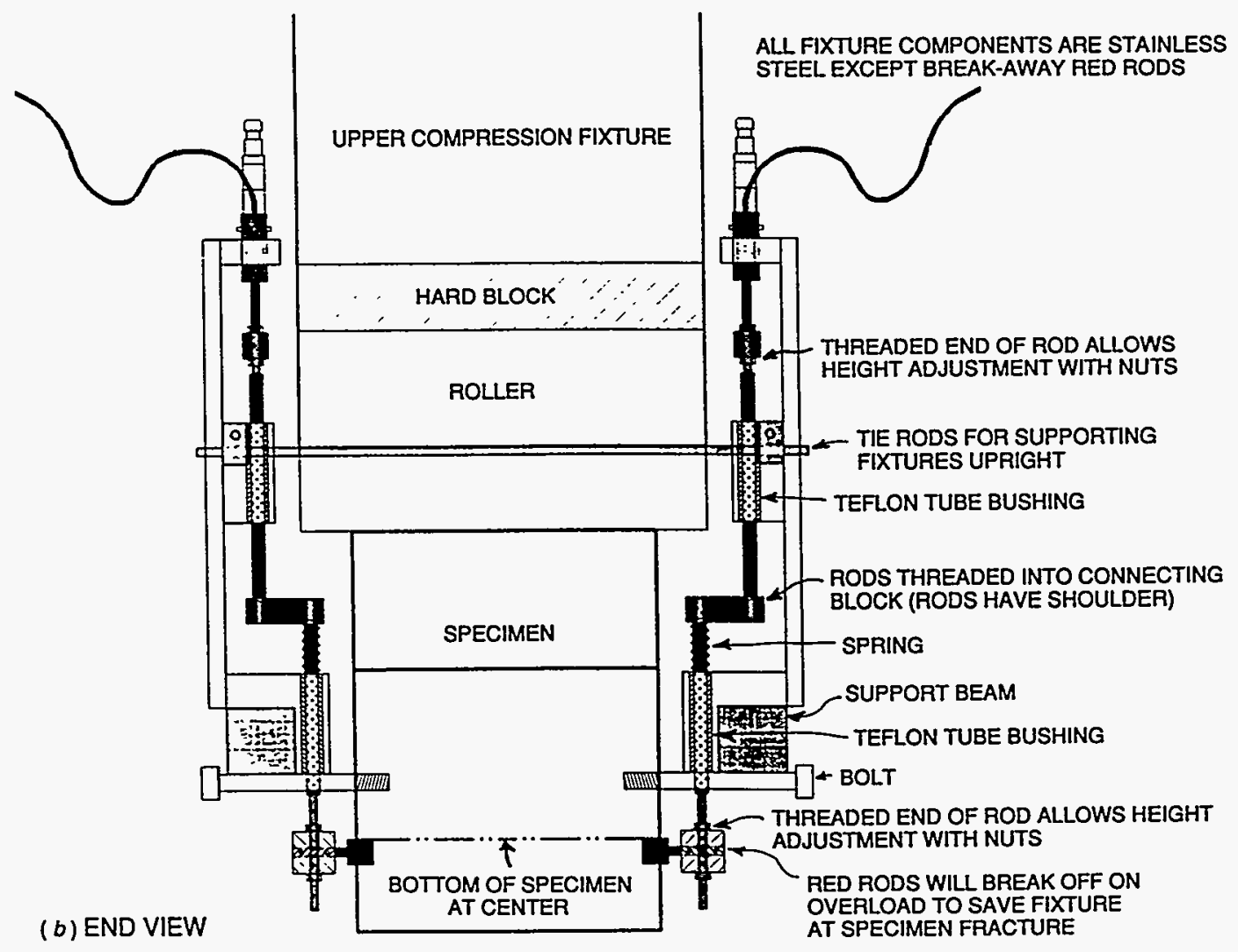

Figure 2.20 Fixture used to measure LLD on clad beam tests: $(a)$ side view and $(b)$ end view 

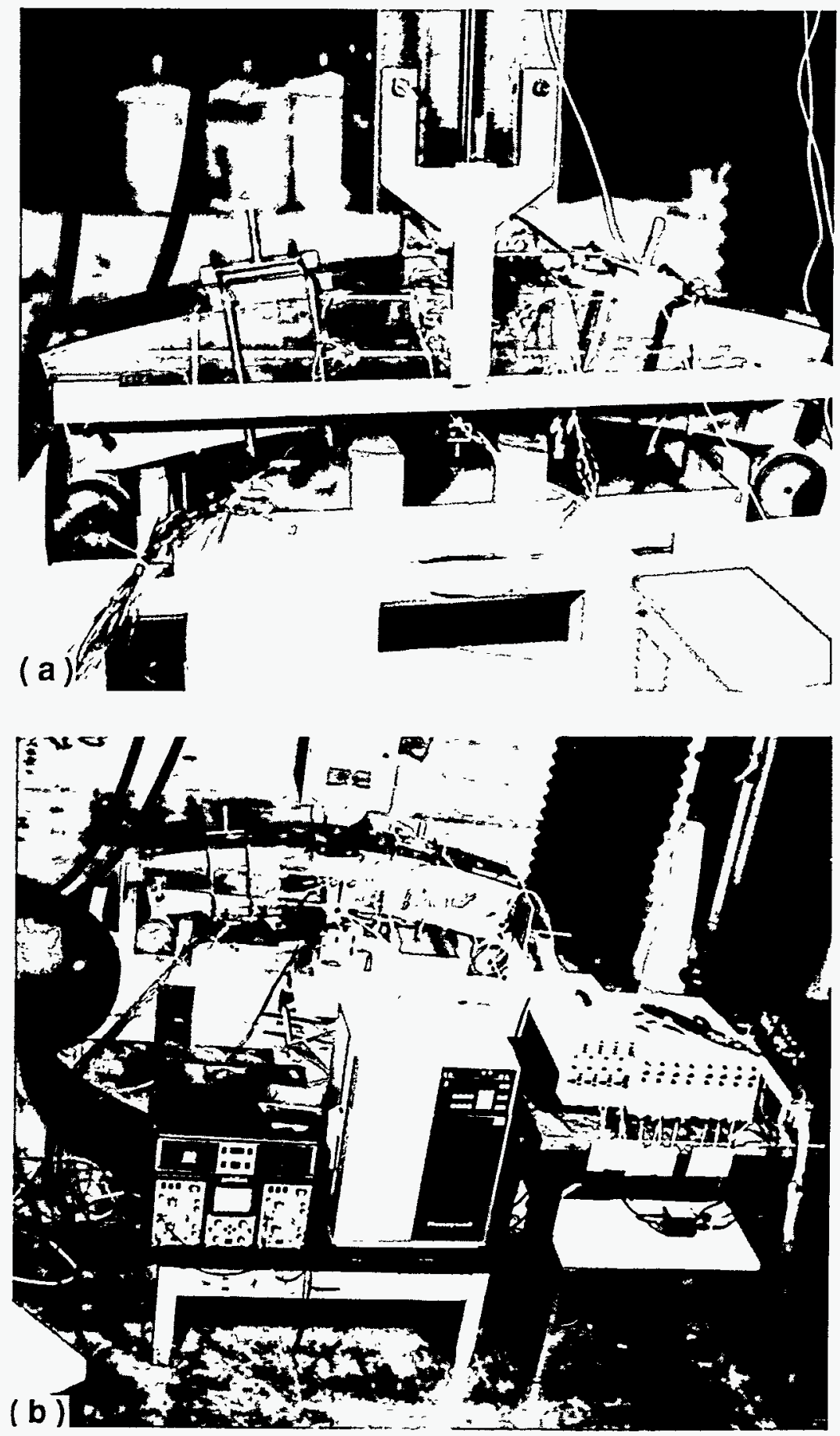

Figure 2.21 (a) Full-thickness clad beam specimen CB-1 shown mounted in test fixture during fatigue precracking and $(b)$ sample, bridge amplifiers, and some of the data collection system shown in relative positions 


\section{Full-Thickness}

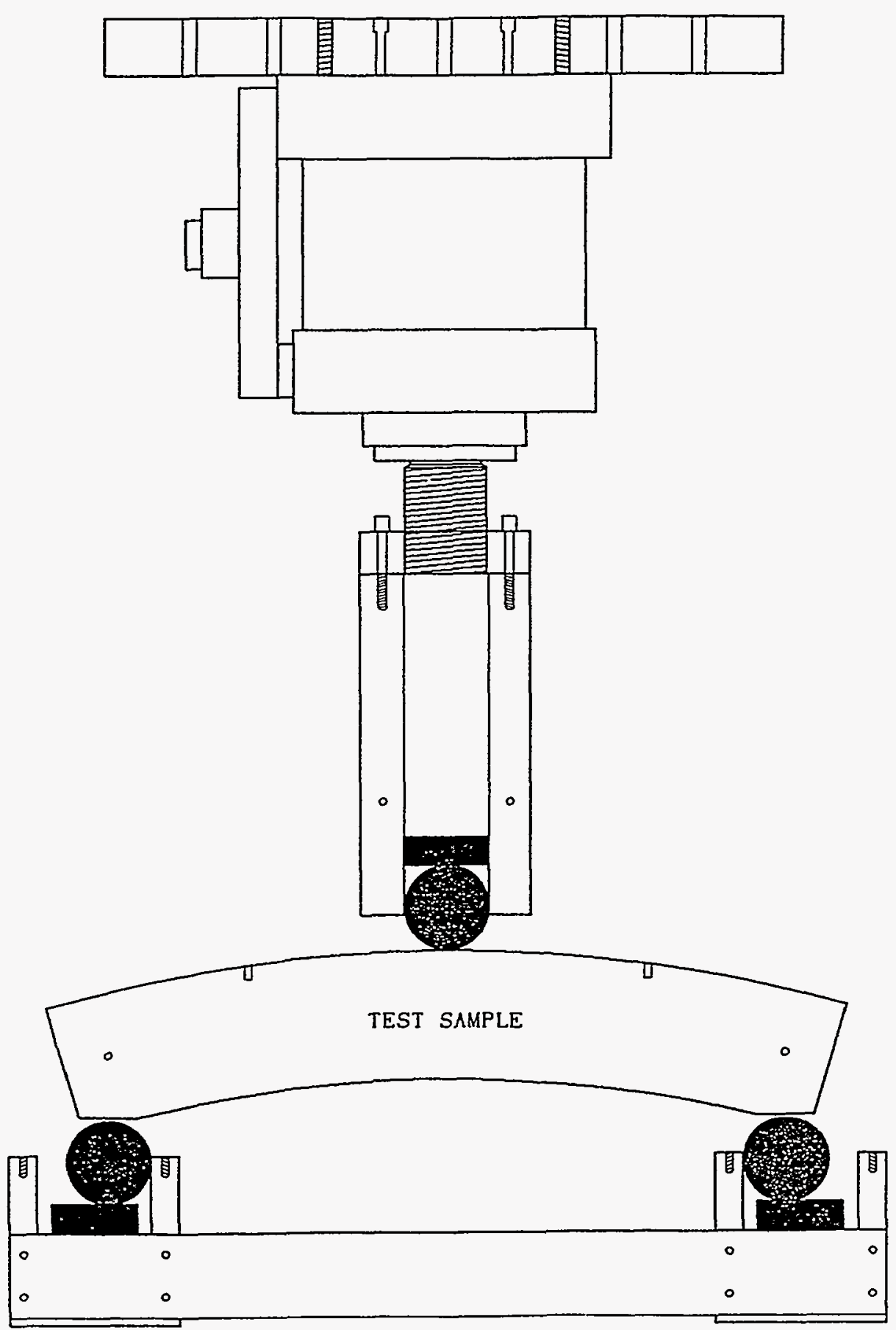

Figure 2.22 Schematic of load system and test beam

curves depict the inelastic behavior in the shallow-crack specimens as fracture conditions are approached. The conditions of each specimen at failure are listed in Table 2.11. The plastic component of the area under each $P$ vs displacement curve (defined as $U_{\mathrm{pl}}$ for $L L D$ and $A_{\mathrm{pl}}$ for CMOD) and the corresponding $\eta$-factors, $\eta_{\mathrm{pl}}^{\ell}$ and $\eta_{\mathrm{pl}}^{\mathrm{c}}$, are also included in Table 2.11. Toughness data for the clad beam specimens were calculated using the techniques described in Ref. 5. The P vs CMOD method, ${ }^{6}$ considered the more accurate of the techniques examined for determining fracture toughness of shallow-crack specimens, is the primary method used for the clad beam analyses. The critical J-integral values were converted to critical elasticplastic, stress-intensity factors $\left(\mathrm{K}_{\mathrm{Jc}}\right)$, using the plane-strain 

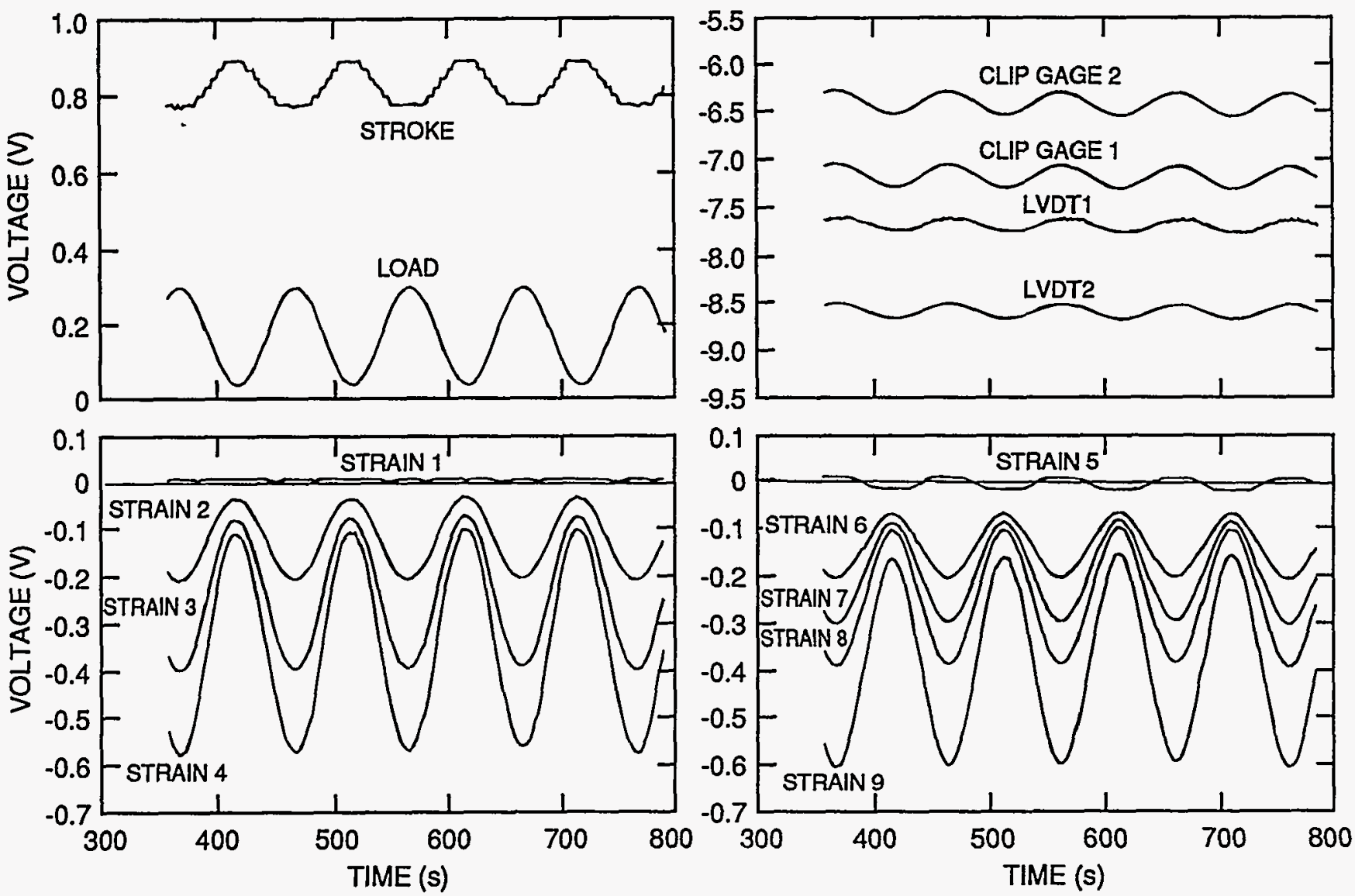

Figure 2.23 Correct operation of all instrumentation and data collection systems demonstrated during fatiguing of demonstration beam CB-1

Table 2.10 Fatigue precracking parameters for fullthickness clad beam specimens

\begin{tabular}{llll}
\hline & CB-1 & CB-2 & CB-3 \\
\hline Temperature, ${ }^{\circ} \mathrm{C}$ & 20.0 & 20.0 & 20.0 \\
$\mathrm{P}_{\max } / \mathrm{P}_{\min }$ & $7-10$ & $7-10$ & $7-10$ \\
$\mathrm{~K}_{\max }, \mathrm{MPa} \sqrt{\mathrm{m}}$ & 33 & 33 & 33 \\
$\Delta \mathrm{K}, \mathrm{MPa} \sqrt{\mathrm{m}}$ & 28 & 28 & 28 \\
\hline
\end{tabular}

formulation. The toughness values determined for the tests, along with the parameters used to estimate the toughness, are included in Table 2.11; details of the analyses are discussed in Chap. 3. These data should be regarded as preliminary, because the potential effects of residual stresses and material gradients in the HAZ (associated with the cladding) were not considered in the toughness determinations. The final data will be made available within the next year.

The fracture toughness data given in Table 2.11 for prototypic submerged-arc pressure vessel weld material are compared in Figs. 2.30-2.33 with SENB and biaxial cruciform data for A $533 \mathrm{~B} \mathrm{steel}^{*}$ previously generated in testing programs by ORNL $4-6$ and by Carderock DivisionNaval Surface Warfare Center (CDNSWC). ${ }^{21}$ (These fracture toughness data for A 533 B plate material and pressure vessel weld material are also tabulated in Appendix A.) In Figs. 2.30 and 2.31, the data are plotted as a function of the reference temperature, $\mathrm{T}-\mathrm{RT}_{\mathrm{NDT}}$. For the deep-crack data (Fig. 2.30), a single curve is adequate to define a lower bound to all three of the deep-crack fracture toughness data sets. For the shallow-crack data (Fig. 2.31), the lower-bound curve to the CDNSWC data is substantially lower than the lower-bound curve to the HSST data and nearly coincident with the lower-bound curve of the combined deep-crack data set.

The choice of the reference temperature can potentially influence interpretation of the shallow-crack toughness data in Fig. 2.31. Reference 15 defines RT NDT in terms of both the NDT and the temperature $\left(\mathrm{T}_{\mathrm{cv}}\right)$ at which the lower-

\footnotetext{
*W. E. Pennell, ORNL, letter to S. N. M. Malik, USNRC, March 18,
} 1994. 
Full-Thickness

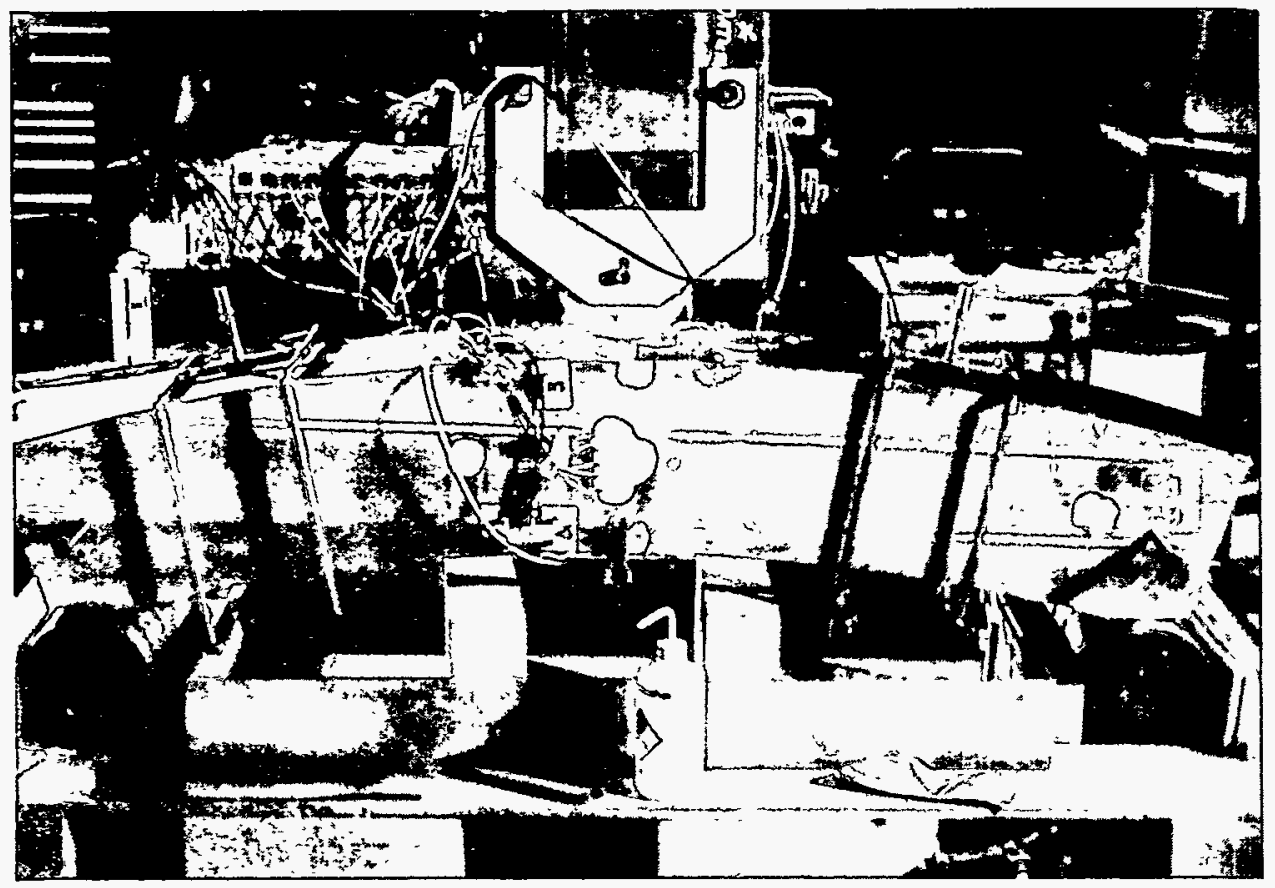

Figure 2.24 Full-thickness clad beam mounted in test fixture before failure test, showing $\mathrm{LN}_{2}$ manifold in place

ORNL-PHOTO 8082-94

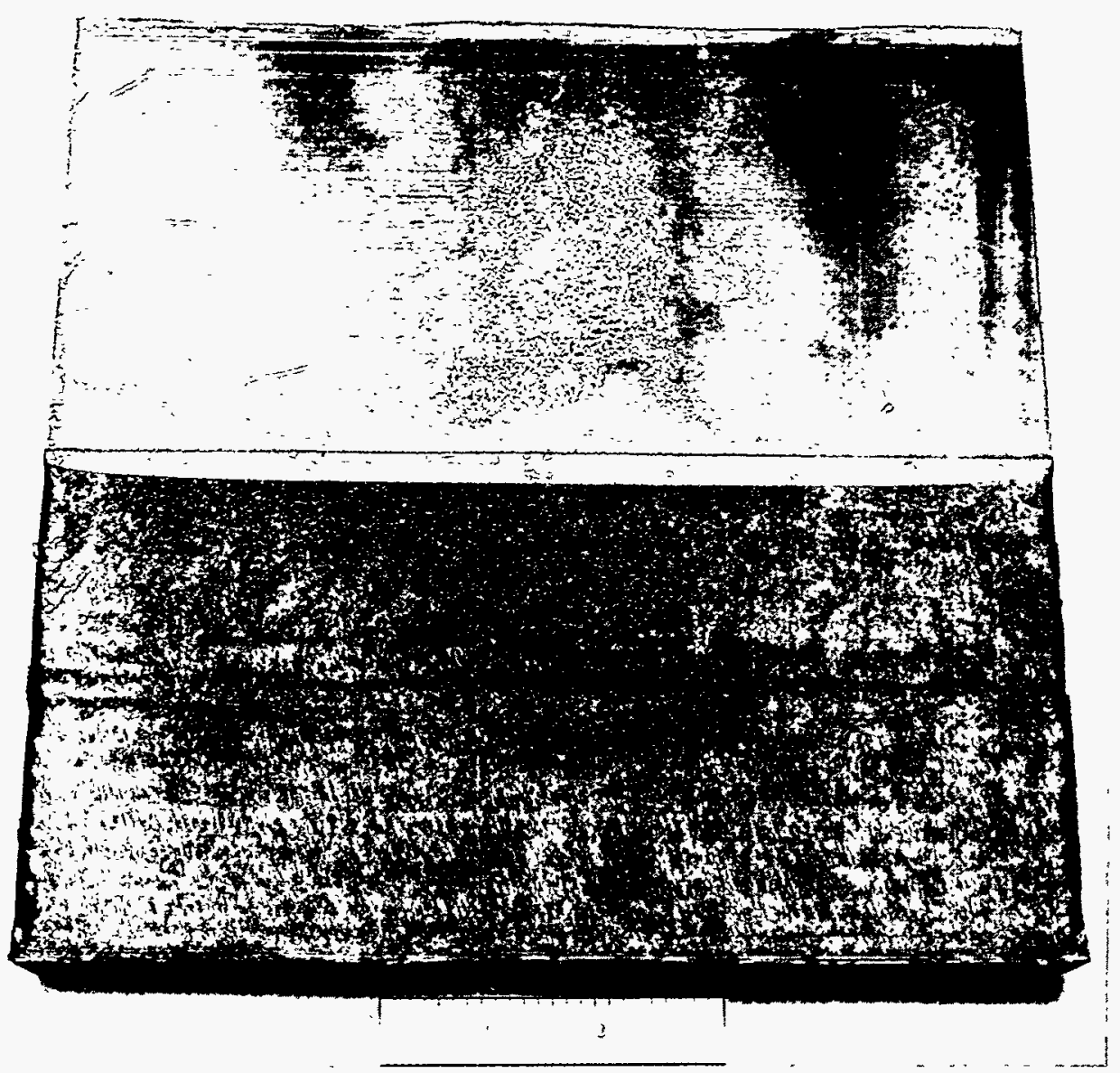

Figure 2.25 Fracture surface of full-thickness clad beam specimen CB-1 
Full-Thickness

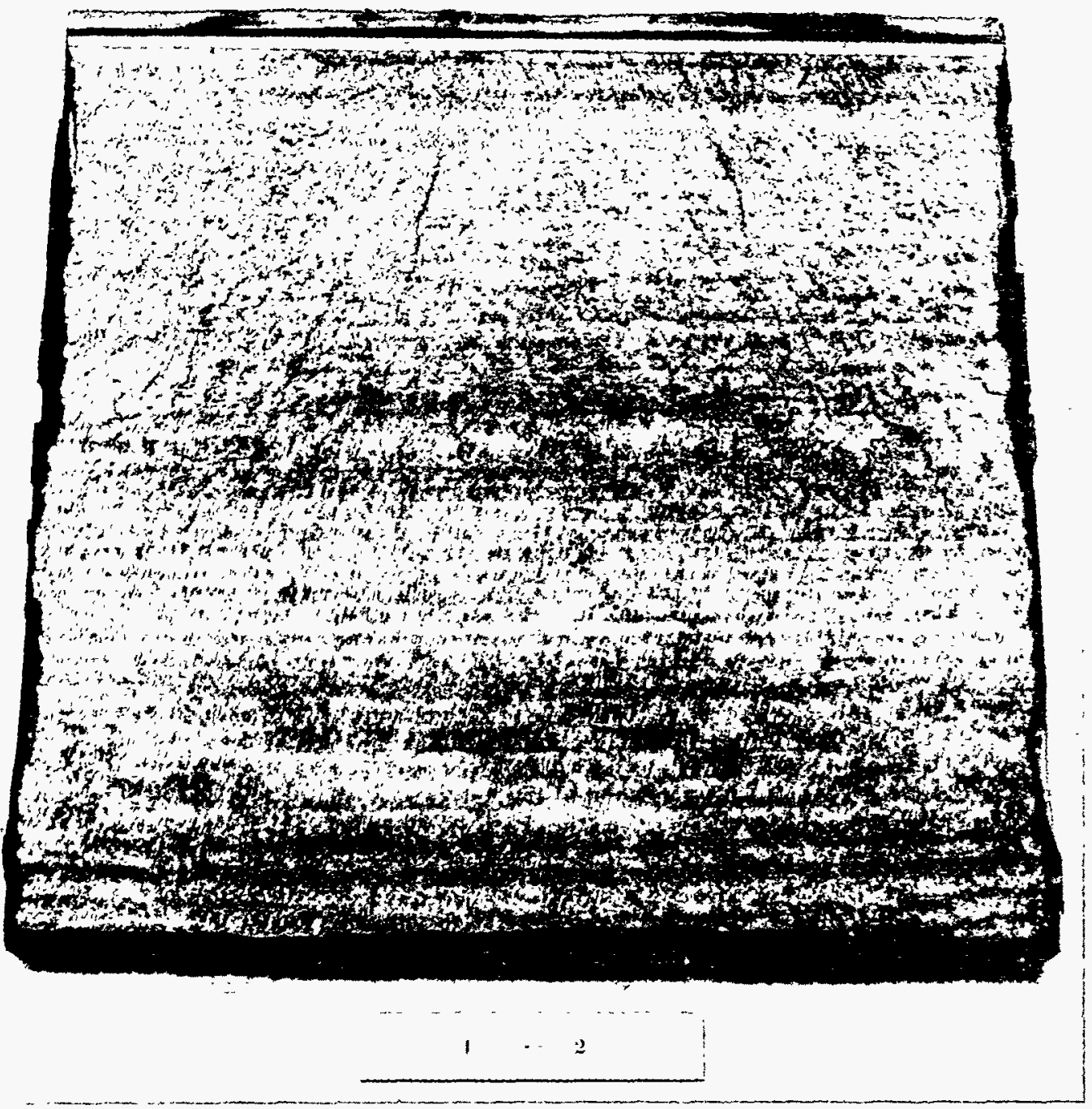

Figure 2.26 Fracture surface of full-thickness clad beam specimen CB-2

bound Charpy energy from three tests is not less than 68-J (50 ft-lb). For a given material, one of these temperatures (NDT or $\mathrm{T}_{\mathrm{C}_{\mathrm{V}}}$ ) will be the controlling temperature in de-

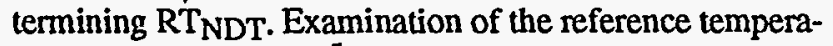
ture data for the materials represented in Figs. 2.30 and

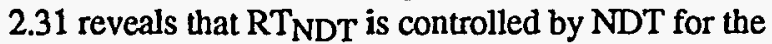
CDNSWC data and by $\mathrm{T}_{c V}$ for the welds in the full-thick-

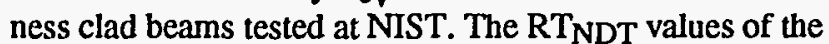
two source plates, HSST plates CE-WP and $13 B,{ }^{4}$ used in generating the HSST A 533 B data are controlled by NDT and $T_{c y}$, respectively. A proposed solution ${ }^{*}$ to this problem is to adopt a common reference temperature for comparing the data sets. In Figs. 2.32 and 2.33, the parameter NDT is employed as the reference temperature. Figure 2.32 indicates that a single curve still defines the lower bound to the

*W. E. Pennell, ORNL, letter to S. N. M. Malik, USNRC, March 18, 1994. deep-crack fracture toughness data sets. In Fig. 2.33, lowerbound curves to the shallow-crack HSST data and to the CDNSWC data are still distinctly separated, but to a lesser degree than in Fig. 2.31 for the comparison based on

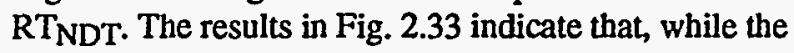
loss of constraint associated with shallow cracks elevates the mean fracture toughness, the increased data scatter in the transition region tends toward the same lower bound associated with highly constrained deep-crack toughness data.

The crack tip in clad beam specimen $\mathrm{CB}-2(\mathrm{a} / \mathrm{W}=0.05)$ was located at a depth of $\sim 10 \mathrm{~mm}$, which is near the boundary of the cladding HAZ in the weld metal. In Fig. 2.33, the fracture toughness result for specimen CB-2 defines the lower bound of the HSST shallow-crack toughness data at 


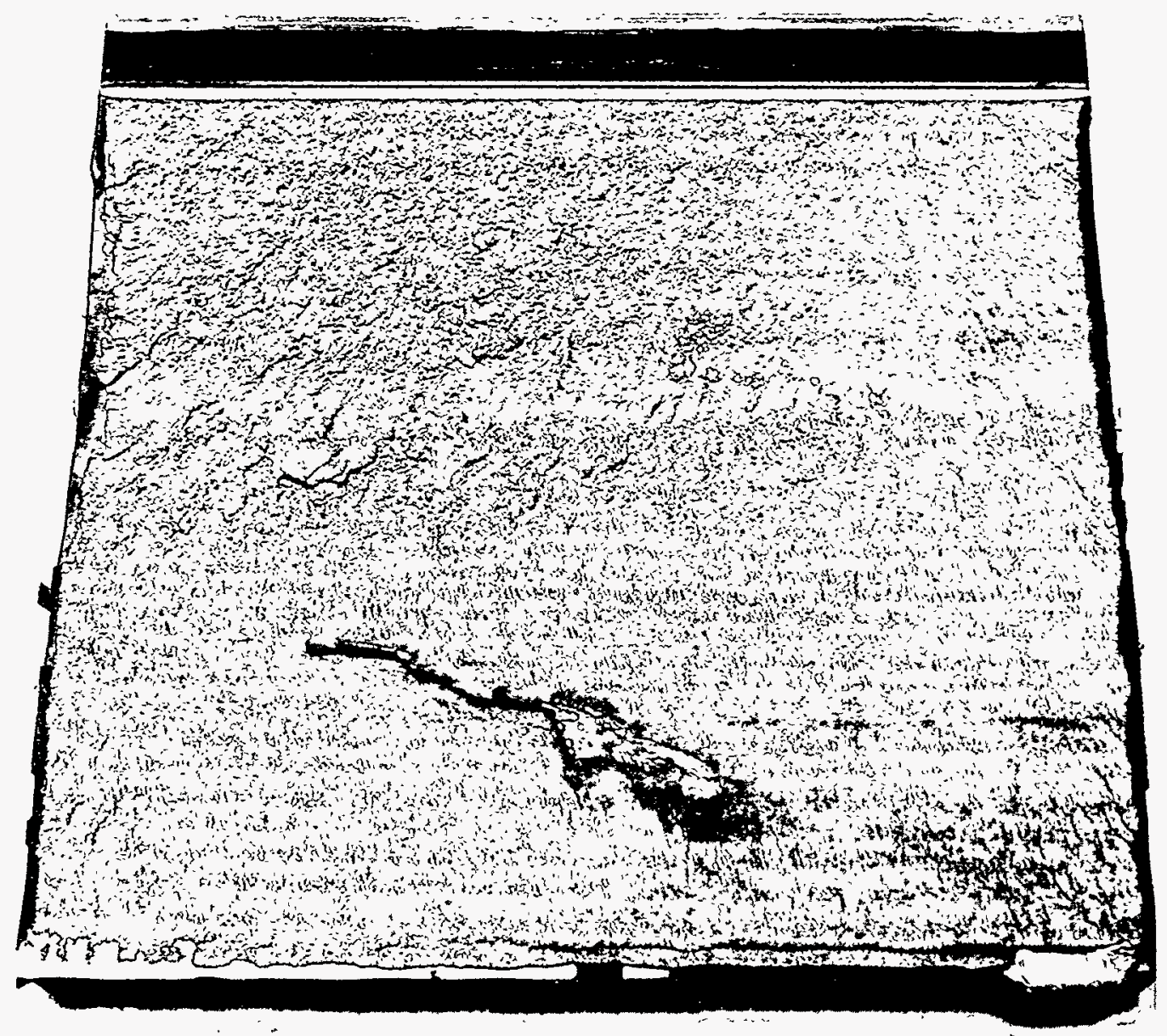

Figure 2.27 Fracture surface of full-thickness clad beam specimen CB-3

the higher temperatures, when NDT is the normalizing parameter. Although material property data are not available for confirmation, the potential exists that metallurgical conditions in the cladding $\mathrm{HAZ}$ region significantly influenced the relatively low initiation toughness measured in the CB-2 test.

A comparison of the shallow-and deep-crack lower-bound curves for the HSST data only, plotted vs T - RT TDT in
Fig. 2.34 and vs T - NDT in Fig. 2.35, indicates that there is less of a separation between the shallow- and deep-crack lower-bound curves at a particular $\mathrm{K}_{\mathrm{Jc}}$. Figure 2.34 shows, by the horizontal arrow, that for a $\mathrm{K}_{\mathrm{Jc}}$ of $150 \mathrm{MPa} \sqrt{\mathrm{m}}$ the temperature shift $\left[\Delta\left(\mathrm{T}-\mathrm{RT} \mathrm{T}_{\mathrm{NDT}}\right)\right]$ is $35^{\circ} \mathrm{C}$, which is close to the temperature shift $[\Delta(\mathrm{T}-\mathrm{NDT})]$ of $31^{\circ} \mathrm{C}$ in Fig. 2.35 for the same toughness. 
Full-Thickness

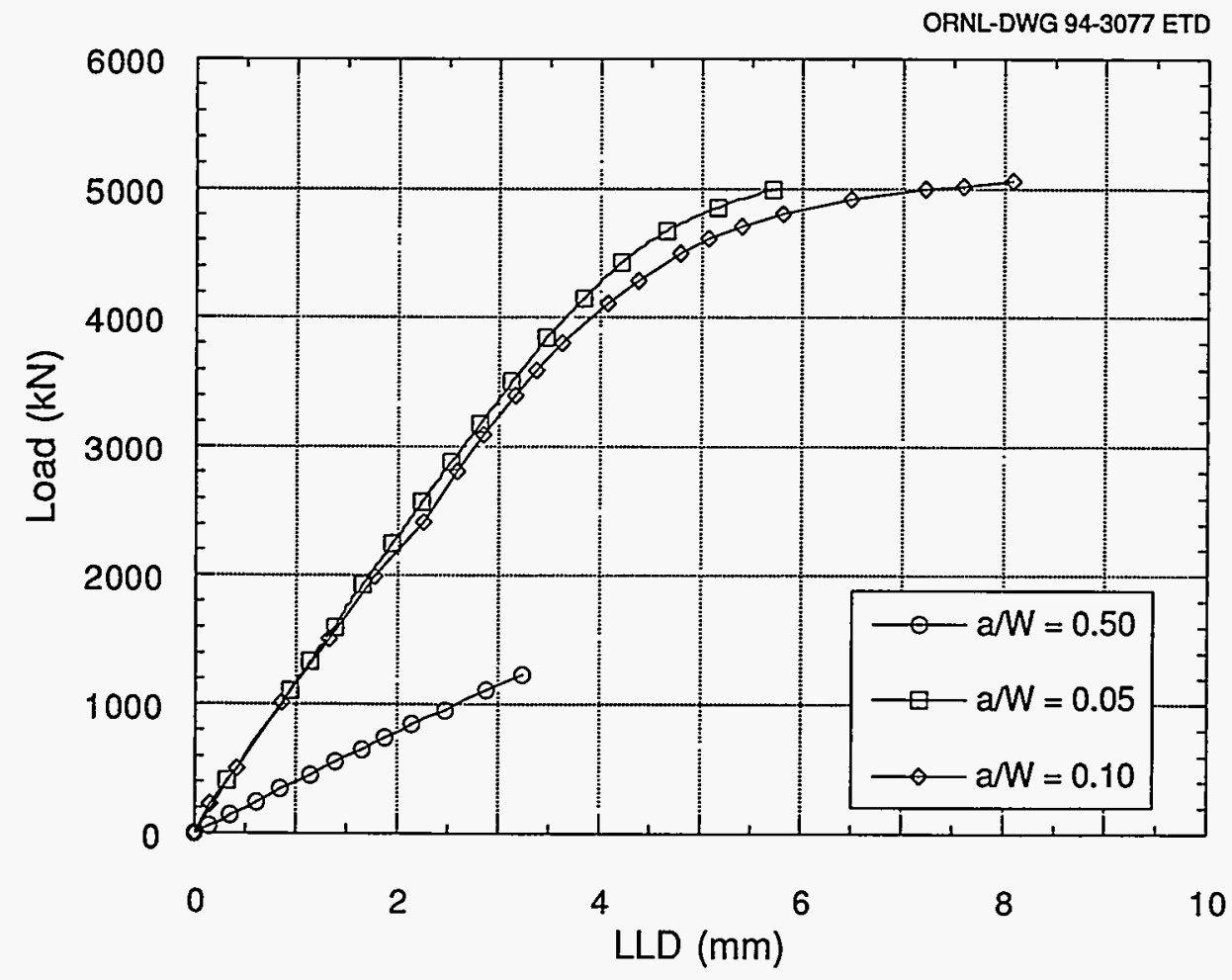

Figure 2.28 Load vs LLD response for clad beam specimens

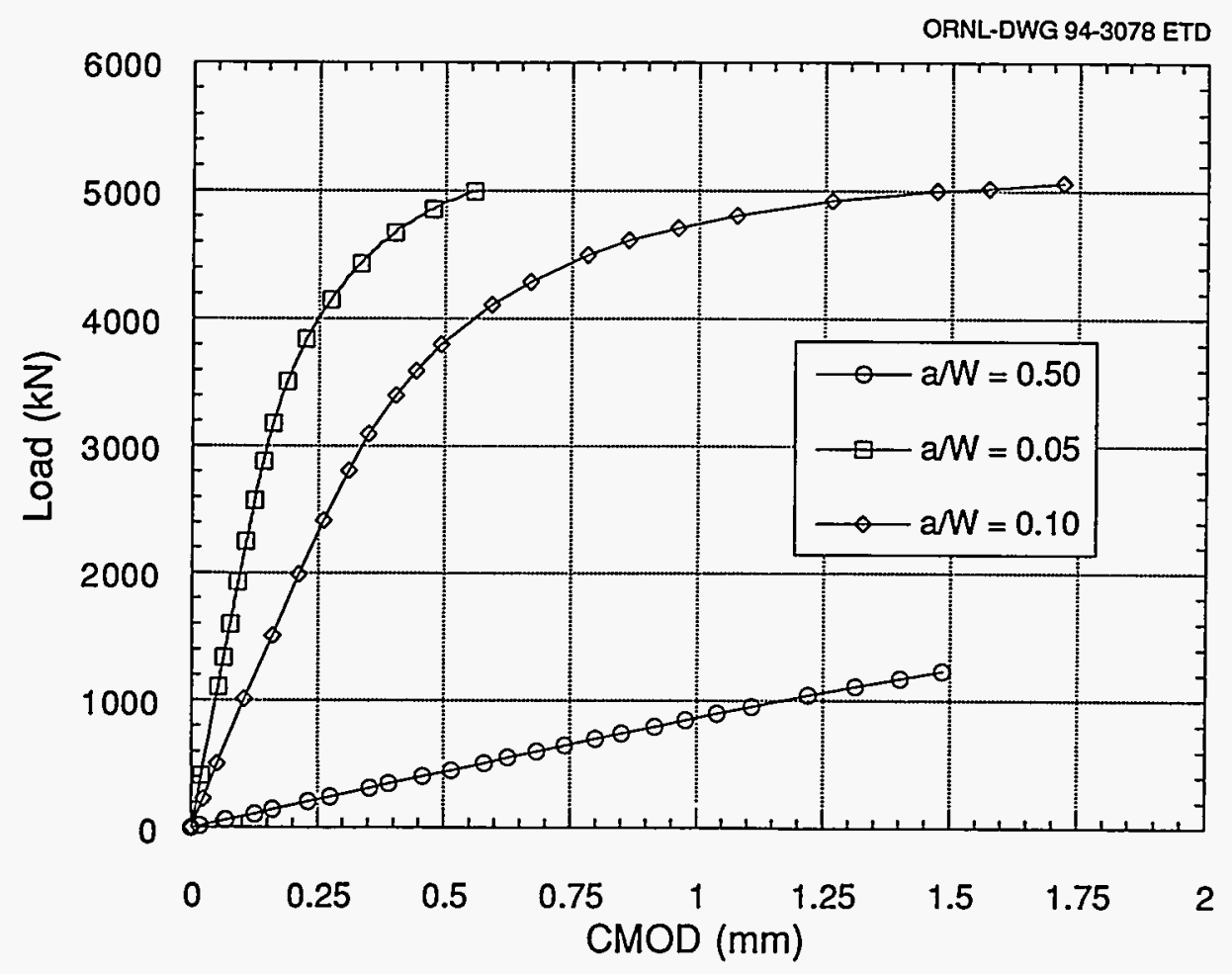

Figure 2.29 Load vs CMOD response for clad beam specimens 
Full-Thickness

Table 2.11 Summary of results from the full-thickness clad beam testing program

\begin{tabular}{|c|c|c|c|}
\hline & CB-1 & $\mathrm{CB}-2$ & $\mathrm{CB}-3$ \\
\hline$a / w$ & 0.50 & 0.05 & 0.10 \\
\hline Temperature, ${ }^{\circ} \mathrm{C}$ & $-25.5 \pm 1.0$ & $-25.0 \pm 1.0$ & $-25.5 \pm 1.0$ \\
\hline Stroke rate, $\mathrm{mm} / \mathrm{min}$ & 2.49 & 8.38 & 6.89 \\
\hline Time to failure, $\mathrm{s}$ & 230 & 366 & 440 \\
\hline \multicolumn{4}{|l|}{ Failure conditions } \\
\hline $\mathrm{P}, \mathrm{kN}$ & 1232.5 & 5002.3 & 5060 \\
\hline LLD, mm & 3.236 & 5.767 & 8.083 \\
\hline $\mathrm{CMOD}, \mathrm{mm}$ & 1.485 & 0.567 & 1.718 \\
\hline $\mathrm{U}_{\mathrm{pl}}, \mathrm{kN}-\mathrm{mm}$ & 135 & 6427 & 16879 \\
\hline$A_{\mathrm{pl}}, \mathrm{kN}-\mathrm{mm}$ & 88 & 1473 & 5486 \\
\hline \multicolumn{4}{|l|}{$\eta$-factors } \\
\hline$\eta_{\mathrm{pl}}^{\ell}$ & 1.37 & 0.79 & 1.05 \\
\hline$\eta_{\mathrm{pl}}^{\mathrm{c} 1}$ & 2.26 & 4.16 & 4.08 \\
\hline \multicolumn{4}{|l|}{ Fracture toughness } \\
\hline \multicolumn{4}{|l|}{ Elastic component } \\
\hline $\mathrm{J}_{\mathrm{el}}, \mathrm{kN} / \mathrm{m}$ & 131.3 & 110.6 & 230.5 \\
\hline $\mathrm{K}_{\mathrm{I}}, \mathrm{MPa} \sqrt{\mathrm{m}}$ & 173.0 & 154.5 & 223.1 \\
\hline \multicolumn{4}{|l|}{ P vs CMOD } \\
\hline $\mathrm{J}_{\mathrm{pl}}, \mathrm{kN} / \mathrm{m}$ & 8.1 & 124.7 & 486.0 \\
\hline Total $\mathrm{J}, \mathrm{kN} / \mathrm{m}$ & 139.4 & 235.3 & 716.5 \\
\hline $\mathrm{KJ}_{\mathrm{c}}, \mathrm{MPa} \sqrt{\mathrm{m}}$ & 173.5 & 225.4 & 393.3 \\
\hline \multicolumn{4}{|l|}{ P vs LLD } \\
\hline $\mathrm{J}_{\mathrm{pl}}, \mathrm{kN} / \mathrm{m}$ & 7.4 & 103.8 & 384.8 \\
\hline Total $\mathrm{J}, \mathrm{kN} / \mathrm{m}$ & 138.7 & 214.4 & 615.3 \\
\hline $\mathrm{K}_{\mathrm{Jc}}, \mathrm{MPa} \sqrt{\mathrm{m}}$ & 173.1 & 215.2 & 364.5 \\
\hline
\end{tabular}




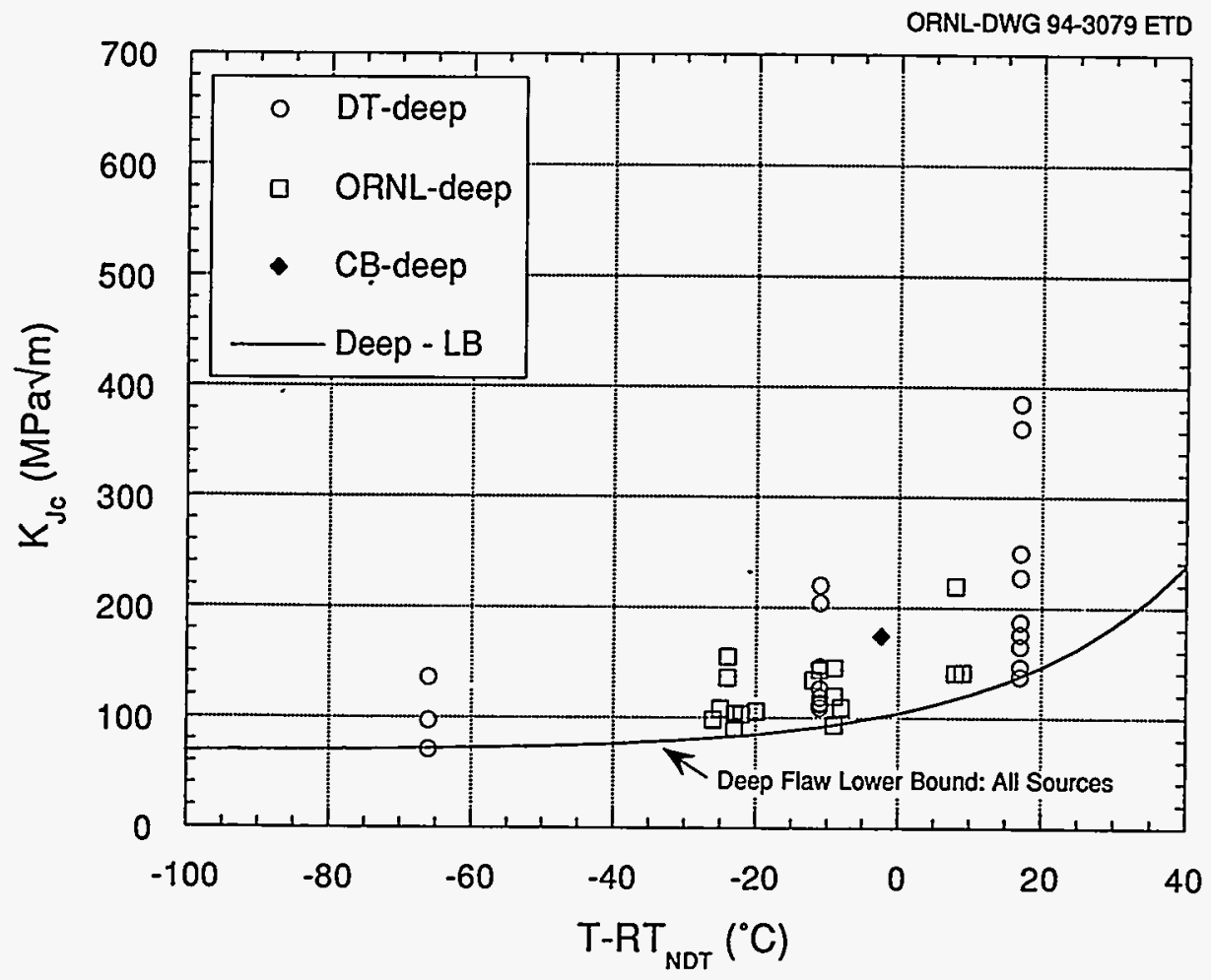

Figure 2.30 Deep-crack fracture toughness results as function of normalized temperature $\mathrm{T}-\mathrm{RT}_{\mathrm{NDT}}$. Note: $\mathrm{DT}=$ David Taylor, $\mathrm{CB}=$ clad beam, and $\mathrm{LB}=$ lower bound

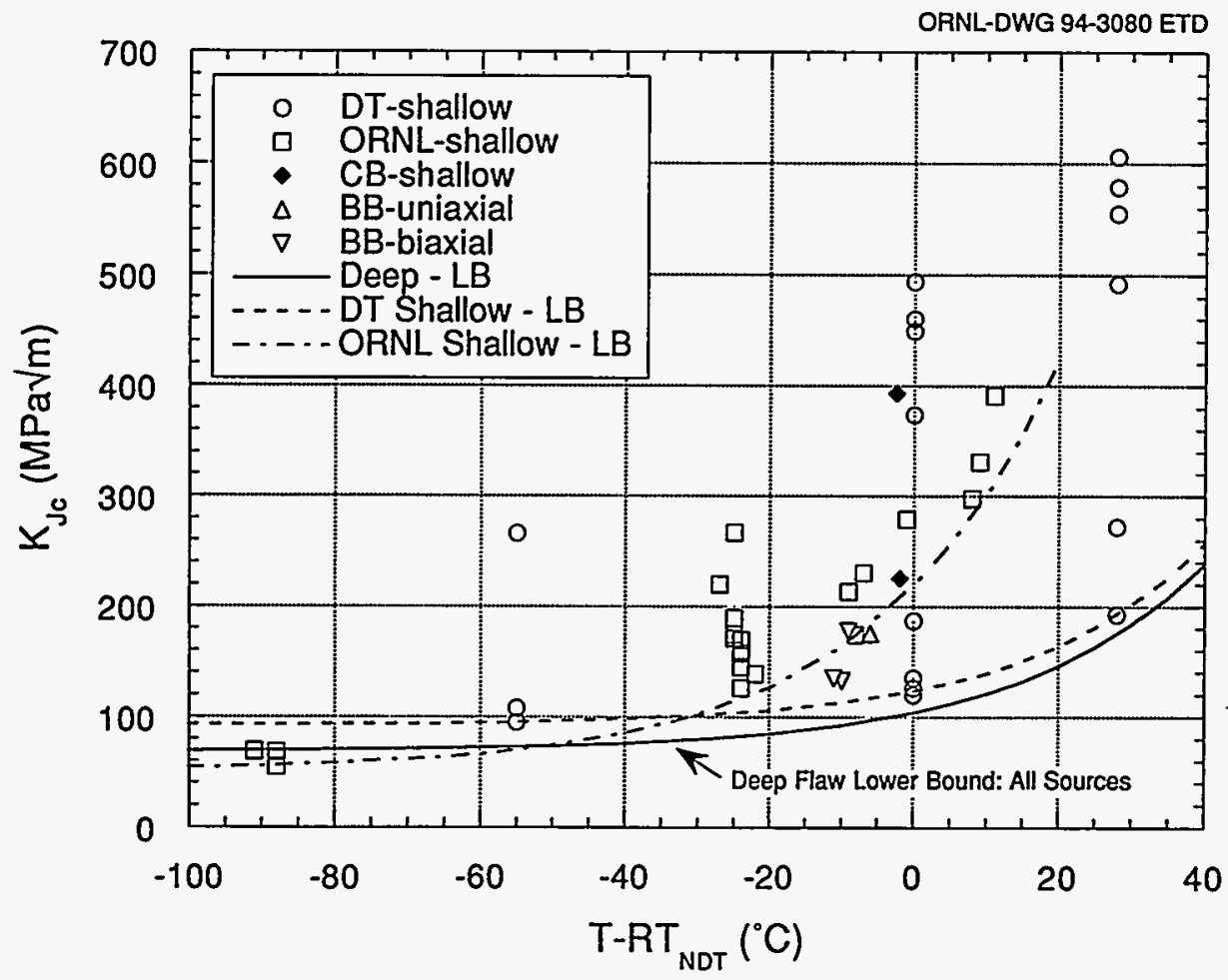

Figure 2.31 Shallow-crack fracture toughness results as function of normalized temperature $\mathbf{T}-\mathbf{R T}_{\mathrm{NDT}} \cdot$ Note: $\mathrm{BB}=$ biaxial beam 
Full-Thickness

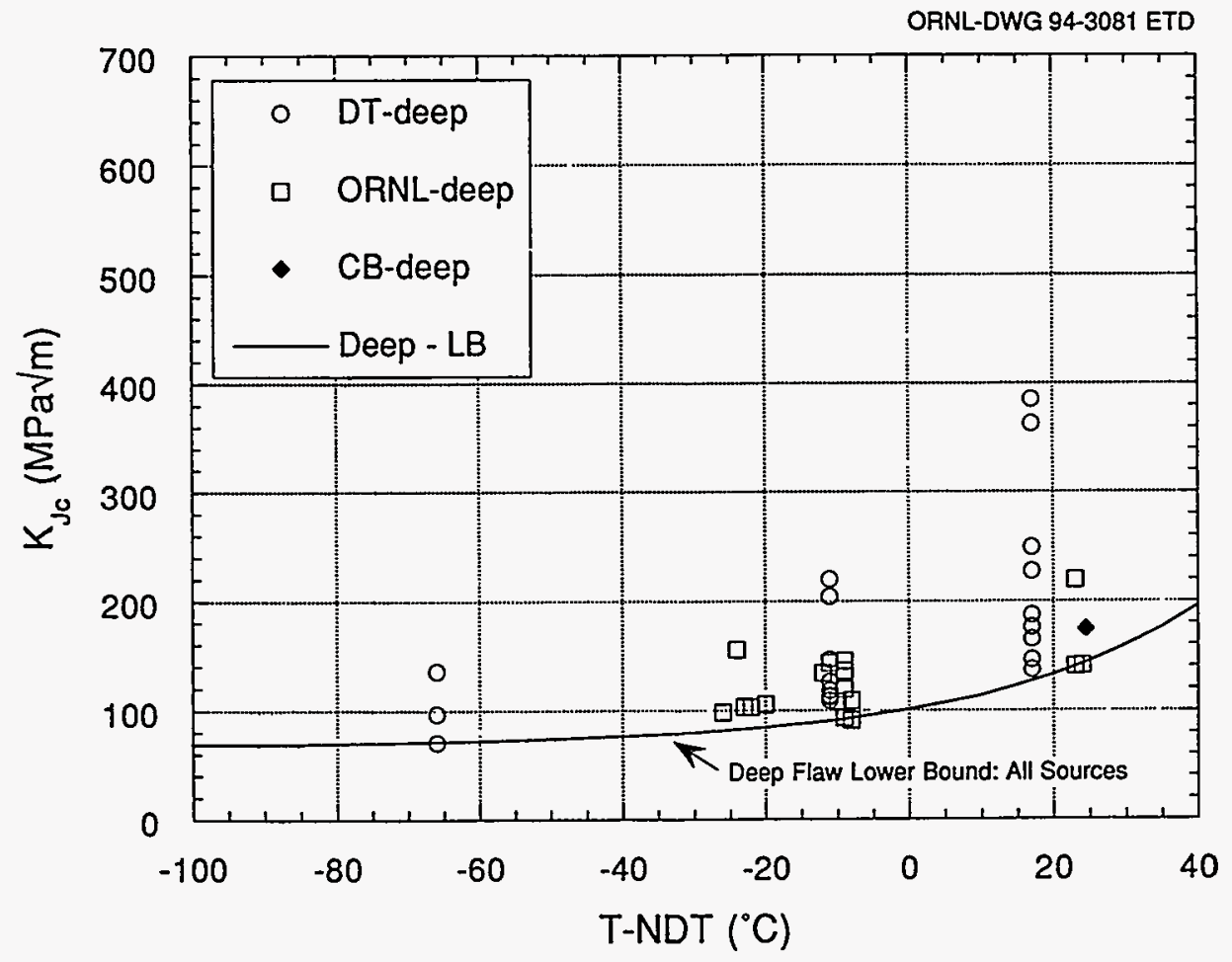

Figure 2.32 Deep-crack fracture toughness results as function of normalized temperature $\mathbf{T}$ - NDT

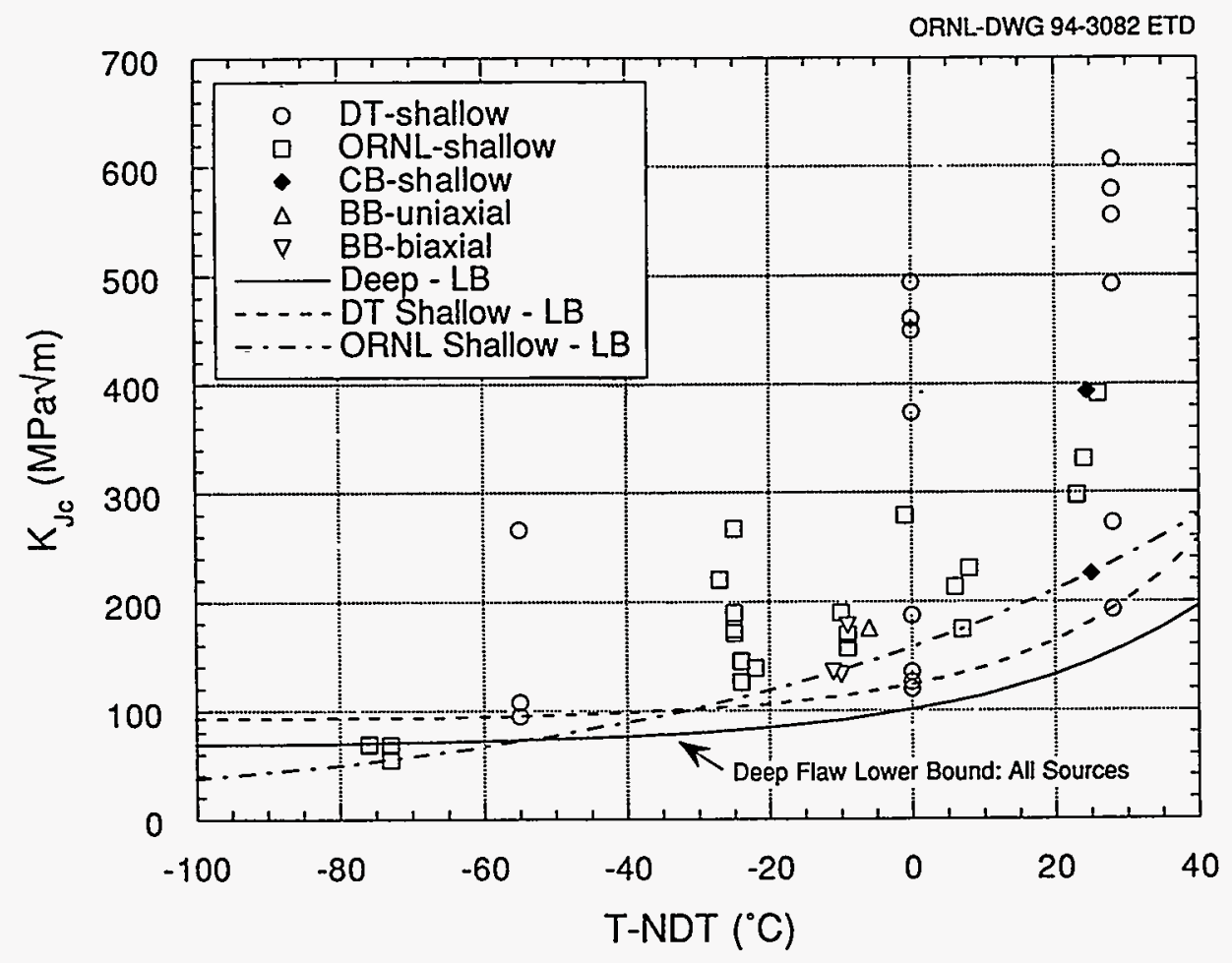

Figure 2.33 Shallow-crack fracture toughness results as function of normalized temperature $\mathrm{T}-\mathrm{NDT}$ 
Full-Thickness

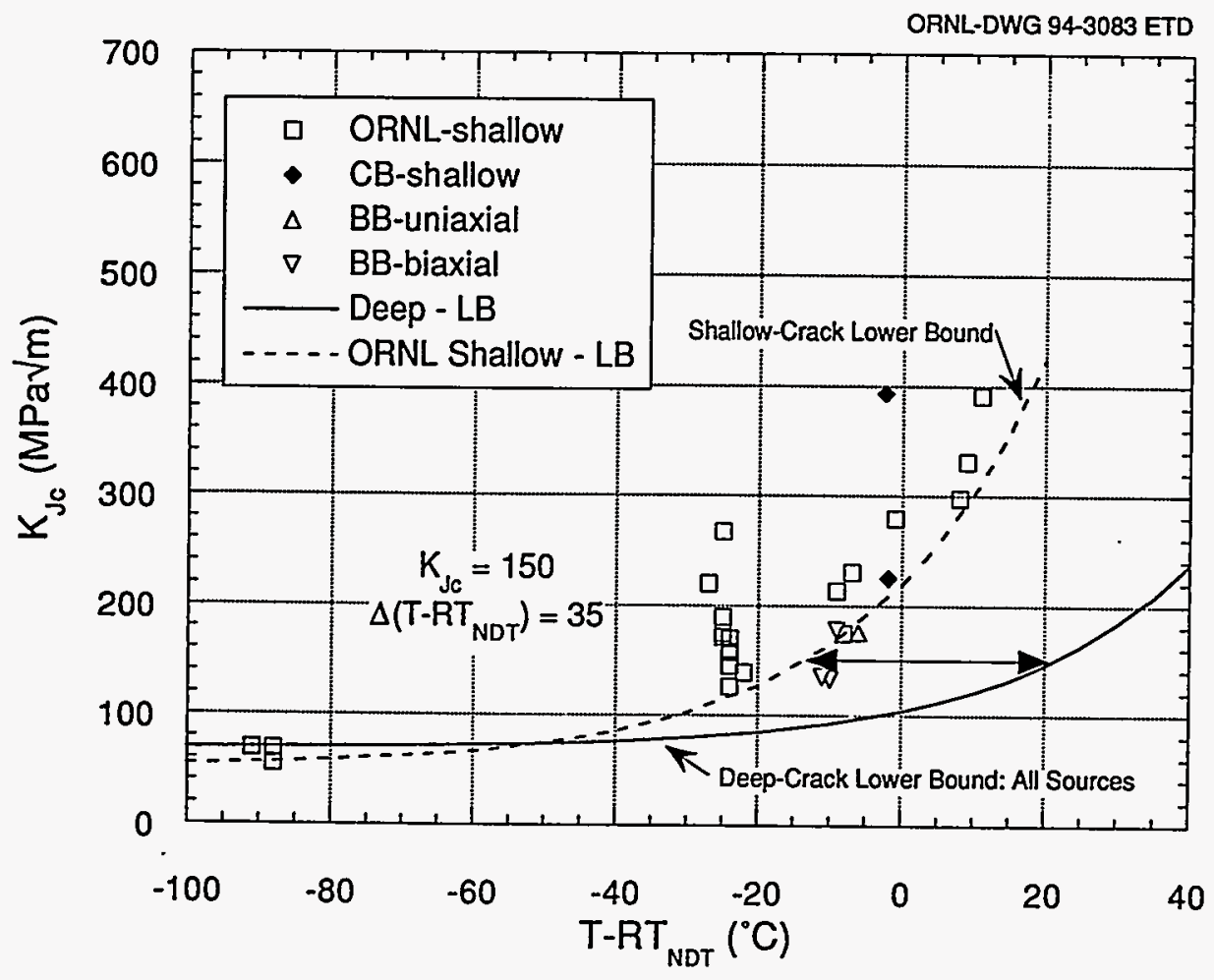

Figure 2.34 HSST shallow-crack fracture toughness results as function of normalized temperature $\mathrm{T}-\mathrm{RT}_{\mathrm{NDT}}$

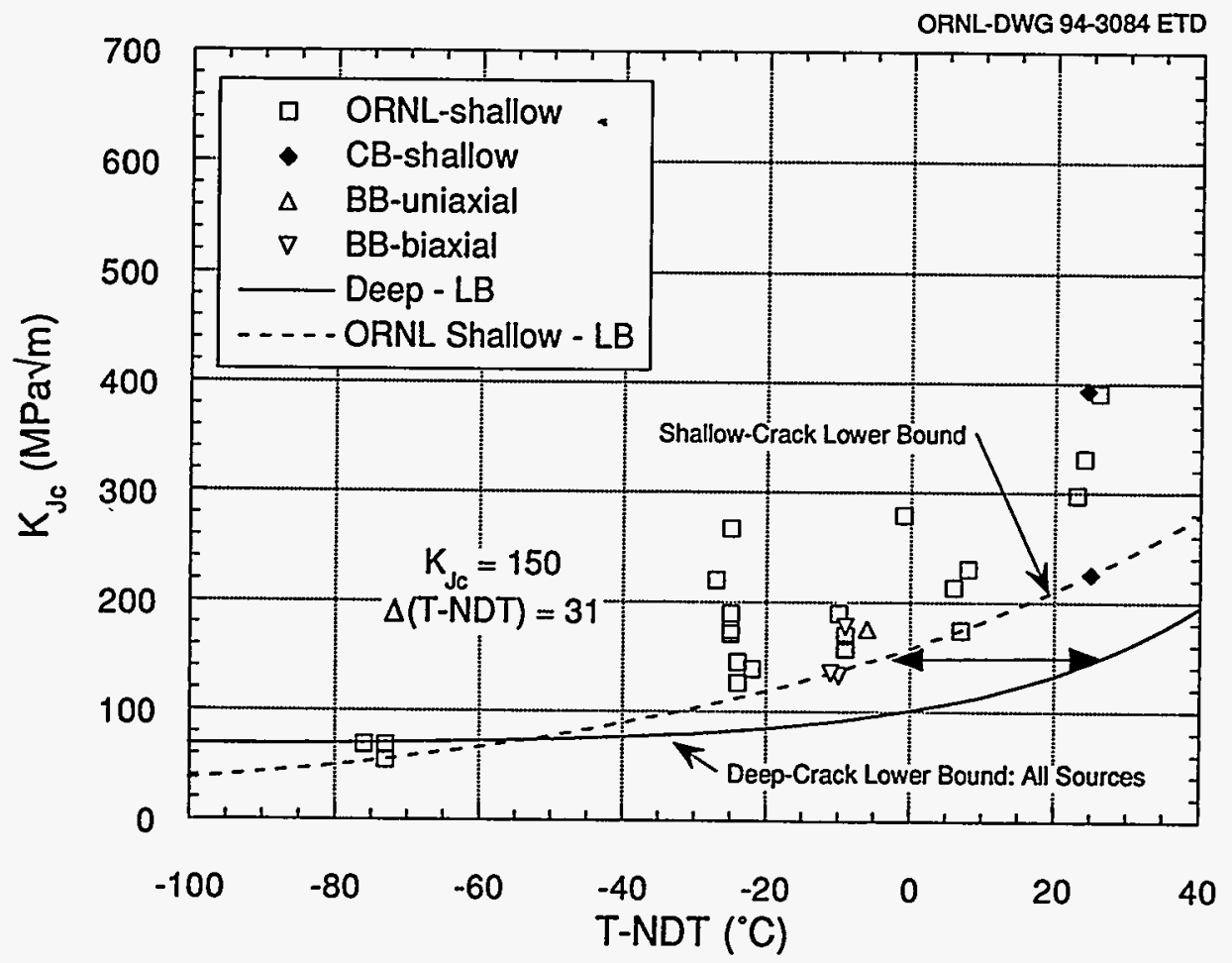

Figure 2.35 HSST shallow-crack fracture toughness results as function of normalized temperature T - NDT 



\section{Clad Beam Posttest Analyses}

\subsection{Finite-Element Analysis}

Two-dimensional (2-D) analyses were performed on the clad beam specimen depicted in Fig. 2.5 using the ABAQUS ${ }^{22}$ finite-element program. The plane-strain analyses were carried out using an incremental elasticplastic constitutive model and small-strain theory. Local crack-tip fields obtained from these analyses are used in the application of stress-based constraint characterization models. A one-half section of the complete clad beam specimen illustrated in Fig. 2.5 is represented in the 2-D finite-element model of Fig. 3.1. The model of the clad beam specimen with $\mathrm{a} / \mathrm{W}=0.05$ in Fig. 3.1 incorporates the curvature of the plate and the flat cut-out where the specimen is supported during loading. The model has a highly refined mesh in the crack-tip region [Fig. 3.1(c)] to provide resolution of stress fields over the normalized distance $2 \leq \mathrm{ro}_{0} / \mathrm{J} \leq 10$ in front of the crack; $r$ is the distance from the crack tip, and $\sigma_{0}$ is the yield stress. The outermost semicircular ring of nodes in the mesh, shown in

\section{ORNL-DWG 94-3085 ETD}

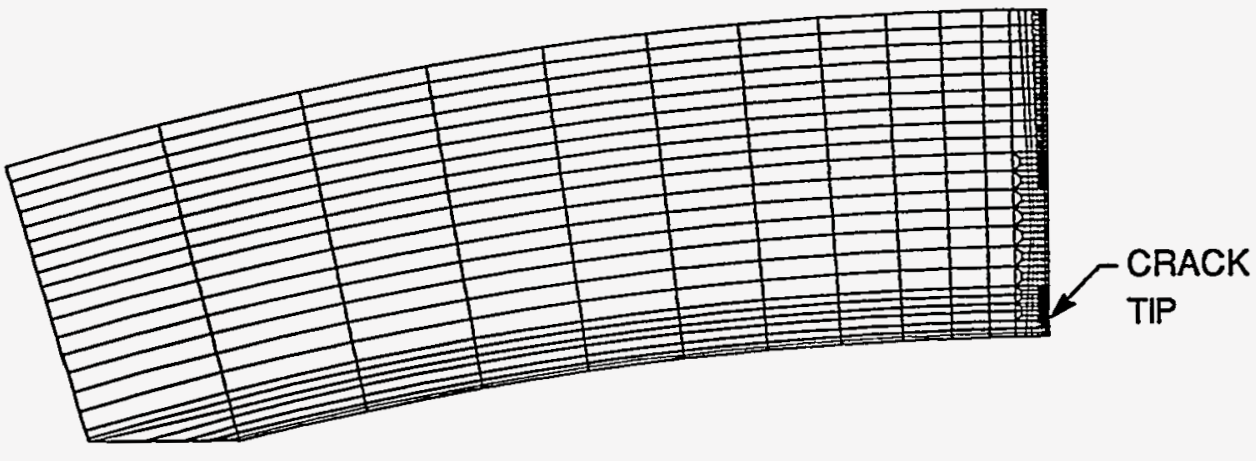

(a)

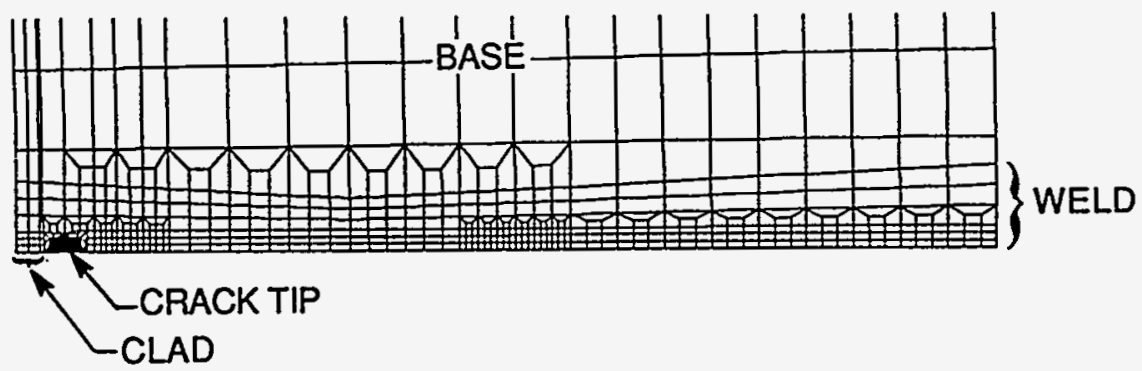

(b)

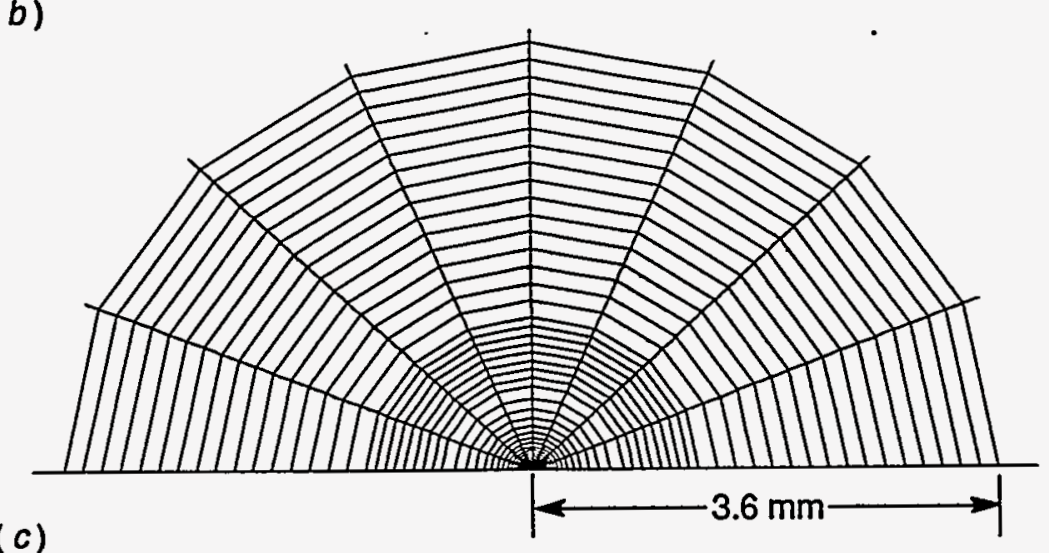

Figure 3.1 (a) Finite-element mesh of clad beam specimen with $a / W=0.05$, $(b)$ crack-plane region, and (c) crack-tip region 
Fig. $3.1(c)$, has a radius of $3.6 \mathrm{~mm}$. The model consists of 3712 nodes and 1155 eight-node isoparametric elements. Collapsed-prism elements arranged in a focused fan configuration at the crack tip are used to produce a $1 / \mathrm{r}$ strain singularity appropriate for inelastic analysis. Reduced integration (less sampling points) was used for all the elements except for the inner ring of elements at the crack tip in the shallow-crack models. The use of full integration for the innermost ring of elements helps in the convergence of the model at high loads.

Material properties used for both pretest and posttest analyses of the clad beam specimens were taken from Table 2.9 and from the multilinear true stress vs true plastic-strain curves given in Fig. 3.2. For the posttest analyses, Young's modulus $(E)$ and $\sigma_{0}$ for the weld metal were reduced from the pretest values by $\sim 2 \%$ and $10 \%$, respectively, to produce better agreement with $P$ vs CMOD data from the tests. The hardening portion of the stress-strain curve was kept consistent with the pretest estimation of material hardening. The technique of lowering $E$ and $\sigma_{0}$ to achieve agreement with the measured $P$ vs CMOD data has been used in previous analytical studies of bend specimens. ${ }^{4}$ This technique was used because the 2-D plane-strain model is too stiff for an exact comparison between measured and calculated $P$ vs CMOD. Analytical evaluations of an uncracked, 2-D, plane-strain model, using an elastic-perfectly plastic mate- rial model, have shown that the limit load is overestimated by $\sim 12 \%$ due to the plane-strain effect. The overestimate of the plane-strain effect can be compensated for by lowering the yield stress. The effective modulus $\left(\mathrm{E}_{\mathrm{m}}\right)$ was calculated for each clad beam specimen based on ASTM E 813,16 which accounts for various uncertainties in testing. Should $E_{m}$ deviate from $E$ by more than $10 \%$, then the test is not considered valid. The percent deviations for $\mathrm{CB}-1, \mathrm{CB}-2$, and $\mathrm{CB}-3$ were $4.7,2.8$, and $0.5 \%$, respectively.

Results from the posttest analyses of tests CB-1, CB-2, and CB-3 are summarized in Figs. 3.3 and 3.4. Comparison of the measured and calculated $\mathrm{P}$ vs displacement responses provides a way to interpret the accuracy of the analysis results and to establish confidence in the calculated fracture mechanics parameters. The calculated $P$ vs LLD curves are compared with measured data for each test in Fig. 3.3. For the shallow-crack specimens, calculated LLD values at a given load were greater than measured values for the full range of loading. In contrast, comparisons of calculated and measured $P$ vs CMOD in Fig. 3.4 show good agreement. The difficulties in analytically modeling the measured responses of $P$ vs LLD and P vs CMOD simultaneously have been described in Refs. 4-6. For the analyses presented herein, emphasis was placed on modeling the $P$ vs CMOD response accurately for use in determining fracture toughness.

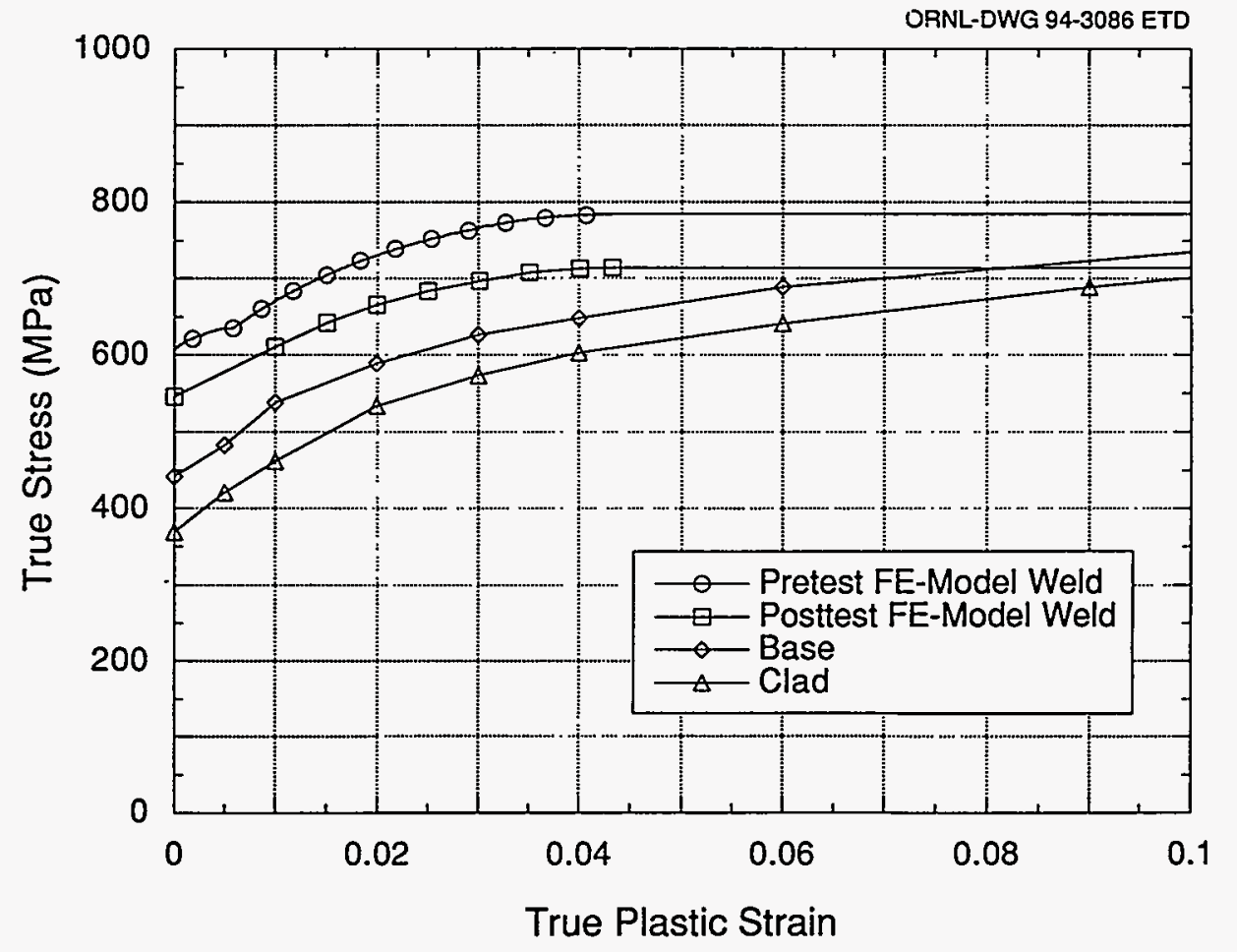

Figure 3.2 Material representation for clad beam at $\mathrm{T}=-25^{\circ} \mathrm{C}$ 


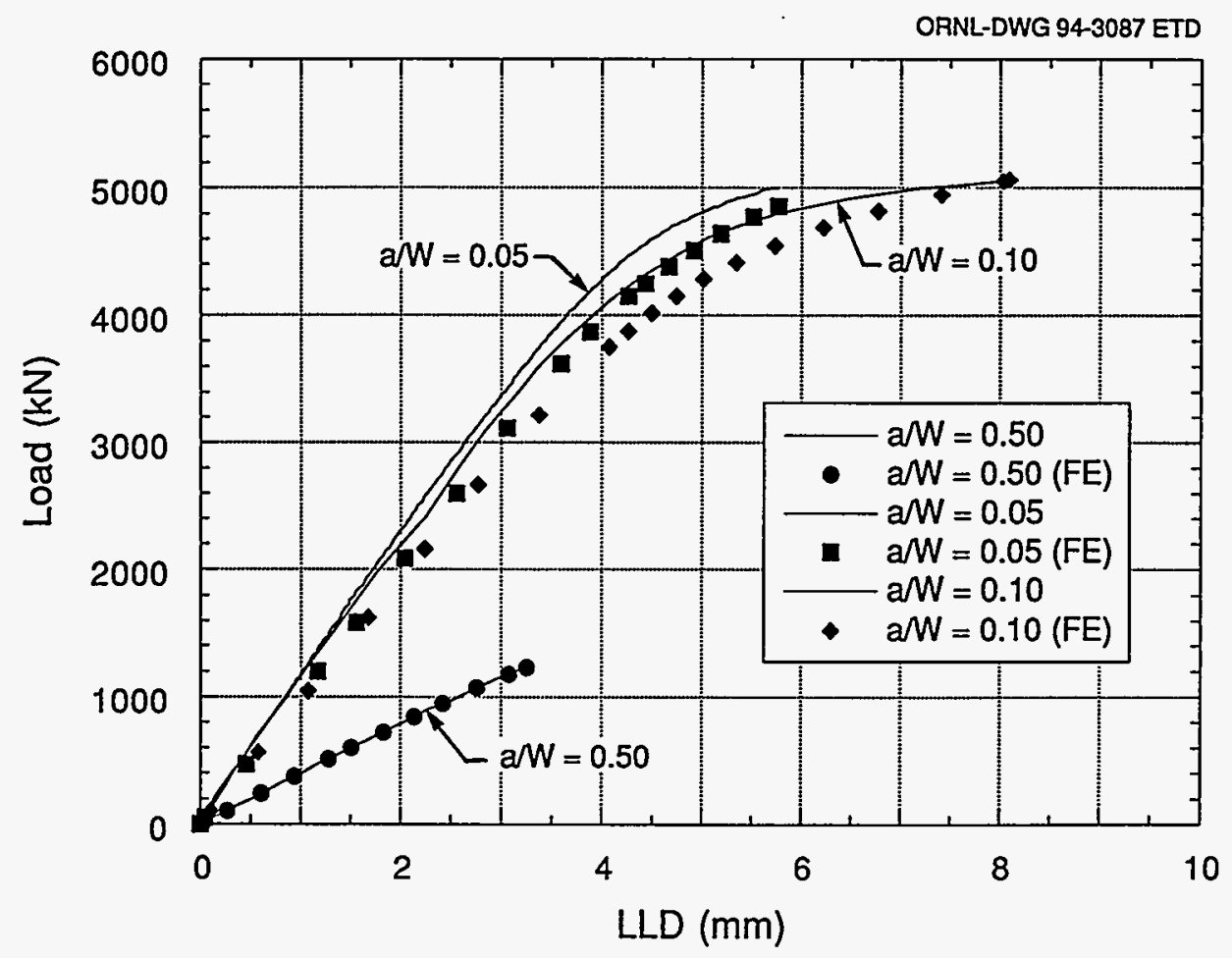

Figure 3.3 Comparison of calculated and measured LLD for clad beam specimens

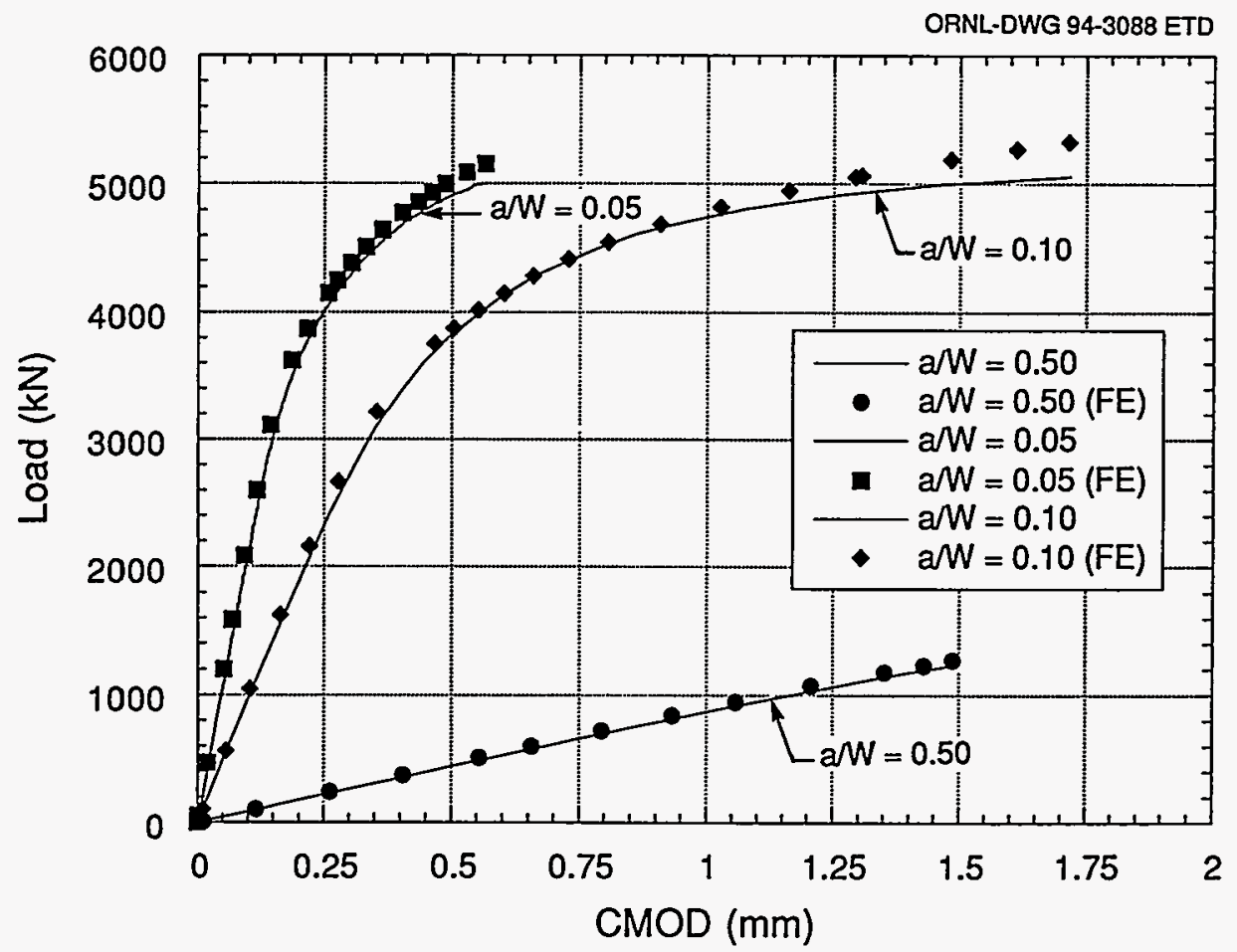

Figure 3.4 Comparison of calculated and measured CMOD for clad beam specimens

\subsection{Toughness Estimation Techniques}

For the clad beam tests, fracture toughness is estimated in terms of the critical J-integral and then converted into an elastic-plastic stress-intensity factor, $\mathrm{K}_{\mathrm{Ic}}$. The two techniques ${ }^{4-6}$ used to determine the critical $\mathrm{J}$ are based on the "work" at the crack tip as measured by the area under the load-displacement (LLD or CMOD) curves. The methods 
require an $\eta$-factor, which relates work at the crack tip to the plastic portion of the crack-driving force. The $\eta$-factor is not affected by the value of $\sigma_{0}$ because the $\eta$-factor is evaluated from the ratio of $J$ to the area under the loaddisplacement curve and both parameters are equally affected by $\sigma_{0}$. The first method of estimating $\mathrm{J}$ is similar to the technique used in ASTM E 813 (Ref. 16) because the $P$ vs LLD test record is used as input for the toughness estimate. The J-integral is divided into elastic and plastic terms given by

$$
\mathrm{J}=\mathrm{J}_{\mathrm{el}}+\mathrm{J}_{\mathrm{pl}} \text {, }
$$

where

$$
\mathrm{J}_{\mathrm{pl}}=\frac{\eta_{\mathrm{pl}}^{\ell} \mathrm{U}_{\mathrm{pl}}}{\mathrm{Bb}}
$$

and $U_{p l}$ is the plastic component of the area under the $P$ vs LLD curve, $B$ is specimen thickness, $b$ is the remaining ligament $(W-a)$, and $\eta_{\mathrm{pl}}^{\ell}$ is the dimensionless constant relating the area term $\left(\mathrm{U}_{\mathrm{pl}}\right)$ to $\mathrm{J}_{\mathrm{pl}}$. Finite-element analysis provides values of $\eta_{\mathrm{pl}}^{\ell}$ as a function of $\mathrm{U}_{\mathrm{pl}}$ for each loading and specimen configuration. Analysis is also required to determine the relationship between $\mathrm{J}_{\mathrm{el}}$ and $\mathrm{P}$. The variations of $\eta_{\mathrm{pl}}^{\ell}$ as a function of $U_{\mathrm{pl}}$ for tests CB-1, $\mathrm{CB}-3$, and CB-2 are shown in Fig. $3.5(a)-(c)$. The $\mathrm{U}_{\mathrm{pl}}$ value from the measured $P$ vs LLD curve and the corresponding value of $\eta_{\mathrm{pl}}^{\ell}$ for each test at cleavage initiation are included in Table 2.11. The value of $\eta_{\mathrm{pl}}^{\ell}$ is expected to be $\sim 2.0$ for deep-crack bend specimens at initiation [ASTM E 813 (Ref. 16)] but was determined to be 1.37 from the finite-element calculations. The low $\eta_{\mathrm{pl}}^{\ell}$ value at initiation may be the result of overestimating the measured LLD, which would lead to a larger value of $U_{p l}$ and ultimately a smaller value for $\eta_{\mathrm{pl}}^{\ell}$.

The second technique for determining the critical J-integral, first proposed by Kirk and Dodds, ${ }^{23}$ uses the plastic component of the area under the $P$ vs CMOD curve $\left(A_{p l}\right)$ to calculate $J_{\mathrm{pl}}$. Finite-element analyses provided the variations of $\eta_{\mathrm{pl}}^{\mathrm{c}}$ as a function of $\mathrm{A}_{\mathrm{pl}}$, shown in Fig. 3.6 $(a)-(c)$ for tests CB-1, CB-3, and CB-2, respectively. The values of $A_{p l}$ (from the measured $P$ vs CMOD data) and $\eta_{\mathrm{pl}}^{\mathrm{c}}$ for each test at initiation are listed in Table 2.11. The range of values for $\eta_{\mathrm{pl}}^{\ell}$ and $\eta_{\mathrm{pl}}^{\mathrm{c}}$ obtained from the finite-element results are tabulated in Appendix B.

The values of $\mathrm{J}$ calculated from the two $\eta$-factor techniques are compared to $\mathrm{J}$ determined from finite-element analyses for the three specimens in Fig. $3.7(a)-(c)$. In Fig. $3.7(a)$, the $\mathrm{P}$ vs $\mathrm{J}$ curve for $\mathrm{CB}-1$ from the finite-element analysis is above the curves generated from toughness estimation
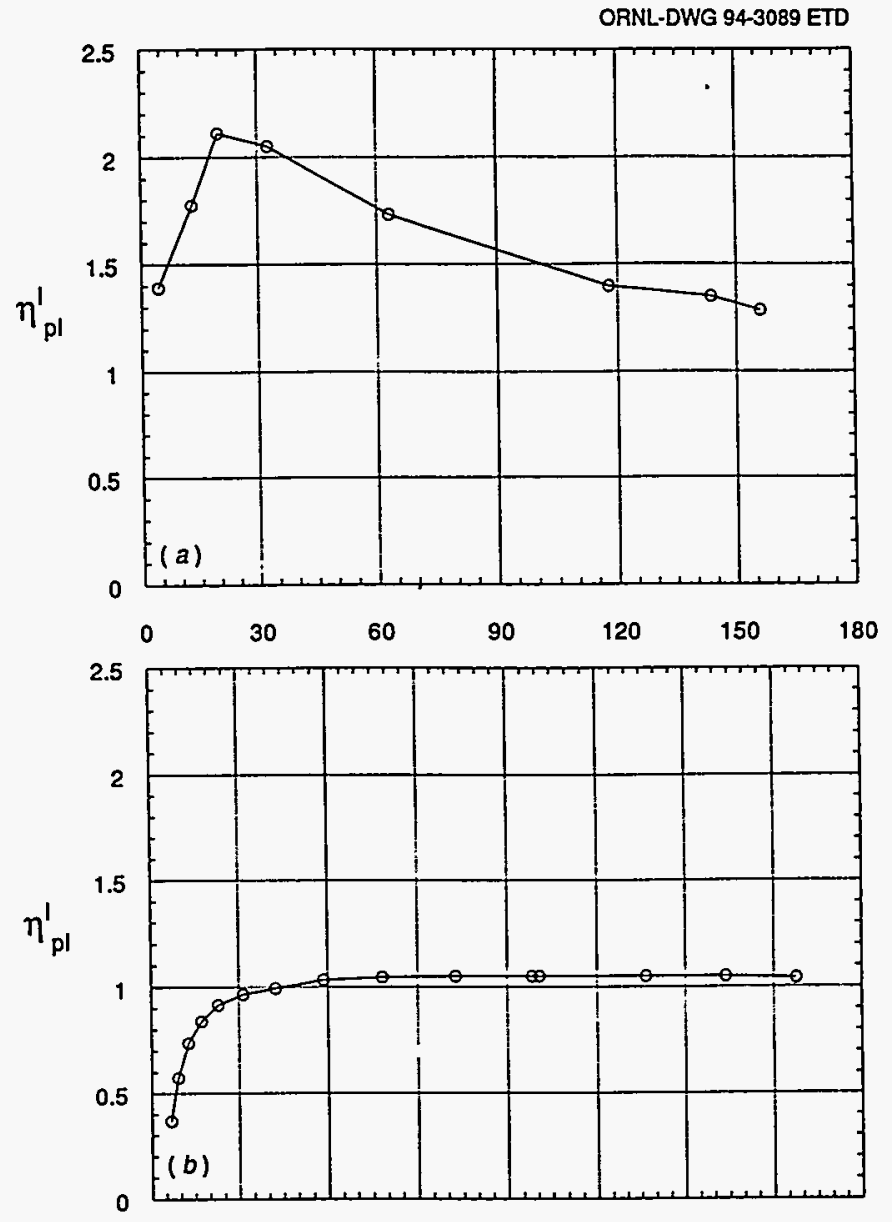

$\begin{array}{lllllllll}0 & 3000 & 6000 & 9000 & 1.210^{4} & 1.510^{4} & 1.810^{4} & 2.110^{4} & 2.410^{4}\end{array}$

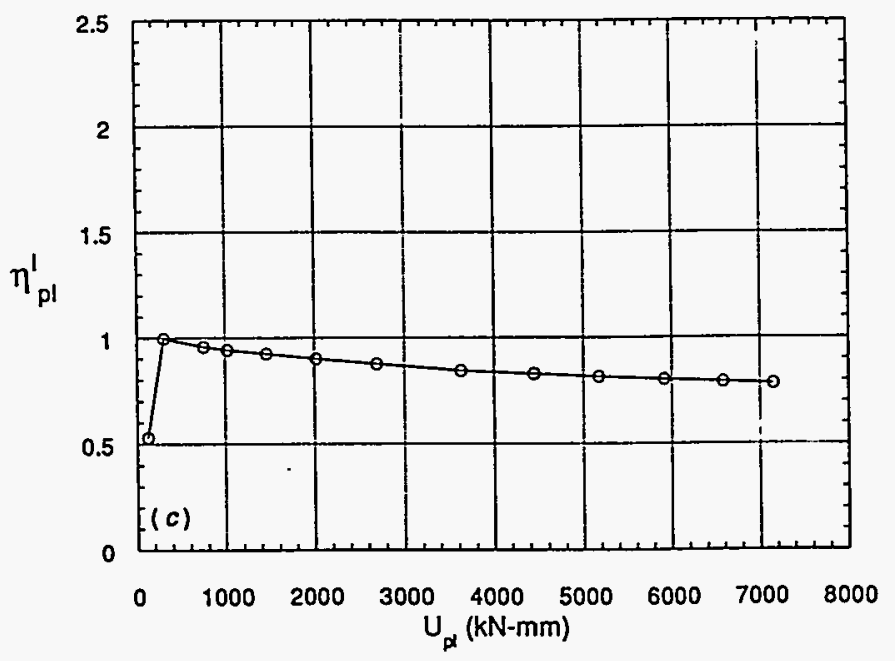

Figure 3.5 Variation of $\eta_{\mathrm{pl}}^{\ell}$ with $\mathrm{U}_{\mathrm{pl}}$ (based on LLD) for clad beam specimens: $(a) \mathrm{a} / \mathrm{W}=\mathbf{0 . 5 0}$, (b) $\mathrm{a} / \mathrm{W}=0.10$, and $(c) \mathrm{a} / \mathrm{W}=0.05$

techniques. This may be related to the variation of $\eta_{\mathrm{pl}}$ with increasing plastic area for the CB-1 specimen, while a constant value of $\eta_{\mathrm{pl}}$ is used in the estimation techniques. The shallow-crack specimens did not have as large a variation in $\eta_{\mathrm{pl}}$ (or became asymptotic) and showed good agreement among the three methods of calculating J. 

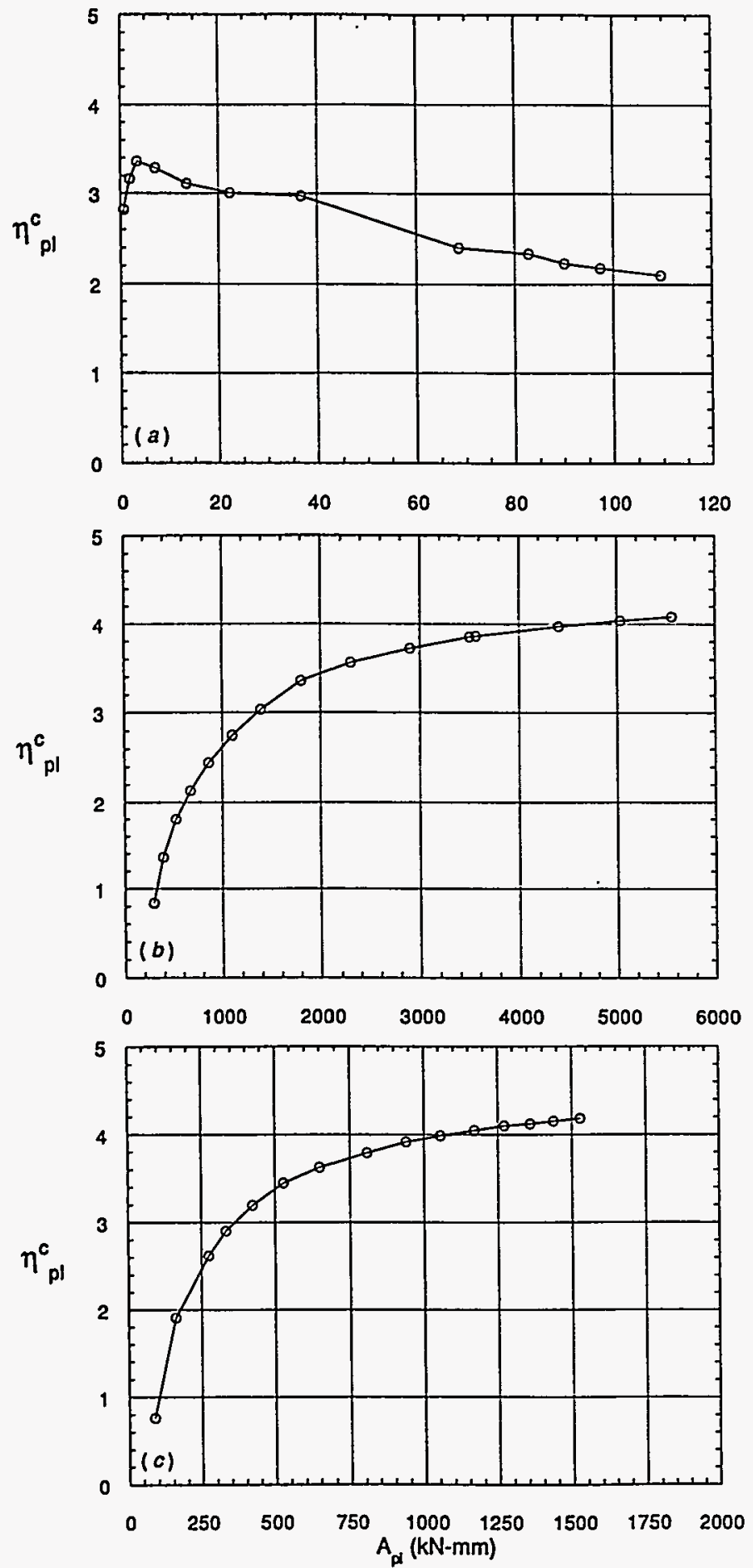

Figure 3.6 Variation of $\eta_{\mathrm{pl}}^{c}$ with $A_{\mathrm{pl}}$ (based on CMOD) for clad beam specimens: (a) $\mathrm{a} / \mathrm{W}$ $=0.50,(b) \mathrm{a} / \mathrm{W}=0.10$, and $(c) \mathrm{a} / \mathrm{W}=0.05$

\subsection{Constraint Analyses}

One of the methods previously used to assess the effects of shallow-crack depths and biaxial loading on crack-tip stress
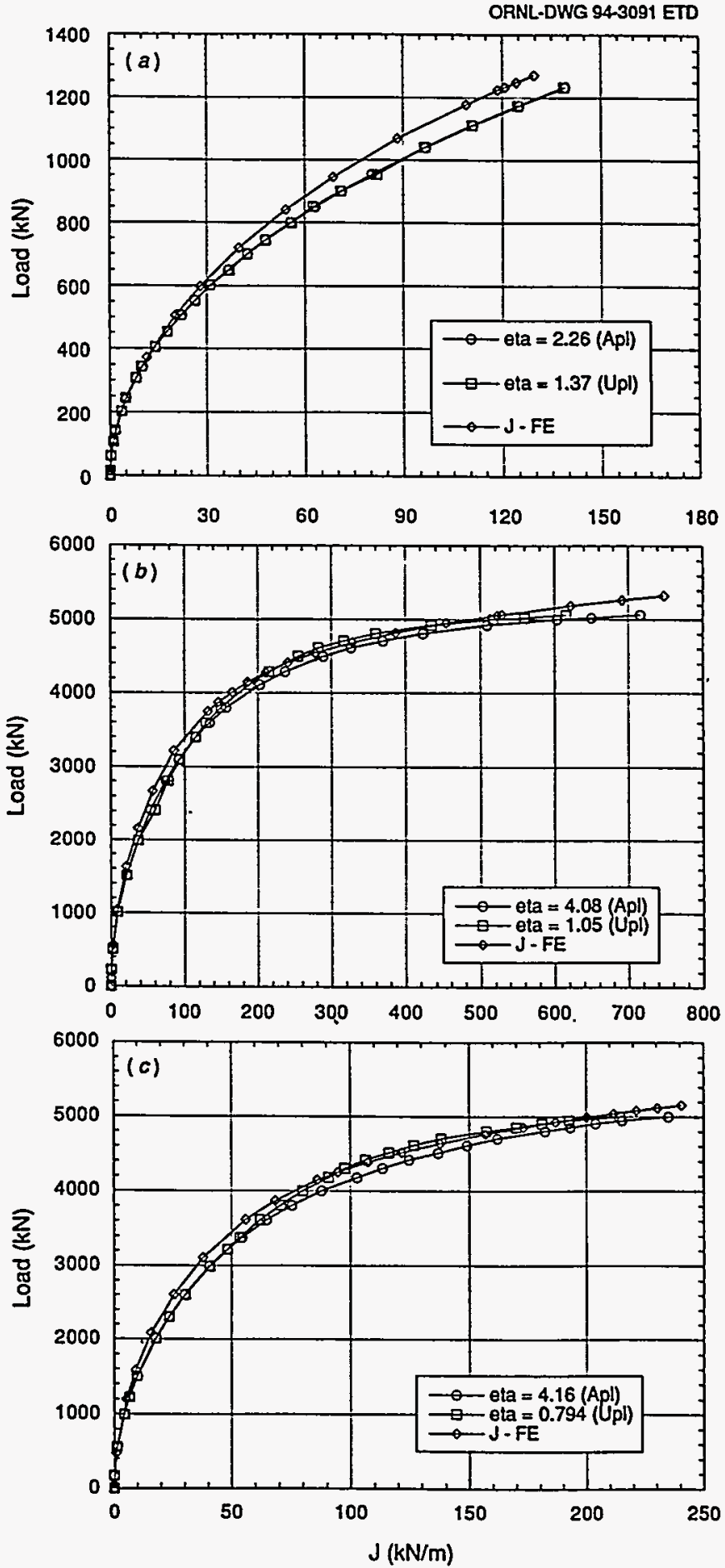

Figure 3.7 Comparison of calculated J values for clad beam specimens: $(a) \mathrm{a} / \mathrm{W}=0.50,(b) \mathrm{a} / \mathrm{W}=$ 0.10 , and $(c) \mathrm{a} / \mathrm{W}=0.05$

triaxiality is the $\mathrm{J}-\mathrm{Q}$ methodology. ${ }^{4-6}$ In this section, the $\mathrm{J}-\mathrm{Q}$ methodology is applied to the clad beam specimens using results from analyses described in Sect. 3.1. The definition of $Q$ employed here is given by O'Dowd and Shih $^{11}$ in the form 


$$
\mathrm{Q}(\overline{\mathrm{r}})=\frac{\sigma_{\theta \theta}(\overline{\mathrm{I}})-\left[\sigma_{\theta \theta}(\overline{\mathrm{I}})\right]_{\text {ssy }}}{\sigma_{0}}
$$

where $\bar{r}=r /\left(J / \sigma_{0}\right)$ is a normalized distance measured in the crack plane ahead of the crack tip $(\theta=0)$, and the $r, \theta$ polar coordinate system is centered at the crack tip such that $\theta=$ 0 corresponds to the crack plane ahead of the tip. In Eq. (3.3), $Q$ measures the departure of the opening-mode stress $\sigma_{\theta \theta}$ from the reference plane-strain small-scale yielding (SSY) solution, normalized by $\sigma_{0}$.

Using a modified boundary layer formulation, $O^{\prime}$ Dowd and $S_{\text {Shih }}{ }^{11}$ showed that $Q$ characterizes the magnitude of a spatially uniform (approximately) hydrostatic stress state in a forward sector ( $|\theta| \leq \pi / 2$ and $1 \leq \overline{\mathrm{I}} \leq 5)$ of the crack-tip region. The coefficient $Q$, although found to be independent of $\overline{\mathrm{T}}$, was formally defined at $\overline{\mathrm{r}}=2$, which falls just outside the finite strain blunting zone. For conditions ahead of the crack that do not conform to a spatially uniform hydrostatic stress field, O'Dowd and Shih ${ }^{11}$ introduced Eq. (3.3) to emphasize the explicit dependence of $Q$ upon distance $\overline{\mathrm{r}}$.

The J-Q methodology was used to assess crack-tip stress triaxiality in the clad beam specimens. In these analyses, results for the deep-crack specimen (CB-1) at a J value of $43.63 \mathrm{kN} / \mathrm{m}\left[J_{c}=139.4 \mathrm{kN} / \mathrm{m}\right.$ (in Table 2.11)] are employed as an approximation to the SSY reference solution. Earlier analyses ${ }^{4}$ have shown that $Q \approx 0$ for the deep-crack specimens under these loading conditions. This observation is supported by results shown in Fig. 3.8 for the normalized opening-mode stress $\left(\sigma_{y y} / \sigma_{0}\right)$ distributions vs $\overline{\mathrm{I}}$ for the deep-crack specimen $\mathrm{CB}-1$. The opening-mode stresses ahead of the crack tip for the shallow-crack specimens (CB-2 and CB-3), shown in Fig. 3.9, exhibit an essentially uniform deviation from the SSY solution over a distance of $2 \leq \bar{I} \leq 10$ (i.e., spatially uniform). Both shallow-crack clad beam specimens were found to have $Q$ values of about -0.78 at failure (for $\overline{\mathrm{I}}=2$ ), which represents a significant loss of constraint. The normalized stress distributions did not change for $\mathrm{J}$ values ranging from 200 to $240 \mathrm{kN} / \mathrm{m}$ for CB-2 $\left(J_{c}=235.3 \mathrm{kN} / \mathrm{m}\right)$ and from 522 to $750 \mathrm{kN} / \mathrm{m}$ for $\mathrm{CB}-3\left(\mathrm{~J}_{\mathrm{c}}=716.5 \mathrm{kN} / \mathrm{m}\right)$. The $\mathrm{Q}$ value for the shallow-crack clad beam specimens was very similar to the value for the shallow-crack SENB specimens previously tested at $\mathrm{ORNL}^{4}(\mathrm{Q} \approx-0.70)$.

\subsection{Fracture Toughness Scaling Model}

The Dodds-Anderson (or D-A) scaling model ${ }^{13}$ analyzes constraint conditions by utilizing the area (or volume for

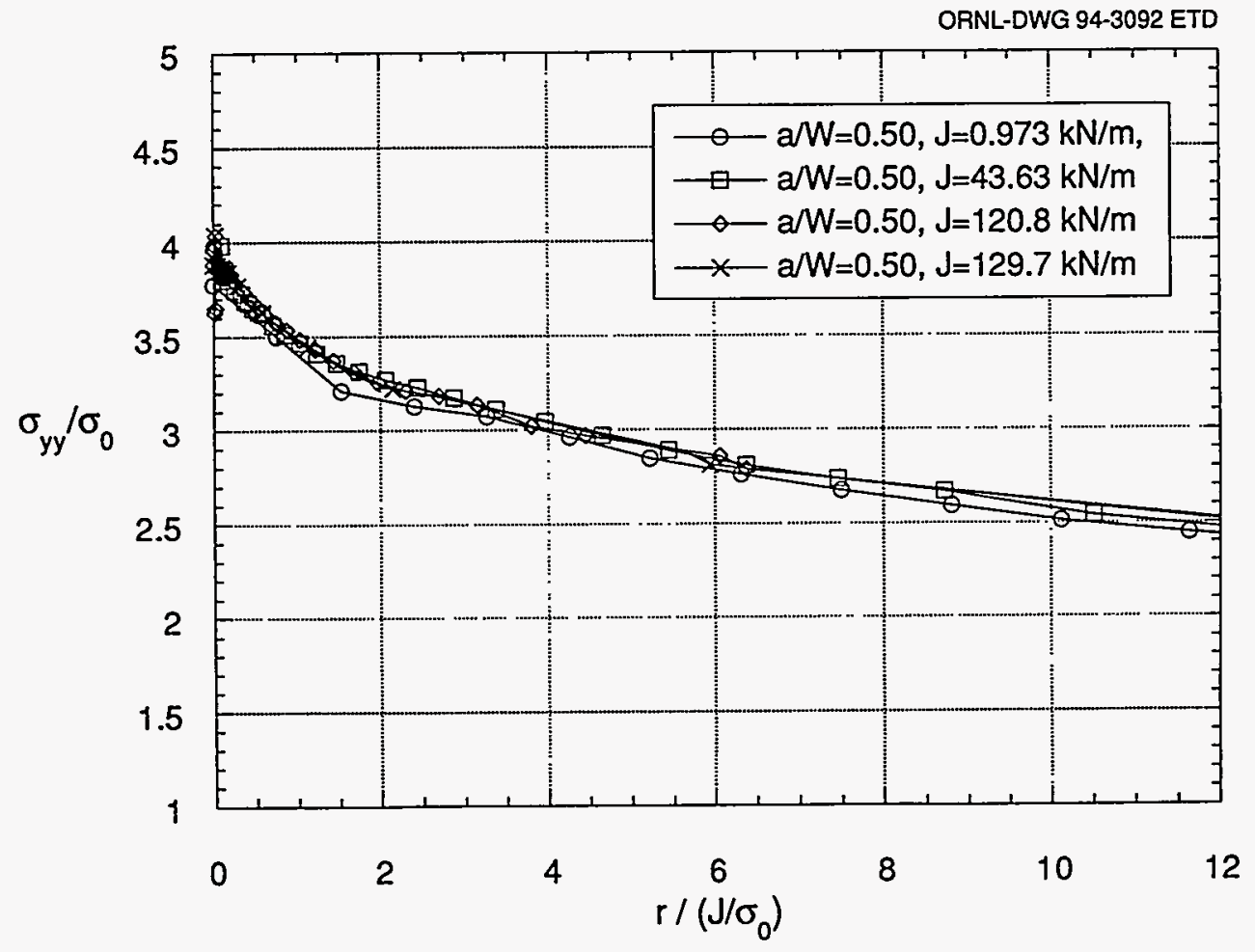

Figure 3.8 Distributions of normalized opening-mode stress for deep-crack clad beam specimen as function of applied $\mathrm{J}$ up to crack initiation 
ORNL-DWG 94-3093 ETD

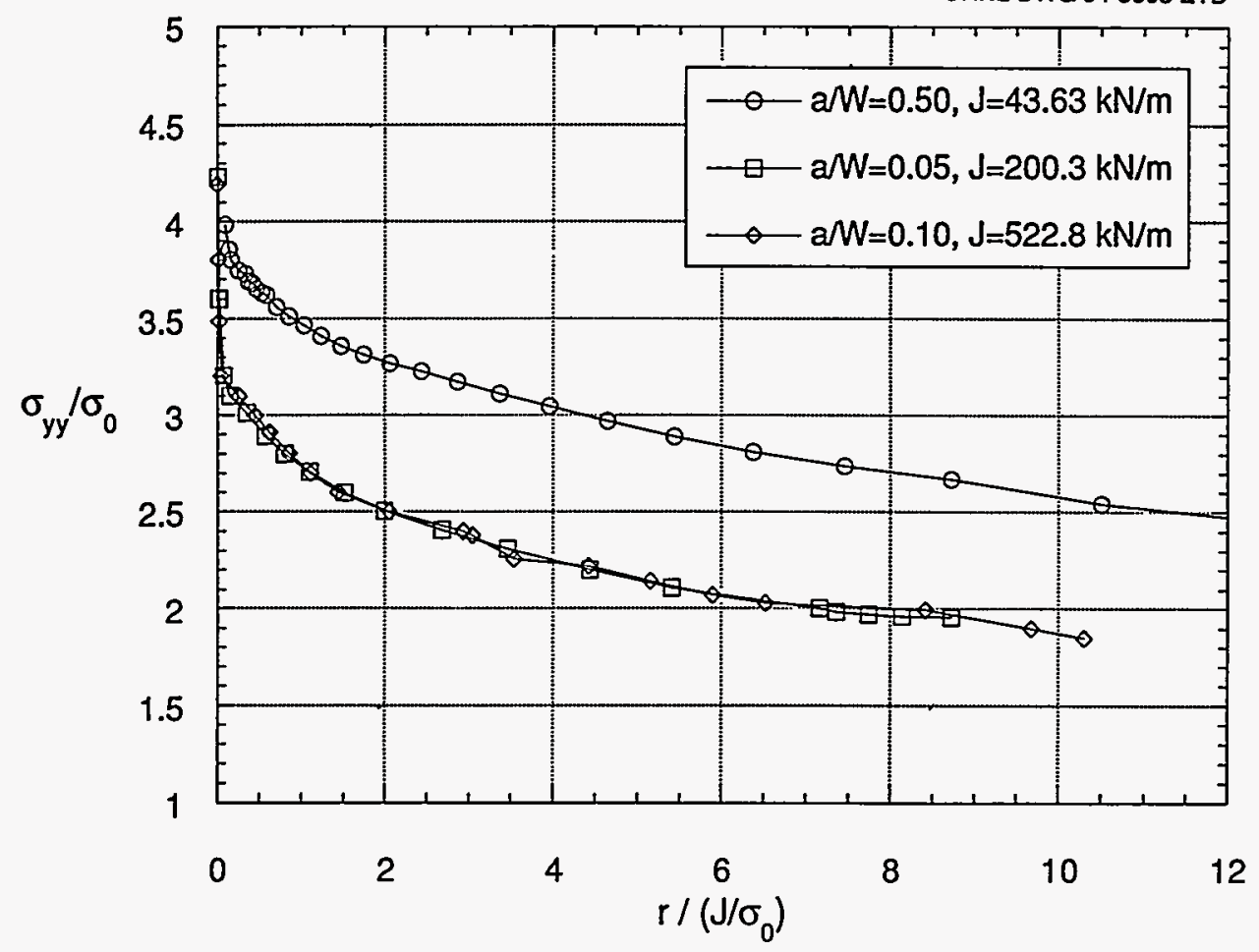

Figure 3.9 Distributions of normalized opening-mode stress for clad beam specimens as function of applied $\mathrm{J}$ up to crack initiation

3-D geometries) within principal stress contours to correlate toughness values from finite-body geometries with SSY conditions. The SSY state is then considered to yield fracture toughness results independent of specimen size or loading mode and is comparable to a specimen of infinite size. The scaling model has been successfully applied to fracture toughness results exhibiting either a loss of inplane constraint (i.e., shallow cracks) or out-of-plane constraint (i.e., thickness effects). ${ }^{13}$ The scaling model assumes that the volume of critically stressed material surrounding the crack tip is the same in different specimens with different constraint conditions. As a result, the SSY critical fracture toughness can be determined in a highconstraint geometry and then applied to a low-constraint geometry or vice versa.

The D-A scaling model was used to investigate in-plane constraint loss in the clad beam test specimens. Application of the model was based on information available in the literature ${ }^{24}$ that obviates additional crack-tip analysis. Fracture toughness data from the HSST clad beam, shallow-crack, and biaxial cruciform programs are shown in Fig. 3.10 as a function of normalized temperature ( $\mathrm{T}$ NDT). A lower-bound curve to the uniaxial shallow-crack data is drawn as a straight line. Figure $\mathbf{3 . 1 0}$ indicates an increase in toughness and data scatter with decreased constraint.
The following criterion developed by Dodds and Anderson ${ }^{13}$ determines dimensions in deep-crack (a/W $\geq$ $0.5)$ specimens necessary for SSY:

$$
a, b, B \geq 200 J_{\mathcal{c}} / \sigma_{f}
$$

In Eq. (3.4) $\mathrm{a}$ is the crack depth, $\mathrm{b}$ is the remaining ligament, $B$ is the specimen thickness, $\mathrm{J}_{\mathrm{c}}$ is the cleavage $\mathrm{J}$-integral toughness, and $\sigma_{\mathrm{f}}$ is the flow stress of the material. Specimens not meeting the criterion are expected to exhibit a toughness increase due to the loss of constraint. The ratio $a \sigma_{\mathrm{f}} / \mathrm{J}_{\mathrm{c}}$ determined for each clad beam specimen is listed in Table 3.1. As expected, the ratio exceeds 200 for the deep-crack specimen and is considerably less than 200 for the shallow-crack specimens.

Using the D-A analysis results, ${ }^{13}$ Wallin has quantified inplane constraint loss by the following equation: 24

$$
\mathrm{J}_{\mathrm{o}} \approx \mathrm{J}_{\mathrm{FB}} /\left\{1+\left[\mathrm{A} \cdot \mathrm{J}_{\mathrm{FB}} /\left(\mathrm{a} \cdot \sigma_{0}\right)\right]^{\mathrm{B}}\right\},
$$

where

$$
\begin{array}{ll}
A=38.1 \cdot \ln (N / 3.14), & 5 \leq N \leq 50 \\
B=1.27+N / 104.0, & 5 \leq N \leq 50
\end{array}
$$




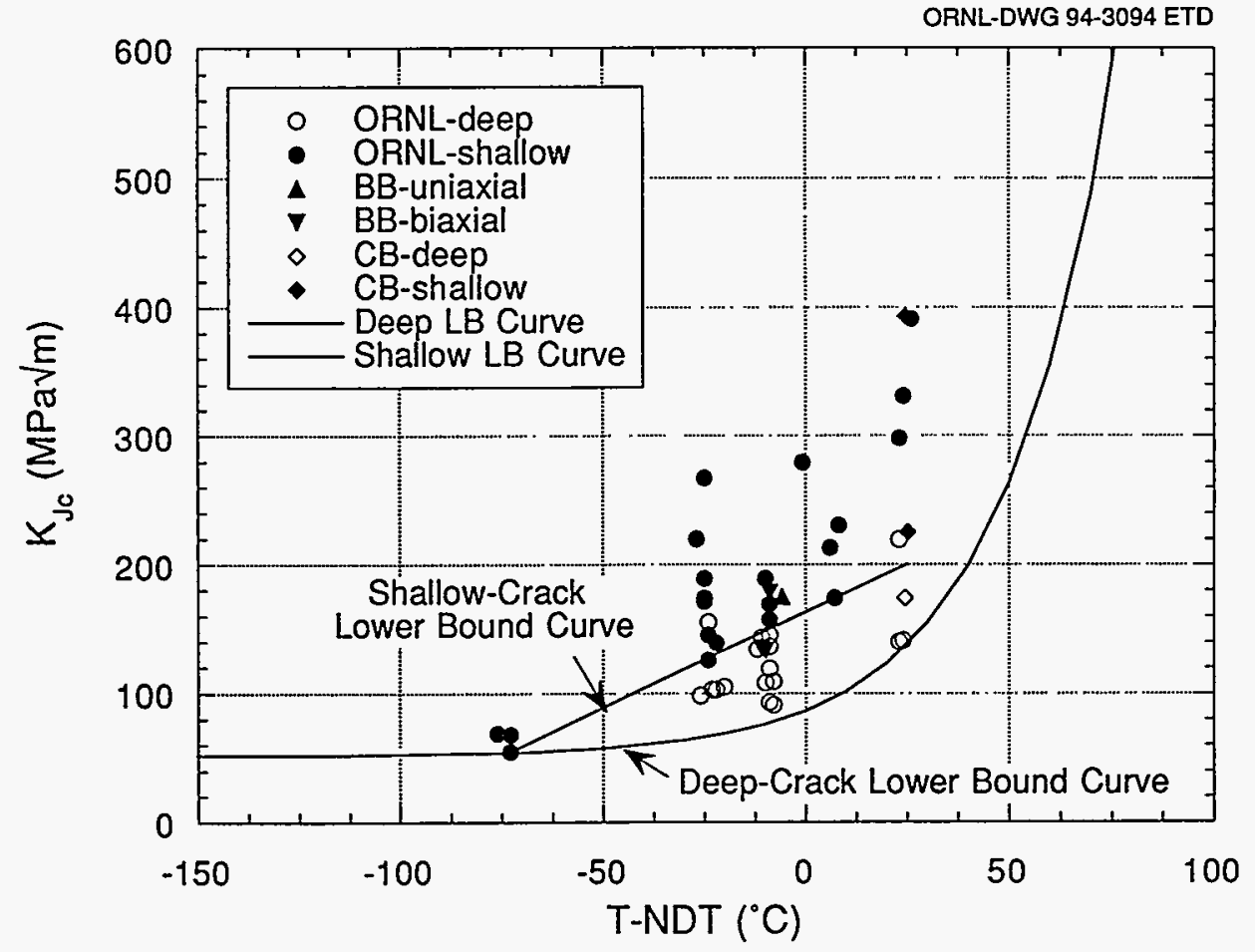

Figure 3.10 HSST fracture toughness results as function of normalized temperature T - NDT

Table 3.1 Results of scaling model applied to clad beam data

\begin{tabular}{cccccc}
\hline $\begin{array}{c}\text { HSST } \\
\text { clad } \\
\text { beam }\end{array}$ & $\begin{array}{c}\mathbf{a} \\
(\mathbf{m m})\end{array}$ & $\begin{array}{c}\mathbf{K} \mathbf{j c} \\
(\mathbf{M P a} \sqrt{\mathbf{m}})\end{array}$ & $\mathbf{a} /\left(\mathrm{J} / \sigma_{\mathbf{f}}\right)$ & $\mathbf{J}_{\mathbf{F B}} / \mathbf{J}_{\mathbf{0}}$ & $\begin{array}{c}\mathbf{K}_{\mathbf{0}} \\
(\mathbf{M P a} \sqrt{\mathbf{m}})\end{array}$ \\
\hline CB-1 & 117.5 & 174 & 499 & 1.04 & 170 \\
CB-2 & 10.84 & 225 & 27 & 3.12 & 128 \\
CB-3 & 23.69 & 393 & 20 & 4.35 & 189 \\
\hline
\end{tabular}

and $\mathrm{J}_{\mathrm{o}}$ is the $S S Y$ or reference value of $\mathrm{J}, \mathrm{J}_{\mathrm{FB}}$ is the value of $\mathrm{J}$ in the finite-body geometry, and $\mathrm{N}$ is the hardening exponent. It is recommended in Ref. 13 that the scaling model not be used in situations in which $\mathrm{J}_{\mathrm{FB}} / \mathrm{J}_{\mathrm{O}}>4$. The SSY value $\left(J_{O}\right)$ was computed from Eq. (3.5) for each clad beam specimen using $\mathrm{N}=10$, and the results are listed in Table 3.1 as $\mathrm{J}_{\mathrm{FB}} / \mathrm{J}_{\mathrm{O}}$ and $\mathrm{K}_{\mathrm{o}}$. The $\mathrm{K}_{\mathrm{o}}$ results for the HSST clad beam, shallow-crack SENB, ${ }^{6}$ and biaxial cruciform ${ }^{6}$ programs are shown in Fig. 3.11 as a function of T - NDT. The $\mathrm{K}_{\mathrm{O}}$ results show no toughness increase associated with the shallow-crack specimens. The $\mathrm{K}_{\mathrm{o}}$ values evaluated for specimens that exhibited $\mathrm{J}_{\mathrm{FB}} / \mathrm{J}_{\mathrm{O}}>4$ do not represent the SSY toughness value, and were not included in Fig. 3.11. The scaling model appears to be effective in adjusting the HSST test data to account for in-plane loss of constraint. 
Clad Beam

ORNL-DWG 94-3095 ETD

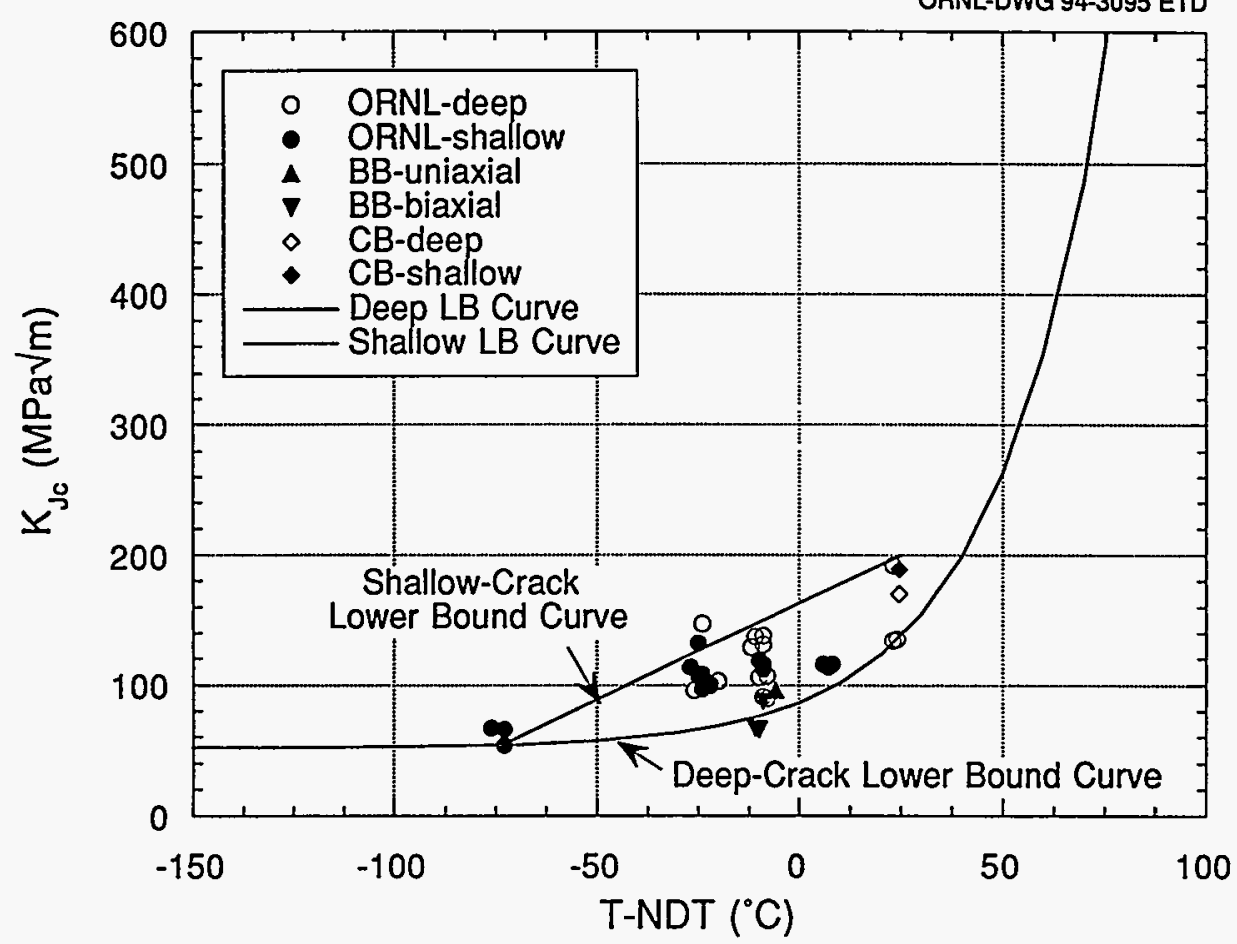

Figure 3.11 SSY toughness $\left(K_{0}\right)$ results as function of normalized temperature $T$ - NDT 

$-\longrightarrow$ 


\section{Summary and Conclusions}

This report describes preliminary results from an HSST testing program that is utilizing full-thickness clad beam specimens fabricated from the RPV of a canceled nuclear plant. The beam specimens, which incorporate RPV fabrication welds, base plate, and weld-overlay cladding, are providing fracture toughness data for shallow cracks in material for which metallurgical conditions are prototypic of those found in RPVs. Factors influencing the fracture toughness of RPV material containing shallow cracks include metallurgical gradients, weld inhomogeneities, the cladding process, and residual stresses.

Of particular interest is the marked difference in $\sigma_{0}$ between the weld and the plate material. The $\sigma_{0}$ for weld material is $36 \%$ higher than that associated with the base material. Article G-2000 for vessels ${ }^{15}$ states that the critical (or reference) $\mathrm{K}_{\mathrm{IR}}$ curve is used for steels that have specified minimum yield strengths at room temperature greater than $345 \mathrm{MPa}$ (50 ksi) but not exceeding $621 \mathrm{MPa}$ (90 ksi). The value of $\sigma_{0}$ for the weld material at room temperature is $565 \mathrm{MPa}$ (82 ksi). Conceptually, an irradiation-induced increase in yield strength could result in a $\sigma_{0}$ value that exceeds the ASME upper limit where the $\mathrm{K}_{\mathrm{IR}}$ curve is valid. The high $\sigma_{0}$ values for prototypic weld material may have implications for RPV structural integrity assessments.

In the initial testing phase, three full-thickness clad beam specimens were fabricated with through-thickness cracks in weld metal that ranged in depth from 10 to $114 \mathrm{~mm}(0.05 \leq$ $\mathrm{a} / \mathrm{W} \leq 0.5)$. These specimens were tested in three-point bending at temperatures in the transition region of the weld metal fracture toughness curve $\left(\mathrm{T}-\mathrm{NDT} \approx 25^{\circ} \mathrm{C}\right)$. Fracture toughness estimates were obtained from $P$ vs LLD and $P$ vs CMOD data using finite-element techniques and estimation schemes based on the $\eta$-factor method. These toughness data were compared with other shallow- and deep-crack uniaxial beam and cruciform data generated previously from A 533 B plate material. When NDT is adopted as the normalizing temperature parameter, the fracture toughness result for the clad beam specimen $\mathrm{CB}-2(\mathrm{a} / \mathrm{W}=0.05)$ defines the lower bound of the HSST shallow-crack toughness data at the higher temperatures (see Fig. 2.33). Also note that the crack tip for specimen CB-2 had a depth of $\sim 10 \mathrm{~mm}$, which is near the boundary of the cladding HAZ in the weld material. While statistical variability associated with shallow-crack testing in the transition region must be considered as a contributing factor, the potential exists that metallurgical conditions in the cladding $\mathrm{HAZ}$ region significantly influenced the relatively low toughness measured in the CB-2 test. Determining these metallurgical conditions in the weld and base metal regions near the cladding is important for interpreting the shallow-crack test results and, consequently, should be included in the HSST Program plan for future work. Also, any significant residual stress effects must be quantified and incorporated into shallow-crack fracture toughness determinations.

The compilation of the shallow-crack fracture toughness data from testing programs conducted by the HSST Program and by CDNSWC revealed that data interpretation can be significantly influenced by the selection of a normalizing temperature parameter. Within this combined shallow-crack data set, a mix of two parameters from fundamentally different tests (i.e., drop-weight and Charpy) governs the magnitude of the normalizing temperature in the case of RT $\mathrm{TDT}_{\mathrm{N}}$. Difficulties encountered in interpreting lower-bound curves constructed from the shallow-crack data normalized to RT $\mathrm{NDT}$ were essentially eliminated by adopting a single normalizing parameter for the comparison [i.e., the NDT temperature (see Fig. 2.33)]. When normalized to NDT, the combined shallow-crack data base exhibits an elevated mean fracture toughness due to loss of constraint, accompanied by increased data scatter that tends toward the same lower bound associated with the highly constrained deep-crack toughness data.

Additional full-thickness clad beam tests are planned to complete the investigation of fracture toughness of shallow cracks located in prototypical full-thickness weld and plate material. Two clad beam specimens will be fabricated to duplicate the $\mathrm{CB}-2$ and $\mathrm{CB}-3$ shallow-crack tests in weld metal. Shallow-crack fracture toughness results from these specimens should provide additional data that are essential to a better understanding of the effects of metallurgical conditions in the region of the clad HAZ. Three additional specimens will be available for testing of shallow cracks in the A 533 B plate material and to respond to further testing needs derived from results of the existing test matrix. 
. 


\section{References}

1. W. Marshall et al., "An Assessment of the Integrity of PWR Pressure Vessels," United Kingdom Atomic Energy Agency Study Group Reports, March 1982."

2. U. S. Nuclear Regulatory Commission Regulatory Guide 1.154, "Format and Content of Plant-Specific Pressurized Thermal Shock Safety Analysis Reports for Pressurized Water Reactors," January $1987 .^{\dagger}$

3. R. D. Cheverton and D. G. Ball, Martin Marietta Energy Systems, Inc., Oak Ridge Natl. Lab., "Pressurized-Thermal-Shock Evaluation of the Calvert Cliffs Nuclear Power Plant," pp. 201-244, USNRC Report NUREG/CR-4022 (ORNL/TM-9408), September 1985. $¥$

4. T. J. Theiss, D. K. M. Shum, and S. T. Rolfe, Martin Marietta Energy Systems, Inc., Oak Ridge Natl. Lab., "Experimental and Analytical Investigation of the Shallow-Flaw Effect in Reactor Pressure Vessels," USNRC Report NUREG/CR-5886 (ORNL/TM12115), July $1992 . \ddagger$

5. T. J. Theiss et al., Martin Marietta Energy Systems, Inc., Oak Ridge Natl. Lab., "Initial Results of the Influence of Biaxial Loading on Fracture Toughness,"USNRC Report NUREG/CR-6036 (ORNL/TM-12349), June 1993.

6. B. R. Bass et al., Martin Marietta Energy Systems, Inc., Oak Ridge Natl. Lab., "Biaxial Loading and Shallow-Flaw Effects on Crack-Tip Constraint and Fracture Toughness," USNRC Report NUREG/CR6132 (ORNL/TM-12498), January 1994. $\ddagger$

7. G. R. Irwin and X. J. Zhang, University of Maryland, "Gradient Study of a Large Weld Joining Two Forged A 508 Shells of the Midland Reactor Vessel," USNRC Report NUREG/CR-5867 (ORNL/Sub/79-7778/10), June 1992.

8. The American Society of Mechanical Engineers Boiler and Pressure Vessel Code, Section XI, "Rules for Inservice Inspection of Nuclear Power Plant Components," Appendix A, "Analysis of Flaws," Article A-4000, Material Properties, American Society of Mechanical Engineers, New York, 1989. ${ }^{\dagger}$
9. N. P. O'Dowd and C. F. Shih, "Family of Crack-Tip Fields Characterized by a Triaxiality Parameter: Part I-Structure of Fields," J. Mech. Phys. Solids 39, 989-1015 (1991). $\S$

10. N. P. O'Dowd and C. F. Shih, "Family of Crack-tip Fields Characterized by a Triaxiality Parameter: Part II-Fracture Applications," J. Mech. Phys. Solids 40, 939-963 (1992).\$

11. N.P. O'Dowd and C. F. Shih, Naval Surface Warfare Center, "Two Parameter Fracture Mechanics: Theory and Applications," USNRC Report NUREG/CR-5958 (CDNSWC/SME-CR-16-92), February 1993.

12. R. H. Dodds, T. L. Anderson, and M. T. Kirk, "A Framework to Correlate a/W Ratio Effects on ElasticPlastic Fracture Toughness $\left(\mathrm{J}_{\mathrm{c}}\right)$," Int. J. Frac. 48, 1-22 (1991). $\S$

13. T. L. Anderson and R. H. Dodds, "Specimen Size Requirements for Fracture Toughness Testing in the Ductile-Brittle Transition Region," J. Test. Eval. 19, 123-134 (1991).§

14. R. H. Dodds, C. F. Shih, and T. L. Anderson, Department of Civil Engineering, University of Illinois, "Continuum and Micromechanics Treatment of Constraint in Fracture," Report UILU-ENG-922014, November 1992

15. American Society of Mechanical Engineers Boiler and Pressure Vessel Code, Section III, "Rules for Construction of Nuclear Power Plant Components," American Society of Mechanical Engineers, New York, 1989.\$

16. Annual Book of ASTM Standards, Volume 03.01, American Society for Testing and Materials, Philadelphia, Pa., 1994. $\S$

17. R. K. Nanstad, D. E. McCabe, R. L. Swain, and M. K. Miller, Martin Marietta Energy Systems, Inc., Oak Ridge Natl. Lab., "Chemical Composition and RTNDT, Determinations for Midland Weld WF-70," USNRC Report NUREG/CR-5914 (ORNL-6740), December 1992. $\ddagger$ 


\section{References}

18. G. R. Irwin, "Linear Fracture Mechanics, Fracture Transition, and Fracture Control," Eng. Frac. Mech., 1. 241-247 (1968). $\S$

19. F. M. Haggag, "In-Situ Measurements of Mechanical Properties Using Novel Automated Ball Indentation System," Small Specimen Test Techniques Applied to Nuclear Reactor Vessel Thermal Annealing and Plant Life Extension, ASTM STP 1023, W. R. Corwin, F. M. Haggag, and W. L. Server, Eds., American Society for Testing and Materials, Philadelphia, $27-44$ (1993).§

20. T. J. Theiss, Martin Marietta Energy Systems, Inc., Oak Ridge Natl. Lab., "Specification for the FullThickness Clad Beam Fracture-Toughness Tests," Specification No. HSST-H10-92-001, Rev. 1, Jan. 13, 1992.**

21. R. E. Link and J. A. Joyce, "Experimental Investigation of Fracture Toughness Scaling Models," Constraint Effects in Fracture: Theory and Applications, ASTM STP 1244, Mark Kirk and Ad Bakker, Eds., American Society for Testing and Materials, Philadelphia, 1994.\$

22. ABAQUS Theory Manual, Version 5-2, (Hibbit, Karlson, and Sorensen, Inc., Providence, R. I., 1992). ${ }^{* *}$
23. M. T. Kirk and R. H. Dodds, Jr., Department of Civil Engineering, University of Illinois, "J and CTOD Estimation Equations for Shallow Cracks in Single Edge Notch Bend Specimens," USNRC Report NUREG/CR-5969 (CDNSWC/SME-CR-17-92), July 1993. $\ddagger$

24. K. Wallin, "Statistical Aspects of Constraint with Emphasis on Testing and Analysis of Laboratory Specimens in the Transition Region," pp. 264-288 in Constraint Effect in Fracture, ASTM STP 1171, E. M. Hackett, K. H. Schwalbe, and R. H. Dodds, Eds., American Society for Testing and Materials, $1993 . \S$

\footnotetext{
*Available in NRC Public Document Room for inspection and copying for a fee.

$t_{\text {Copies are available from U.S. Government Printing Office, }}$ Washington, D.C. 20402. ATTN: Regulatory Guide Account.

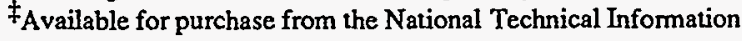
Service, Springfield, VA 22161.

$\S$ Available from public technical libraries.

**Available for purchase from organization sponsoring the cited publication, and/or from authors, and/or recipients.
} 


\section{Appendix A}

\section{Summary of SENB Shallow- and Deep-Crack Fracture Toughness Data for A 533 B Plate Material and Submerged-Arc Pressure Vessel Weld Material}

Table A.1 Fracture toughness data

\begin{tabular}{|c|c|c|c|c|c|c|c|}
\hline $\begin{array}{c}\text { Temperature } \\
\text { ('C) }\end{array}$ & $\begin{array}{r}\text { NDT } \\
\text { ("C) }\end{array}$ & $\begin{array}{c}\mathrm{RT}_{\mathrm{NDT}} \\
\left({ }^{\circ} \mathrm{C}\right)\end{array}$ & $\begin{array}{c}\mathrm{T}-\mathrm{NDT} \\
(\mathrm{C})\end{array}$ & $\begin{array}{c}\mathrm{T}-\mathrm{RT}_{\mathrm{NDT}} \\
\left({ }^{\circ} \mathrm{C}\right)\end{array}$ & $\begin{array}{c}\mathbf{a} \\
(\mathrm{mm})\end{array}$ & $\begin{array}{c}W \\
(\mathrm{~mm})\end{array}$ & $\begin{array}{c}\mathrm{KJc}_{\mathrm{Jc}} \\
(\mathrm{MPa} \sqrt{\mathrm{m}})\end{array}$ \\
\hline \multicolumn{8}{|c|}{ ORNL deep-crack SENB data on A 533 B } \\
\hline-61 & -35 & -35 & -26 & -26 & 51.8 & 100 & 98 \\
\hline-55 & -35 & -35 & -20 & -20 & 51.2 & 99 & 105 \\
\hline-59 & -35 & -35 & -24 & -24 & 51.9 & 100 & 155 \\
\hline-57 & -35 & -35 & -22 & -22 & 49.8 & 95 & 103 \\
\hline-58 & -35 & -35 & -23 & -23 & 50 & 94 & 103 \\
\hline-44 & -35 & -35 & -9 & -9 & 51 & 94 & 119 \\
\hline-46 & -35 & -35 & -11 & -11 & 50.8 & 94 & 143 \\
\hline-44 & -35 & -35 & -9 & -9 & 50.2 & 93 & 145 \\
\hline-44 & -35 & -35 & -9 & -9 & 50.8 & 93 & 93 \\
\hline-47 & -35 & -35 & -12 & -12 & 50.7 & 94 & 134 \\
\hline-43 & -35 & -35 & -8 & -8 & 51.9 & 94 & 109 \\
\hline-6 & -30 & -15 & 24 & 9 & 52.6 & 102 & 141 \\
\hline-7 & -30 & -15 & 23 & 8 & 52 & 102 & 219 \\
\hline-39 & -30 & -15 & -9 & -24 & 52 & 102 & 136 \\
\hline-40 & -30 & -15 & -10 & -25 & 51.5 & 102 & 108 \\
\hline-7 & -30 & -15 & 23 & 8 & 51.7 & 102 & 140 \\
\hline-38 & -30 & -15 & -8 & -23 & 51.6 & 102 & 91 \\
\hline \multicolumn{8}{|c|}{ ORNL shallow-crack SENB data on A 533 B } \\
\hline-36 & -35 & -35 & -1 & -1 & 10 & 100 & 279 \\
\hline-59 & -35 & -35 & -24 & -24 & 10.2 & 94 & 145 \\
\hline-60 & -35 & -35 & -25 & -25 & 9.6 & 94 & 267 \\
\hline-62 & -35 & -35 & -27 & -27 & 9.5 & 94 & 220 \\
\hline-60 & -35 & -35 & -25 & -25 & 14 & 94 & 189 \\
\hline-57 & -35 & -35 & -22 & -22 & 8.4 & 94 & 139 \\
\hline-60 & -35 & -35 & -25 & -25 & 8.8 & 94 & 174 \\
\hline-60 & -35 & -35 & -25 & -25 & 8.7 & 93 & 171 \\
\hline-59 & -35 & -35 & -24 & -24 & 8.7 & 94 & 126 \\
\hline-24 & -30 & -15 & 6 & -9 & 10.6 & 102 & 213 \\
\hline-4 & -30 & -15 & 26 & 11 & 10.8 & 101 & 391 \\
\hline-23 & -30 & -15 & 7 & -8 & 10.7 & 102 & 174 \\
\hline-7 & -30 & -15 & 23 & 8 & 10.9 & 102 & 298 \\
\hline-40 & -30 & -15 & -10 & -25 & 11 & 102 & 189 \\
\hline-22 & -30 & -15 & 8 & -7 & 10.7 & 102 & 230 \\
\hline-6 & -30 & -15 & 24 & 9 & 10.3 & 102 & 331 \\
\hline-103 & -30 & -15 & -73 & -88 & 11.1 & 102 & 68 \\
\hline-103 & -30 & -15 & -73 & -88 & 10.7 & 102 & 55 \\
\hline-106 & -30 & -15 & -76 & -91 & 10.4 & 102 & 69 \\
\hline-39 & -30 & -15 & -9 & -24 & 10.8 & 102 & 169 \\
\hline-39 & -30 & -15 & -9 & -24 & 10.8 & 102 & 157 \\
\hline \multicolumn{8}{|c|}{ ORNL deep-crack clad beam data on SA weld metal } \\
\hline-25.5 & -50 & -23 & 24.5 & -2.5 & 117.5 & 225.8 & 174 \\
\hline
\end{tabular}


Table A.1 (continued)

\begin{tabular}{|c|c|c|c|c|c|c|c|}
\hline $\begin{array}{c}\text { Temperature } \\
\left({ }^{\circ} \mathrm{C}\right)\end{array}$ & $\begin{array}{l}\text { NDT } \\
\left({ }^{\circ} \mathrm{C}\right)\end{array}$ & $\begin{array}{c}\mathrm{RT}_{\mathrm{NDT}} \\
\left({ }^{\circ} \mathrm{C}\right)\end{array}$ & $\begin{array}{c}\mathrm{T}-\mathrm{NDT} \\
\left({ }^{\circ} \mathrm{C}\right)\end{array}$ & $\begin{array}{c}\mathrm{T}-\mathrm{RT}_{\mathrm{NDT}} \\
\left({ }^{\circ} \mathrm{C}\right)\end{array}$ & $\begin{array}{c}\mathbf{a} \\
(\mathbf{m m})\end{array}$ & $\begin{array}{c}W \\
(\mathbf{m m})\end{array}$ & $\begin{array}{c}\mathrm{K}_{\mathbf{J c}} \\
(\mathrm{MPa} \sqrt{\mathrm{m}})\end{array}$ \\
\hline \multicolumn{8}{|c|}{ ORNL shallow-crack clad beam data on SA weld metal } \\
\hline $\begin{array}{l}-25 \\
-25.5\end{array}$ & $\begin{array}{l}-50 \\
-50\end{array}$ & $\begin{array}{l}-23 \\
-23\end{array}$ & $\begin{array}{l}25 \\
24.5\end{array}$ & $\begin{array}{l}-2 \\
-2.5\end{array}$ & $\begin{array}{l}10.8 \\
23.7\end{array}$ & $\begin{array}{l}224.3 \\
224.3\end{array}$ & $\begin{array}{l}225 \\
393\end{array}$ \\
\hline \multicolumn{8}{|c|}{ ORNL biaxial shallow-crack specimen with uniaxial loading on $A 533 B$} \\
\hline-41 & -35 & -35 & -6 & -6 & 10.6 & 91 & $214^{a}\left(175^{b}\right)$ \\
\hline \multicolumn{8}{|c|}{ ORNL biaxial shallow-crack specimen with biaxial loading on $A 533 B$} \\
\hline $\begin{array}{l}-45 \\
-46 \\
-44\end{array}$ & $\begin{array}{l}-35 \\
-35 \\
-35\end{array}$ & $\begin{array}{l}-35 \\
-35 \\
-35\end{array}$ & $\begin{array}{r}-10 \\
-11 \\
-9\end{array}$ & $\begin{array}{r}-10 \\
-11 \\
-9\end{array}$ & $\begin{array}{l}11.1 \\
10.1 \\
10\end{array}$ & $\begin{array}{l}91 \\
91 \\
91\end{array}$ & $\begin{array}{l}175^{a}\left(133^{b}\right) \\
178^{a}\left(135^{b}\right) \\
178^{a}\left(178^{b}\right)\end{array}$ \\
\hline \multicolumn{8}{|c|}{ David Taylor deep-crack data on A 533 B } \\
\hline $\begin{array}{l}-62 \\
-62 \\
-62 \\
-7 \\
-7 \\
-7 \\
-7 \\
-7 \\
-7 \\
-7 \\
-7 \\
21 \\
21 \\
21 \\
21 \\
21 \\
21 \\
21 \\
21 \\
21\end{array}$ & $\begin{array}{l}4 \\
4 \\
4 \\
4 \\
4 \\
4 \\
4 \\
4 \\
4 \\
4 \\
4 \\
4 \\
4 \\
4 \\
4 \\
4 \\
4 \\
4 \\
4 \\
4\end{array}$ & $\begin{array}{l}4 \\
4 \\
4 \\
4 \\
4 \\
4 \\
4 \\
4 \\
4 \\
4 \\
4 \\
4 \\
4 \\
4 \\
4 \\
4 \\
4 \\
4 \\
4 \\
4\end{array}$ & $\begin{array}{l}-66 \\
-66 \\
-66 \\
-11 \\
-11 \\
-11 \\
-11 \\
-11 \\
-11 \\
-11 \\
-11 \\
17 \\
17 \\
17 \\
17 \\
17 \\
17 \\
17 \\
17 \\
17\end{array}$ & $\begin{array}{r}-66 \\
-66 \\
-66 \\
-11 \\
-11 \\
-11 \\
-11 \\
-11 \\
-11 \\
-11 \\
-11 \\
17 \\
17 \\
17 \\
17 \\
17 \\
17 \\
17 \\
17 \\
17\end{array}$ & $\begin{array}{l}45.1 \\
45.5 \\
45.9 \\
44.7 \\
45.5 \\
45.1 \\
46.3 \\
45.6 \\
45.6 \\
45.7 \\
46.2 \\
46.2 \\
45.7 \\
45.6 \\
45.5 \\
45.9 \\
45.8 \\
45.9 \\
45.9 \\
45.9\end{array}$ & $\begin{array}{l}83 \\
83 \\
83 \\
83 \\
83 \\
83 \\
83 \\
83 \\
83 \\
83 \\
83 \\
75 \\
83 \\
83 \\
83 \\
83 \\
83 \\
83 \\
83 \\
83\end{array}$ & $\begin{array}{l}71 \\
136 \\
97 \\
109 \\
126 \\
204 \\
146 \\
112 \\
220 \\
118 \\
113 \\
146 \\
363 \\
385 \\
187 \\
176 \\
137 \\
249 \\
165 \\
227\end{array}$ \\
\hline \multicolumn{8}{|c|}{ David Taylor shallow-crack data on A 533 B } \\
\hline-62 & -7 & -7 & -55 & -55 & 8.4 & 83 & 108 \\
\hline-62 & -7 & -7 & -55 & -55 & 8.4 & 83 & 95 \\
\hline-62 & -7 & -7 & -55 & -55 & 8.4 & 83 & 266 \\
\hline-7 & -7 & -7 & 0 & 0 & 8.4 & 83 & 135 \\
\hline-7 & -7 & -7 & 0 & 0 & 8.3 & 83 & 126 \\
\hline-7 & -7 & -7 & 0 & 0 & 8.7 & 83 & 187 \\
\hline-7 & -7 & -7 & 0 & 0 & 8.3 & 83 & 374 \\
\hline-7 & -7 & -7 & 0 & 0 & 8.4 & 83 & 460 \\
\hline-7 & -7 & -7 & 0 & 0 & 8.2 & 83 & 494 \\
\hline-7 & -7 & -7 & 0 & 0 & 8.7 & 83 & 449 \\
\hline-7 & -7 & -7 & 0 & 0 & 8.2 & 83 & 120 \\
\hline 21 & -7 & -7 & 28 & 28 & 8.3 & 83 & 606 \\
\hline 21 & -7 & -7 & 28 & 28 & 8.9 & 83 & 192 \\
\hline 21 & -7 & -7 & 28 & 28 & 8.3 & 83 & 555 \\
\hline 21 & -7 & -7 & 28 & 28 & 8.7 & 83 & 579 \\
\hline 21 & -7 & -7 & 28 & 28 & 8.5 & 83 & 492 \\
\hline 21 & -7 & -7 & 28 & 28 & 8.1 & 83 & 272 \\
\hline
\end{tabular}

${ }^{a}$ Centerline value.

$b_{\text {Initiation site value. }}$

Source: W. E. Pennell, ORNL, letter to S. N. M. Malik, USNRC, March 18, 1994 


\section{Appendix B}

\section{Analytical Results}

Table B.1 Analytical results for specimen CB-1

\begin{tabular}{rccccccc}
\hline $\begin{array}{c}\text { Load } \\
(\mathbf{k N})\end{array}$ & $\begin{array}{c}\text { CMOD } \\
(\mathbf{m m})\end{array}$ & $\begin{array}{c}\mathbf{L L D} \\
(\mathbf{m m})\end{array}$ & $\begin{array}{c}\mathbf{J} \\
(\mathbf{k N} / \mathbf{m})\end{array}$ & $\begin{array}{c}\mathbf{A}_{\mathbf{p l}} \\
(\mathbf{k N}-\mathbf{m m})\end{array}$ & $\begin{array}{c}\mathbf{U}_{\mathbf{p l}} \\
(\mathbf{k N}-\mathbf{m m})\end{array}$ & $\eta_{\mathbf{p l}}^{\mathbf{c}}$ & $\boldsymbol{\eta}_{\mathbf{p l}}^{\ell}$ \\
\hline 0.0 & 0.000 & 0.000 & 0.00 & & & & \\
11.8 & 0.013 & 0.030 & 0.01 & & & & \\
106.8 & 0.116 & 0.268 & 0.97 & & & & \\
241.2 & 0.262 & 0.605 & 4.79 & & & & \\
371.8 & 0.406 & 0.936 & 11.5 & & & & \\
505.9 & 0.554 & 1.280 & 20.3 & & & & \\
598.8 & 0.658 & 1.510 & 28.0 & 3.4 & 2.5 & 3.360 & \\
720.0 & 0.795 & 1.830 & 40.1 & 7.0 & 13.0 & 3.287 & 1.777 \\
840.0 & 0.934 & 2.140 & 54.3 & 13.5 & 20.0 & 3.114 & 2.111 \\
945.9 & 1.058 & 2.420 & 68.8 & 22.3 & 32.7 & 3.009 & 2.050 \\
1069.4 & 1.207 & 2.760 & 88.3 & 36.7 & 63.1 & 2.975 & 1.732 \\
1177.5 & 1.352 & 3.080 & 109.1 & 68.6 & 117.8 & 2.404 & 1.399 \\
1224.6 & 1.415 & 3.220 & 118.6 & 82.8 & 143.6 & 2.342 & 1.350 \\
1232.5 & 1.430 & 3.250 & 120.8 & 90.0 & 156.0 & 2.231 & 1.287 \\
1248.1 & 1.453 & 3.300 & 124.3 & 97.3 & 170.1 & 2.180 & 1.248 \\
1270.6 & 1.487 & 3.380 & 129.7 & 109.6 & 199.1 & 2.103 & 1.157 \\
1294.1 & 1.525 & 3.460 & 135.9 & 125.7 & 226.7 & 2.006 & 1.112 \\
\hline
\end{tabular}

Table B.2 Analytical results for specimen CB-2

\begin{tabular}{cccccccc}
\hline $\begin{array}{c}\text { Load } \\
(\mathbf{k N})\end{array}$ & $\begin{array}{c}\text { CMOD } \\
(\mathbf{m m})\end{array}$ & $\begin{array}{c}\text { LLD } \\
(\mathbf{m m})\end{array}$ & $\begin{array}{c}\mathbf{J} \\
(\mathbf{k N} / \mathbf{m})\end{array}$ & $\begin{array}{c}\mathbf{A}_{\mathbf{p l}} \\
(\mathbf{k N}-\mathbf{m m})\end{array}$ & $\begin{array}{c}\mathbf{U}_{\mathrm{pl}} \\
(\mathbf{k N}-\mathbf{m m})\end{array}$ & $\eta_{\mathbf{p l}}^{\mathbf{c}}$ & $\eta_{\mathbf{p l}}^{\ell}$ \\
\hline 0.00 & 0.00 & 0.00 & 0.00 & & & & \\
51.5 & 0.002 & 0.051 & 0.0111 & & & & \\
470.4 & 0.020 & 0.461 & 0.893 & & & & \\
1196.0 & 0.053 & 1.174 & 5.38 & & & & \\
1587.8 & 0.070 & 1.559 & 9.35 & & & & \\
2082.7 & 0.093 & 2.043 & 15.9 & & & & \\
2603.4 & 0.118 & 2.558 & 25.6 & & & & \\
3108.6 & 0.144 & 3.058 & 38.0 & & & & \\
3619.0 & 0.186 & 3.590 & 55.8 & 87.2 & 126.1 & 0.767 & 0.530 \\
3866.4 & 0.217 & 3.881 & 68.4 & 160.6 & 307.3 & 1.908 & 0.997 \\
4144.8 & 0.257 & 4.265 & 86.1 & 274.7 & 753.2 & 2.624 & 0.957 \\
4247.9 & 0.276 & 4.432 & 94.7 & 332.9 & 1026.7 & 2.905 & 0.942 \\
4381.9 & 0.302 & 4.664 & 107.4 & 423.4 & 1464.0 & 3.195 & 0.924 \\
4510.8 & 0.332 & 4.917 & 121.7 & 528.3 & 2022.7 & 3.447 & 0.900 \\
4639.7 & 0.364 & 5.190 & 137.5 & 649.7 & 2694.6 & 3.627 & 0.875 \\
4768.5 & 0.403 & 5.515 & 156.9 & 807.7 & 3631.9 & 3.791 & 0.843 \\
4856.2 & 0.434 & 5.771 & 173.1 & 940.2 & 4445.6 & 3.920 & 0.829 \\
4928.3 & 0.461 & 5.990 & 186.8 & 1056.7 & 5173.4 & 3.988 & 0.815 \\
4995.4 & 0.487 & 6.205 & 200.3 & 1171.5 & 5913.6 & 4.048 & 0.802 \\
5041.8 & 0.509 & 6.384 & 211.8 & 1271.3 & 6584.0 & 4.099 & 0.792 \\
5083.0 & 0.528 & 6.537 & 221.5 & 1358.7 & 7153.5 & 4.124 & 0.783 \\
5119.1 & 0.545 & 6.674 & 230.5 & 1438.1 & 7671.7 & 4.151 & 0.778 \\
5155.2 & 0.565 & 6.828 & 240.7 & 1528.5 & 8280.9 & 4.184 & 0.772 \\
\hline
\end{tabular}


Appendix B

Table B.3 Analytical results for specimen CB-3

\begin{tabular}{rccccccc}
\hline $\begin{array}{c}\text { Load } \\
(\mathbf{k N})\end{array}$ & $\begin{array}{c}\text { CMOD } \\
(\mathbf{m m})\end{array}$ & $\begin{array}{c}\mathbf{L L D} \\
(\mathbf{m m})\end{array}$ & $\begin{array}{c}\mathbf{J} \\
\mathbf{( k N / \mathbf { m } )}\end{array}$ & $\begin{array}{c}\mathbf{A}_{\mathbf{p l}} \\
(\mathbf{k N}-\mathbf{m m})\end{array}$ & $\begin{array}{c}\mathbf{U}_{\mathbf{p l}} \\
(\mathbf{k N}-\mathbf{m m})\end{array}$ & $\eta_{\mathbf{p l}}^{\mathbf{c}}$ & $\eta_{\mathbf{p l}}^{\ell}$ \\
\hline 0.0 & 0.000 & 0.000 & 0.000 & & & & \\
107.0 & 0.011 & 0.110 & 0.105 & & & & \\
561.7 & 0.056 & 0.578 & 2.66 & & & & \\
1043.1 & 0.104 & 1.075 & 8.70 & & & & \\
1626.1 & 0.165 & 1.681 & 20.9 & & & & \\
2161.0 & 0.221 & 2.238 & 37.1 & & & & \\
2669.2 & 0.278 & 2.772 & 56.6 & & & & \\
3214.8 & 0.354 & 3.378 & 85.8 & & & & \\
3749.7 & 0.467 & 4.071 & 132.0 & 296.7 & 677.9 & 0.841 & 0.368 \\
3872.8 & 0.504 & 4.264 & 146.6 & 391.3 & 928.7 & 1.363 & 0.574 \\
4011.8 & 0.551 & 4.496 & 165.4 & 524.4 & 1280.8 & 1.801 & 0.737 \\
4145.6 & 0.602 & 4.742 & 186.1 & 677.3 & 1720.5 & 2.134 & 0.840 \\
4279.3 & 0.660 & 5.018 & 210.7 & 862.8 & 2304.4 & 2.447 & 0.916 \\
4413.0 & 0.728 & 5.348 & 241.2 & 1101.6 & 3142.8 & 2.754 & 0.965 \\
4546.7 & 0.806 & 5.733 & 277.8 & 1391.9 & 4248.0 & 3.034 & 0.994 \\
4685.8 & 0.908 & 6.224 & 328.9 & 1800.5 & 5855.4 & 3.357 & 1.032 \\
4819.5 & 1.026 & 6.778 & 386.8 & 2299.0 & 7834.9 & 3.560 & 1.045 \\
4947.9 & 1.162 & 7.410 & 454.6 & 2897.0 & 10276.3 & 3.724 & 1.050 \\
5054.9 & 1.293 & 8.030 & 522.8 & 3502.5 & 12826.7 & 3.850 & 1.051 \\
5065.6 & 1.306 & 8.091 & 529.5 & 3562.9 & 13080.2 & 3.859 & 1.051 \\
5188.6 & 1.482 & 8.917 & 622.2 & 4403.0 & 16665.0 & 3.973 & 1.050 \\
5268.9 & 1.611 & 9.519 & 691.5 & 5035.3 & 19381.3 & 4.039 & 1.049 \\
5327.7 & 1.716 & 10.003 & 748.3 & 5557.7 & 21784.5 & 4.084 & 1.042 \\
\hline
\end{tabular}




\section{Internal Distribution}

1. D. J. Alexander

2-5. B. R. Bass

6. J.W. Bryson

7. W. R. Corwin

8. T. L. Dickson

9-10. R. G. Gilliland

11. F. M. Haggag

12. D. M. Hetrick

13. W. F. Jackson

14-17. S. K. Iskander

18-22. J. A. Keeney

23-26. W. J. McAfee

27. D. E. McCabe
28. J. G. Merkle

29. R. K. Nanstad

30-34. W. E. Pennell

35. C. E. Pugh

36. M. C. Rao

37. C. C. Southmayd

38. G. W. Whitesides

39. ORNL Patent Section

40. Central Research Library

41. Document Reference Section

42-43. Laboratory Records

44. Laboratory Records(RC)

\section{External Distribution}

45. J. W. Craig, Deputy Director, Division of Engineering, RES, U.S. Nuclear Regulatory Commission, Washington, DC 20555-0001

46. A. L. Hiser, Division of Engineering, RES, U.S. Nuclear Regulatory Commission, Washington, DC 20555-0001

47. P. T. Kuo, Division of Engineering, RES, U.S. Nuclear Regulatory Commission, Washington, DC 20555-0001

48. L. C. Shao, Director, Division of Engineering, RES, U.S. Nuclear Regulatory Commission, Washington, DC 20555-0001

49. T. P. Speis, Deputy Director, Office of Nuclear Regulatory Research, U.S. Nuclear Regulatory Commission, Washington, DC 20555-0001

50-52. S. N. M. Malik, Division of Engineering, U.S. Nuclear Regulatory Commission, Washington, DC 20555-0001

53. M. E. Mayfield, Division of Engineering, U.S. Nuclear Regulatory Commission, Washington, DC 20555-0001

54. G. R. Irwin, Department of Mechanical Engineering, University of Maryland, College Park, MD 20742

55. C. F. Shih, Box D, Division of Engineering, Brown University, Providence, RI 02912

56. R. Dodds, 3140 Newmark Laboratory, 205 North Matthews, Urbana, IL 61801

57. R. Fields, National Institute of Standards and Technology, Bldg. 223, B 144, Gaithersburg, MD 20899

58. W. L. Fourney, Department of Mechanical Engineering, University of Maryland, College Park, MD 20742

59. S. T. Rolfe, The University of Kansas, Lawrence, KS 66045-2235

60. C. W. Schwartz, Department of Civil Engineering, University of Maryland, College Park, MD 20742

61. Office of Assistant Manager for Energy Research and Development, DOE-ORO, Oak Ridge, TN 37831

62-63. Office of Scientific and Technical Information, P.O. Box 62, Oak Ridge, TN 37831

64. Y. J. Chao, Mechanical Engineering, The University of South Carolina, Columbia Campus, Columbia, SC 29208

65. T. L. Anderson, Department of Mechanical Engineering, Texas A\&M University, College Station, TX 77843

66. J. M. Joyce, U.S. Naval Academy, Annapolis, MD 21402 


\begin{tabular}{|c|c|}
\hline $\begin{array}{l}\text { U.S. NUCLEAR REGULATORY COMMISSION } \\
\text { BIBLIOGRAPHIC DATA SHEET } \\
\text { (See instructions on the reverse) }\end{array}$ & \multirow[t]{2}{*}{ 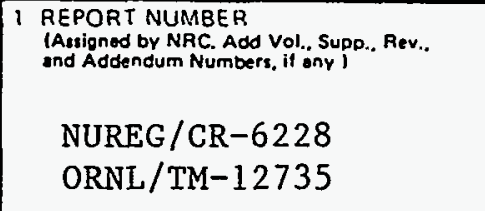 } \\
\hline 2. TITLE AND SUBTITLE & \\
\hline \multirow{3}{*}{$\begin{array}{l}\text { Preliminary Assessment of the Fracture Behavior of Weld } \\
\text { Material in Full-Thickness Clad Beams }\end{array}$} & DATE REPORT PUBLISHED \\
\hline & \multirow{3}{*}{\begin{tabular}{l|c} 
MONTH & YEAF \\
OCtOObET & 1994 \\
4. FIN OR GRANT NUMBER \\
BO119 \\
\end{tabular}} \\
\hline & \\
\hline 5. AUTHOR(S) & \\
\hline J. A. Keeney, B. R. Bass, W. J. McAfee, and S. K. Iskander & 7. PERIOD COVERED (InCluswe' Oatr's' \\
\hline \multicolumn{2}{|c|}{ 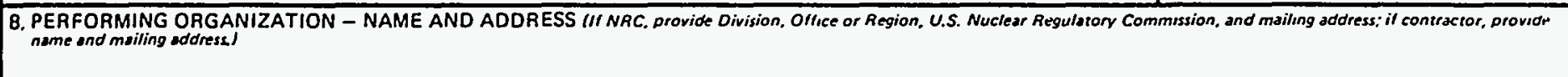 } \\
\hline \multicolumn{2}{|l|}{$\begin{array}{l}\text { Oak Ridge National Laboratory } \\
\text { Oak Ridge, Tennessee } 37831-6285\end{array}$} \\
\hline \multicolumn{2}{|c|}{ 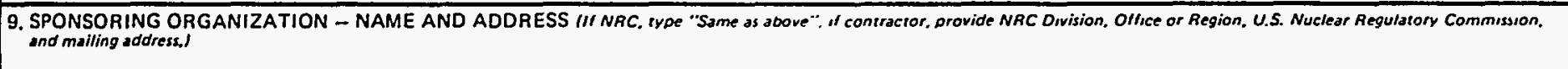 } \\
\hline \multicolumn{2}{|l|}{$\begin{array}{l}\text { Division of Engineering } \\
\text { Office of Nuclear Regulatory Research } \\
\text { U.S. Nuclear Regulatory Commission } \\
\text { Washington, DC 20555-0001 }\end{array}$} \\
\hline \multicolumn{2}{|l|}{ 10. SUPPLEMENTARY NOTES } \\
\hline \multicolumn{2}{|l|}{ 11. ABSTRACT (200 vroords or less) } \\
\hline \multicolumn{2}{|c|}{$\begin{array}{l}\text { A testing program is described that utilizes full-thickness clad beam specimens to quantify fracture toughness } \\
\text { for shallow cracks in material for which metallurgical conditions are prototypic of those found in reactor } \\
\text { pressure vessels (RPVs). The beam specimens are fabricated from a section of an RPV wall (removed from a } \\
\text { canceled nuclear plant) that includes weld, plate and clad material. Metallurgical factors potentially influencing } \\
\text { fracture toughness for shallow cracks in the beam specimens include material gradients due to welding and } \\
\text { cladding applications, as well as material inhomogeneities in welded regions due to reheating in multiple weld } \\
\text { passes. Summaries of the testing program and analytical studies are provided. Fracture toughness data from } \\
\text { the three clad beam specimens are compared with other shallow- and deep-crack uniaxial beam and cruciform } \\
\text { data generated previously from A } 533 \text { Grade B plate material. Difficulties with interpreting lower-bound } \\
\text { fracture toughness curves constructed from the shallow-crack data are essentially resolved by adopting a single } \\
\text { normalizing temperature parameter, namely, the nil-ductility temperature (NDT). When normalized to NDT, } \\
\text { the combined shallow-crack data base from the plate and weld material exhibit an elevated mean fracture } \\
\text { toughness in the transition temperature region, accompanied by increased data scatter that tends toward the } \\
\text { same lower bound associated with highly-constrained deep-crack data. Additional full-thickness clad beam } \\
\text { testing is proposed to complete the investigation of shallow-crack fracture toughness behavior in prototypic } \\
\text { weld and plate material. This report is designated as HSST Report No. } 143 \text {. }\end{array}$} \\
\hline \multirow[t]{2}{*}{ 12. KEY WORDS/DESCR!PTORS / List words or ohroses that will assists researchers in focating the reporr. } & 13. AVAILABILITY STATEMENT \\
\hline & $\begin{array}{l}\text { Unlimited } \\
\text { i4. SECURITY CLASSIFICATION }\end{array}$ \\
\hline \multirow{6}{*}{$\begin{array}{l}\text { A533 Grade B Class } 1 \text { steel } \\
\text { Full-thickness clad beam } \\
\text { Shallow-crack beam } \\
\text { Cruciform beam } \\
\text { Constraint Analysis }\end{array}$} & TThis Paser! \\
\hline & Unclassified \\
\hline & TThis Report) \\
\hline & Unclassified \\
\hline & 15. NUMBER OF PAGES \\
\hline & 16. PRICE \\
\hline
\end{tabular}

